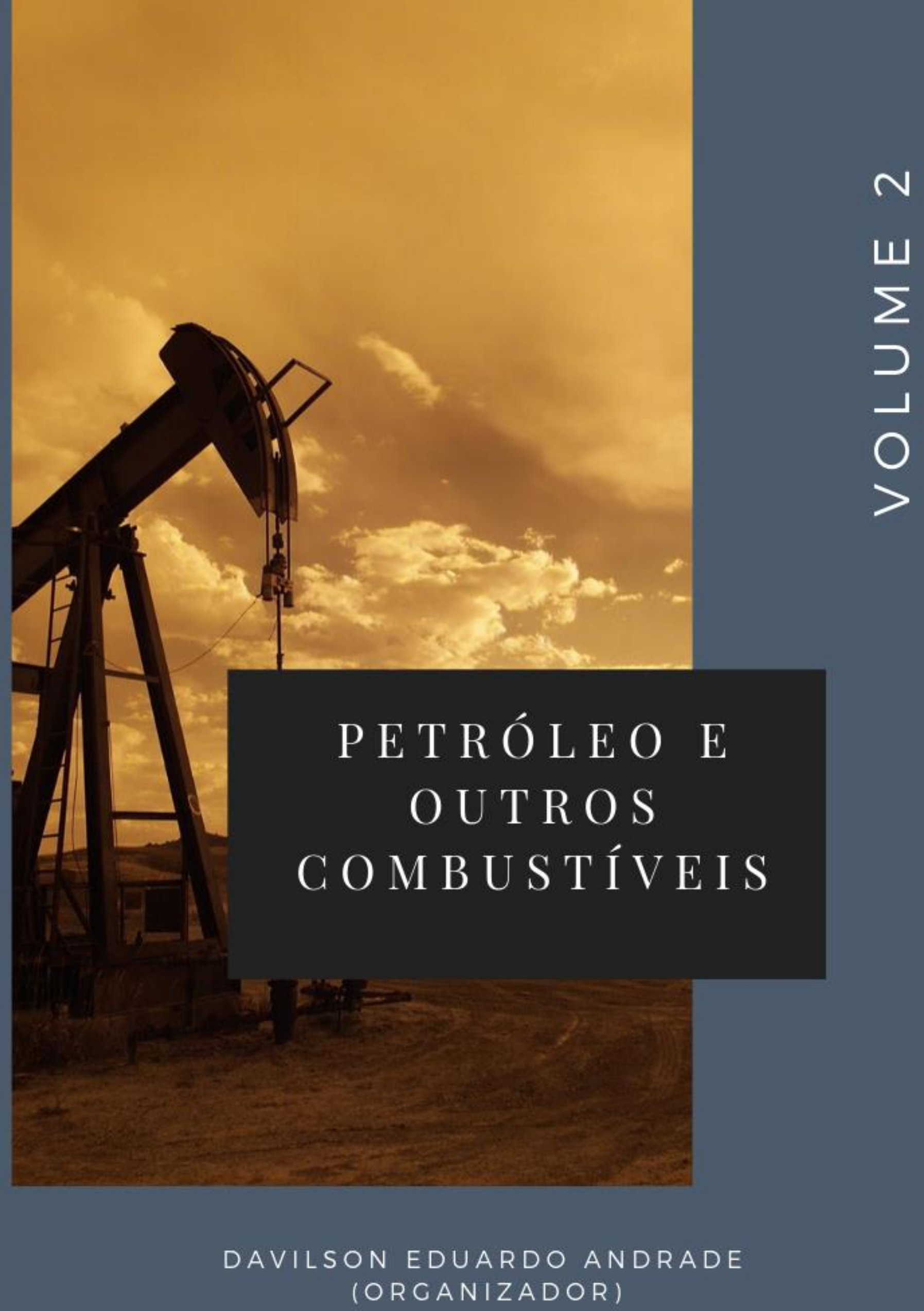


Davilson Eduardo Andrade

(organizador)

\section{Petróleo e outros combustíveis Volume 2}

1a Edição

Belo Horizonte

Poisson

2019 
Editor Chefe: Dr. Darly Fernando Andrade

\section{Conselho Editorial}

Dr. Antônio Artur de Souza - Universidade Federal de Minas Gerais

Msc. Davilson Eduardo Andrade

Dra. Elizângela de Jesus Oliveira - Universidade Federal do Amazonas

Msc. Fabiane dos Santos

Dr. José Eduardo Ferreira Lopes - Universidade Federal de Uberlândia

Dr. Otaviano Francisco Neves - Pontifícia Universidade Católica de Minas Gerais

Dr. Luiz Cláudio de Lima - Universidade FUMEC

Dr. Nelson Ferreira Filho - Faculdades Kennedy

Msc. Valdiney Alves de Oliveira - Universidade Federal de Uberlândia

Dados Internacionais de Catalogação na Publicação (CIP)

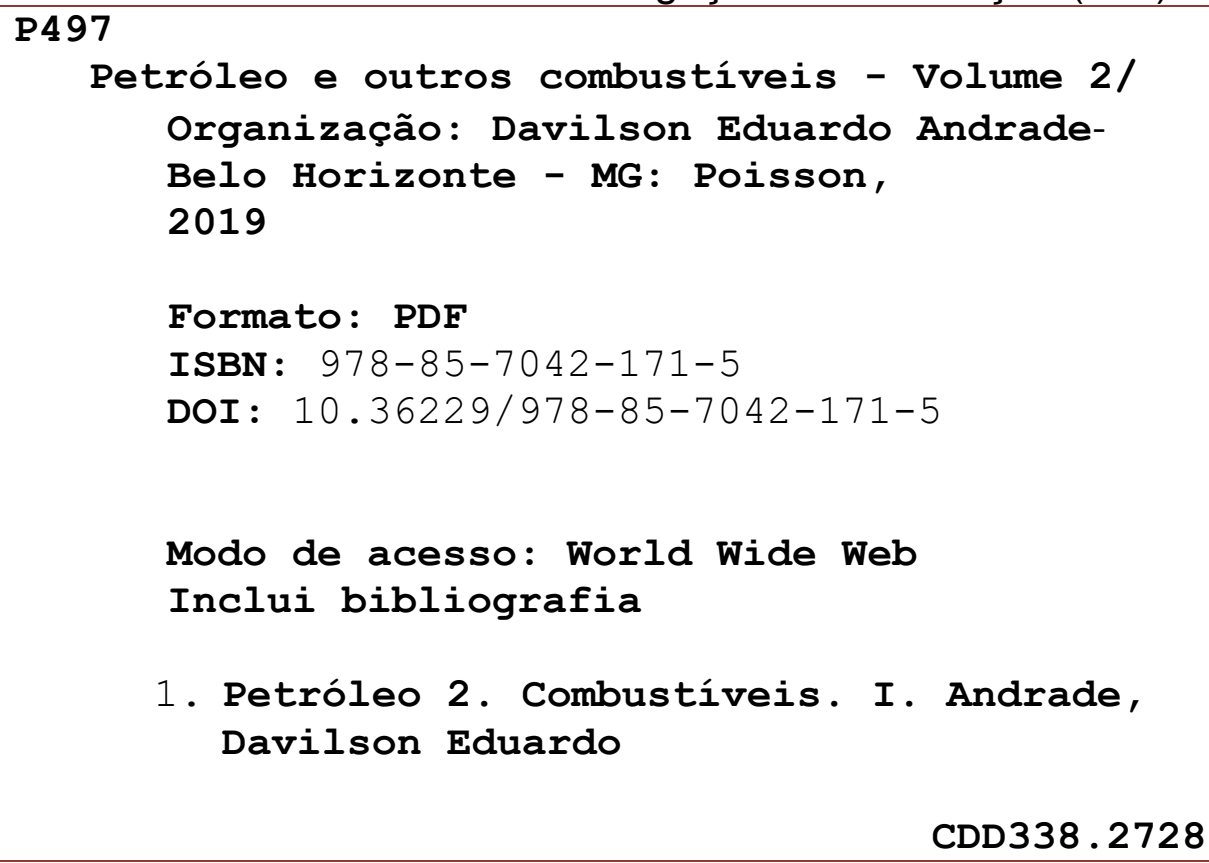

O conteúdo dos artigos e seus dados em sua forma, correção e confiabilidade são de responsabilidade exclusiva dos seus respectivos autores.

Baixe outros títulos gratuitamente em www.poisson.com.br contato@poisson.com.br 


\section{SUMÁRIO}

Capítulo 1: Análise do pedido de licença prévia de perfuração no bloco BM - Seal 100 6

Eduarda Colares Barbosa Ferreira, Lúcia Maria de Araújo Lima Gaudêncio

DOI: 10.36229/978-85-7042-171-5.CAP.01

Capítulo 2: Geomecânica e perfuração em formações Salinas. 12

Vítor Gama Rodrigues, Fernanda Silva Calixto

DOI: 10.36229/978-85-7042-171-5.CAP.02

Capítulo 3: Obtenção e estudo reológico de um fluido de perfuração à base de água17 Mariana Martins do Vale, Alfredo Ismael Curbelo Garnica, Fabíola Dias da Silva Curbelo DOI: 10.36229/978-85-7042-171-5.CAP.03

Capítulo 4: Análise da influência da goma xantana e do tween 80 na viscosidade e no volume de filtrado de fluidos de perfuração hidroargilosos. 25

Allison Ruan de Morais Silva, Francisco Klebson Gomes dos Santos, Geraldine Angélica Silva da Nóbrega, Diego Ângelo de Araújo Gomes

DOI: $10.36229 / 978-85-7042-171-5 . C A P .04$

Capítulo 5: Variação das propriedades de um fluído de perfuração com biodiesel com o tempo e a temperatura.

Elba Gomes dos Santos Leal, Rui Carlos de Sousa Mota, Ricardo Guilherme Kuentzer, Ricardo Matos Santos, Pedro Luis Araujo dos Santos, Caio Ramos Valverde

DOI: 10.36229/978-85-7042-171-5.CAP.05

Capítulo 6: Um estudo sobre função porosidade da região de compactação no movimento gravitacional de uma suspensão particulada em proveta. 39

Antônio Santos Silva, Hariel Udi Santana Mendes, Edilson de Jesus Santos, Paulo Victor Vieira Cunha, Victor Hugo dos Santos Ramos

DOI: $10.36229 / 978-85-7042-171-5 . C A P .06$

Capítulo 7: Comparação do uso do método térmico de recuperação para oléos de diferentes graus API a partir de simulação computacional

Bianca Gabriel de Souza, Karolline Dewanele Santana Rocha, Hariel Udi Santana Mendes, Acto de Lima Cunha

DOI: $10.36229 / 978-85-7042-171-5 . C A P .07$ 


\section{SUMÁRIO}

Capítulo 8: Influência da redução do teor de enxofre sobre as propriedades físicoquímicas e na estabilidade oxidativa do óleo diesel.

Camila Gisele Damasceno Peixoto Morais, Josué Santiago de Almeida, Amanda Duarte Gondim, Antonio Souza de Araujo, Valter José Fernandes Junior

DOI: $10.36229 / 978-85-7042-171-5 . C A P .08$

Capítulo 9: Avaliação da perovsquita $\mathrm{BaCeO}_{3}$ como catalisador na conversão de óleo de soja em biodiesel via rota etílica 59

Alexsandro Rocha da Silva, Gustavo Fernandes Quixadá, Paulo Eduardo da Costa Santos, Andarair Gomes dos Santos

DOI: $10.36229 / 978-85-7042-171-5 . C A P .09$

Capítulo 10: Estudo da degradação do óleo de fritura e do sebo bovino utilizados como matérias-primas na produção de biodiesel. 66

Jéssica Violin Berni, Matheus Pereira de Oliveira, Thiago Luiz Belo Pasa, Fernanda Naiara Campos de Almeida, Nehemias Curvelo Pereira

DOI: $10.36229 / 978-85-7042-171-5 . C A P .10$

Capítulo 11: Influência do teor de acidez na produção de biodiesel etílico de canola por rota alcalina. 73

Matheus Pereira de Oliveira, Fernanda Naiara Campos de Almeida, Jéssica Violin Berni, Thiago Luiz Belo Pasa, Nehemias Curvelo Pereira

DOI: $10.36229 / 978-85-7042-171-5 . C A P .11$

Capítulo 12: Gestão do potencial energético de gás de flare em unidades de processamento petroquímicas

Gabriela de Carvalho Brito, Samuel Mathias do Amaral Junior, Tomas Saiter Lins

DOI: $10.36229 / 978-85-7042-171-5 . C A P .12$

Autores: 


\section{Capítulo 1}

Análise do pedido de licença prévia de perfuração no bloco BM - Seal 100

\section{Eduarda Colares Barbosa Ferreira \\ Lúcia Maria de Araújo Lima Gaudêncio}

Resumo: 0 petróleo e o gás natural se constituem em importantes descobertas, sendo essenciais para o desenvolvimento de diversos produtos que utilizam hidrocarbonetos como matéria prima e como insumo energético no mundo inteiro. No entanto, não obstante os efeitos benéficos desses insumos, as atividades de exploração e produção de petróleo e gás trazem consigo uma variedade de impactos negativos de variados graus de significância. Como forma de preservação, melhoria e recuperação da qualidade ambiental, foi instituída, pela Lei no 6.938/1981, a Política Nacional de Meio Ambiente, que estabelece o licenciamento ambiental como instrumento de controle das atividades potencialmente poluidoras. 0 objetivo desse artigo é acompanhar o processo de licenciamento da atividade de perfuração exploratória, no Bloco BM-SEAL 100, destacando os desafios encontrados para obtenção da licença e seus impactos no cumprimento dos prazos da Fase Exploratória do Contrato de Concessão.

Palavras-chave: Licenciamento ambiental, perfuração exploratória offshore, petróleo e gás. 


\section{INTRODUÇÃO}

O petróleo e o gás natural constituem importantes descobertas, sendo essenciais para o desenvolvimento de diversos produtos que utilizam hidrocarbonetos como matérias-primas nas indústrias automobilísticas, farmacêuticas, petroquímicas, dentre outras, além de representarem $46,9 \%$ da oferta de energia interna brasileira e mais de 50\% da matriz energética mundial (BEN, 2019). No entanto, apesar dos grandes benefícios promovidos por esses insumos, as atividades de exploração e produção de petróleo e gás acarretam impactos ambientais, sociais e econômicos de graus de significância variáveis. Para Ramalho et al. (2016) a ocorrência desses impactos negativos advindos das atividades de exploração e produção de petróleo e gás têm levado a discussões que dêem suporte a definição de políticas públicas voltadas à proteção do meio ambiente. Uma das principais contribuições dessas discussões foi a implementação da Lei no 6.938, em 31 de agosto de 1981, que estabelece a Política Nacional do Meio Ambiente (PNMA), cria o Sistema Nacional do Meio Ambiente (SISNAMA) e o Conselho Nacional de Meio Ambiente (CONAMA), sendo o licenciamento ambiental, um dos seus instrumentos. Por meio do licenciamento ambiental, o órgão competente, com base na legislação vigente, estabelece as condições, restrições e medidas de controle que deverão ser obedecidas pelo responsável pela atividade.

De acordo com a Resolução do CONAMA no 237, de 19 de dezembro de 1997, é por meio da licença ambiental que o empreendedor recebe a autorização de localização, instalação, ampliação e operação de atividades potencialmente poluidoras, devendo o empreendedor elaborar estudos específicos para a identificação dos impactos e suas indicar as respectivas medidas de contenção. Segundo Godoy (2005) o licenciamento ambiental é uma forma de manifestação do poder de polícia administrativa, cujo principal sentido é a prevenção do dano ambiental, representando, por isso, um essencial instrumento da política pública de meio ambiente.

Desde a criação desse instrumento da PNMA o licenciamento passou a ser exigido para a realização das atividades de exploração e produção de petróleo e gás. Para tanto, seguiu-se a Resolução CONAMA no 01/1986, que exige a elaboração de estudo de impacto ambiental a ser submetido à aprovação do órgão competente. Esse mesmo documento regulamentador estabelece a realização de audiência pública para informação sobre o projeto e seus impactos ambientais a toda a sociedade. Em 1994, o CONAMA publicou a Resolução no 23, instituindo procedimentos específicos para o licenciamento das atividades relacionadas à exploração e lavra de jazidas de combustíveis líquidos e gás natural. Posteriormente, em 1997, a Resolução CONAMA no 237 realizou alguns ajustes nos procedimentos para o licenciamento das mesmas atividades, promovendo melhorias no procedimento, mas ainda deixando algumas lacunas e dificuldades na transição para a nova regulamentação. Foi somente em 2011, que o Ministério do Meio Ambiente (MMA) publicou a Portaria no 422, possibilitando que a legislação ambiental brasileira desse mais um passo em relação as atividades de exploração e produção de petróleo e gás no ambiente marinho e em zona de transição terra-mar. A Portaria do MMA aborda as diretrizes para o licenciamento da pesquisa sísmica, perfuração de poços, produção e escoamento de petróleo e gás natural, do teste de longa duração, entre outros (BRASIL, 2011). A partir da vigência da nova portaria, , foi possível agilizar o processo de licenciamento de atividades de exploração e produção de petróleo e gás mediante racionalização de documentos, licenciamento de poços por área e disponibilização das informações na internet.

Segundo Neta (2015), a legislação ambiental brasileira, é reconhecida por muitos autores como uma das melhores do mundo, pois estabelece normas e padrões compatíveis com o meio ambiente ecologicamente equilibrado e essencial qualidade de vida. No entanto, as empresas que atuam no segmento upstream de petróleo e gás no Brasil reclamam das dificuldades impostas pelas exigências do licenciamento ambiental das atividades de exploração e produção que, muitas vezes dificultam os cumprimentos de prazos contratuais.

Por motivos de atrasos na obtenção da licença ambiental de perfuração exploratória, algumas empresas petrolíferas têm sido desafiadas a atenderem as condições impostas pelos Contratos de Concessão, levando-as a solicitarem a prorrogação do período exploratório, a fim de cumprirem suas obrigações contratuais. 0 presente trabalho se propõe a realizar o acompanhamento do processo de licenciamento ambiental da perfuração exploratória no Bloco BM-SEAL 100, da operadora Petrobras, localizado na Bacia de Sergipe-Alagoas, destacando os desafios encontrados para a obtenção da licença ambiental e os impactos do processo de licenciamento no cumprimento dos prazos contratuais. 


\subsection{METODOLOGIA}

0 presente artigo se baseia na avaliação do processo de licenciamento da atividade de perfuração exploratória realizada no Bloco BM-SEAL 100 e levantamento da legislação pertinente. Para o acompanhamento do processo de licenciamento ambiental em questão foi realizado um levantamento bibliográfico em livros, artigos publicados em periódicos de reconhecimento científico, monografias, teses e legislação ambiental específica do setor. Por se tratar de uma pesquisa que utiliza o estudo do caso do Bloco BM-SEAL 100, também foi realizada uma pesquisa documental, por meio de acesso ao Sistema de Licenciamento (SISLIC), disponibilizado no site do IBAMA.

Documentos que não se encontravam disponíveis neste canal foram solicitados ao órgão ambiental, por intermédio do Sistema Eletrônico do Serviço de Informação ao Cidadão (e-SIC), disponibilizado por força de Lei de Acesso à Informação (Lei no 12.527, de 18 de novembro de 2011).

Com todo o material bibliográfico e documental devidamente levantado foi feita análise detalhada de cada etapa do processo de licenciamento ambiental da perfuração exploratória no Bloco BM-SEAL 100, da operadora Petrobras, apresentando os desafios enfrentados pela empresa operadora e as dificuldades no atendimento aos prazos contratuais previstos no Contrato de Concessão.

\subsection{RESULTADOS E DISCUSSÃO}

\subsection{INFORMAÇÕES BLOCO BM-SEAL 100}

A Petróleo Brasileiro S. A - Petrobras é a empresa operadora da concessão e responsável pela atividade exploratória desenvolvida no Bloco BM-SEAL 100, que foi objeto da Rodada Zero, ocorrida após a edição da Lei no 9.478/1997, que define o novo marco regulatório do setor de petróleo e gás no Brasil. As atividades exploratórias no referido bloco foram iniciadas logo após a assinatura do contrato de concessão, e no dia 30 de agosto de 2004, foi declarada a comercialidade da área, dando origem ao campo de Piranema, situado na Bacia Sergipe/Alagoas a uma distância de $37 \mathrm{Km}$ da costa, em uma lâmina d'água entre 200 e 2000 m, representado na Figura 1.

Figura 1. Localização do Campo de Piranema (ANP, 2016)

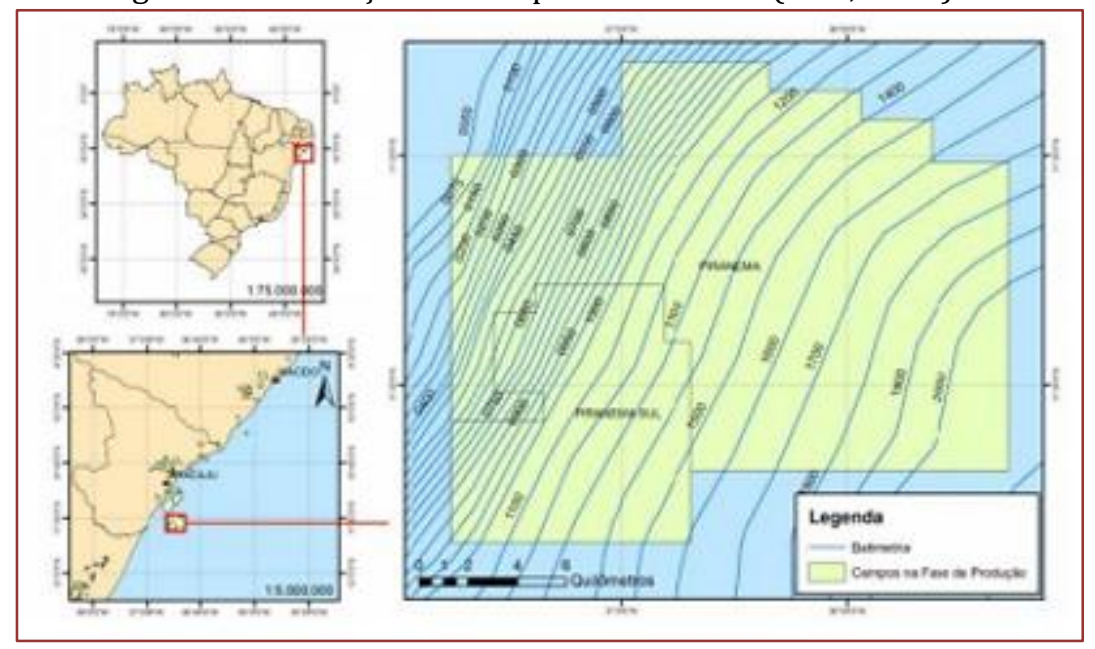

Na Rodada Zero não houve pagamento de bônus de assinatura por parte da empresa operadora, pois não ocorreu um procedimento licitatório propriamente dito, mas apenas a celebração de contratos de concessão entre a União e a Petrobras, nas áreas onde a empresa possuía o interesse de continuar suas atividades (LIMA, 2011). As demais áreas foram licitadas nas chamadas Rodadas de Licitação que passaram a ocorrer sob o comando da Agência Nacional do Petróleo, Gás Natural e Biocombustíveis, a partir de 1999. 


\subsection{PROCESSO DE LICENCIAMENTO ATRAVÉS DA RESOLUÇÃO CONAMA № 237/1997}

Para obtenção da Licença Prévia de Perfuração (LPper), a Petrobras solicitou o Termo de Referência (TR) ao Escritório de Licenciamento de Petróleo e Energia Nuclear (ELPN) do Instituto de Meio Ambiente e dos Recursos Naturais Renováveis (IBAMA), órgão, na época, competente para o licenciamento da atividade. 0 TR emitido definiu as diretrizes para elaboração do estudo ambiental correspondente à exigência do licenciamento, qual seja o Relatório de Controle Ambiental (RCA). No estudo ambiental deveria ser analisada a viabilidade ambiental da atividade pretendida, seguindo as orientações constantes no TR.

\subsection{ACOMPANHAMENTO DO PEDIDO DE LICENÇA PRÉVIA PARA PERFURAÇÃO}

No dia 13 de maio 2005, o ELPN/IBAMA emitiu um Termo de Referência no 09/2005, regulamentado pela Resolução CONAMA no 237/1997, que determina os procedimentos e os critérios necessários para a elaboração do Relatório de Controle Ambiental (RCA). 0 estudo ambiental foi desenvolvido pela empresa Gaia Meio Ambiente Ltda, contratada pela Petrobras e destinava-se à obtenção da licença ambiental denominada Licença Prévia para Perfuração (LPper), para autorização da execução da atividade de perfuração no Bloco BM-SEAL 100. Seguindo as orientações da resolução em vigor, a Petrobras requereu a licença prévia de perfuração, apresentando o RCA, junto ao Protocolo da agora Coordenação Geral de Petróleo e Gás do IBAMA (CGPEG/IBAMA), no dia 30/05/2005, dando início ao processo de licenciamento propriamente dito. O RCA, entregue pela Petrobras, passou a ser analisado pela equipe de analistas ambientais da CGPEG/IBAMA, de acordo com as etapas apresentadas na Tabela 1.

Tabela 1. Cronologia do processo de licenciamento para licença prévia de perfuração. (Adaptado de IBAMA, 2018)

\begin{tabular}{|c|c|c|}
\hline Data & Responsável & Ação \\
\hline $25 / 02 / 2005$ & Petrobras & Solicitação do TR \\
\hline $13 / 05 / 2005$ & IBAMA & Emissão do TR nº 09/2005 \\
\hline $30 / 05 / 2005$ & Petrobras & Encaminhamento do RCA \\
\hline $17 / 10 / 2005$ & IBAMA & Análise do RCA - Relatório técnico nº 017/2005 \\
\hline $15 / 11 / 2005$ & IBAMA & Análise do Relatório de fluidos \\
\hline $12 / 12 / 2005$ & IBAMA & Análise do Relatório de oceanografia \\
\hline $16 / 03 / 2006$ & IBAMA & Emissão de Parecer Técnico (PT) nº 090/2006 \\
\hline $31 / 03 / 2006$ & Petrobras & Resposta do PT no 090/2006 \\
\hline $26 / 06 / 2006$ & IBAMA & Emissão do PT no $167 / 2006$ \\
\hline $20 / 07 / 2006$ & Petrobras & Resposta do PT no $167 / 2006$ \\
\hline $07 / 08 / 2006$ & Petrobras & Encaminhamento de complementação da resposta ao PT no 167/2006 \\
\hline $25 / 08 / 2006$ & Petrobras & Encaminhamento de correções da resposta ao PT no $167 / 2006$ \\
\hline $15 / 09 / 2006$ & IBAMA & Emissão do PT no $300 / 2006$ \\
\hline $04 / 10 / 2006$ & Petrobras & Resposta do PT no 300/2006 \\
\hline $06 / 11 / 2006$ & IBAMA & Emissão do PT no $360 / 2006$ \\
\hline $27 / 11 / 2006$ & Petrobras & Resposta do PT no 360/2006 \\
\hline $12 / 12 / 2006$ & Petrobras & Encaminhamento de complementação da resposta ao PT no 360/2006 \\
\hline $14 / 12 / 2006$ & IBAMA & PT no 419/2006 - Autorizando a LPper \\
\hline $19 / 12 / 2005$ & IBAMA & Emissão de documentação para pagamento dos custos da LPper no 68/2006 \\
\hline
\end{tabular}

Após o requerimento da Licença Prévia de Perfuração no Bloco BM-SEAL 100, apresentado pela Petrobras, no dia 13/05/2005, juntamente com a apresentação do Relatório de Controle Ambiental (RCA), elaborado com base no Termo de Referência no 09/2005, iniciou-se o processo de licenciamento, seguindo a Resolução CONAMA no 237/1997.

Segundo a legislação ambiental vigente, o órgão ambiental competente para o licenciamento, dará início à análise do estudo ambiental apresentado pelo requerente, sendo possível a solicitação de complementações e esclarecimentos sobre os itens do estudo sempre que houver dúvidas ou entendimento dos analistas sobre a necessidade de mais informações.

Conforme o acompanhamento do processo de licenciamento em questão, a CGPEG/IBAMA iniciou a análise do RCA apresentado pela interessada, alguns meses após a entrega do estudo ambiental e, ao longo do período de análise, emitiu 4 Pareceres Técnicos para os quais foram dadas respostas tempestivas por parte da interessada., demonstrando a sua proatividade no processo. 
A LPper no 68/2006 foi emitida no dia 18 de dezembro de 2006, portanto, 688 dias (mais de 22 meses), após a abertura do processo de licenciamento junto ao IBAMA, ou seja, o processo de licenciamento de perfuração teve duração de quase 2 anos. A LPper no 68/2006 autorizou a execução de 7 poços e a completação de 2 poços já existentes na área e tinha validade até 14 de dezembro de 2008. A LPer também definiu a Noble Muravlenko (NS-18), bandeira de Bahamas, de propriedade da empresa Noble Drilling Nederland B.V. como unidade de perfuração autorizada para a realização da atividade de perfuração no Bloco BM SEAL-100, na Bacia de Sergipe/Alagoas.

\subsection{CONCLUSÃO}

A preocupação com o meio ambiente tem sido pauta de diversas discussões desde a promulgação da Lei no 6.938 de 1981 que define a Política Nacional de Meio Ambiente. É possível perceber que as questões ambientais sofreram alterações de ordem normativa e legais ao longo dos anos, como forma de garantir à sociedade a qualidade ambiental e ao empreendedor, a adoção de condutas que levem à segurança operacional das suas atividades.

Para as atividades de petróleo e gás, o licenciamento ambiental surgiu como forma de proteger e minimizar os impactos negativos gerados pelas atividades de exploração e produção, consideradas de significativo potencial poluidor.

No acompanhamento do processo de licenciamento de perfuração exploratória no Bloco BM-SEAL 100 é possível perceber que algumas ações por parte tanto do órgão ambiental quanto do interessado (empresa Petrobras) podem impactar o início da atividade que, por sua vez, está atrelada aos prazos contratuais previstos no Contrato de Concessão.

No caso específico do Bloco BM-SEAL 100 a atividade de perfuração só pode ser iniciada 688 dias após o requerimento junto ao órgão ambiental, mesmo não tendo sido solicitado o estudo ambiental mais exigente, ou seja, o EIA/RIMA. Ou seja, o IBAMA não considerou a atividade de perfuração no bloco como de significativo impacto ambiental, sendo exigida a modalidade de estudo o Relatório de Controle Ambiental (RCA) que configura o nível mais brando de exigência para o licenciamento. Era de se esperar, portanto, que o processo tivesse duração de apenas 6 meses contados a partir da data de entrega do estudo pela interessada, como determina a legislação.

Pela análise, pode-se concluir que a duração do processo maior do que a prevista pela legislação ocorre em função de responsabilidade de ambos os lados. Ou seja, o órgão ambiental emitiu vários pareceres técnicos solicitando complementações e esclarecimentos, quando a regulamentação determina que seja feita uma única solicitação, podendo esta ser reiterada, quando couber. Por outro lado, estas reincidentes solicitações de esclarecimentos ou complementações ocorrem em função da má qualidade do estudo ambiental elaborado, sendo, portanto, de responsabilidade também do interessado. Ainda pode-se apontar como impacto na demora do processo, o tempo de quase 3 meses que o IBAMA levou para emitir o TR, uma vez que a legislação vigente à época não definia prazo para esta etapa preliminar.

Como forma de resolver esse problema a Portaria do Ministério do Meio Ambiente (MMA) no 422/2011 instituiu o prazo de 15 dias para a emissão do Termo de Referência para todas as atividades que venham a ser licenciadas e aliou num único diploma legal as diretrizes para o licenciamento de todas as atividades do segmento upstream de petróleo e gás.

A atividade de perfuração exploratória deve ocorrer dentro do tempo estabelecido no contrato de concessão para o Período Exploratório correspondente. Caso a operadora da concessão não atenda a esta exigência contratual, poderá sofrer sanções e até perder a concessão. No caso do Bloco BM-SEAL 100, mesmo com a emissão da licença prévia de perfuração tardia não houve necessidade da Petrobras solicitar à ANP a prorrogação do período exploratório.

Destaca-se, no entanto, que processos de licenciamento de atividades considerados de significativo potencial de impacto ambiental, serão bem mais demorados em função das exigências do órgão ambiental que levará à solicitação de Estudo de Impacto Ambiental e respectivo Relatório de Impacto Ambiental (EIA/RIMA) e provável exigência de realização de Audiência Pública para sua finalização. 


\section{REFERÊNCIAS}

[1] Agência Nacional do Petróleo, Gás Natural e Biocombustíveis (ANP). Disponível em:< http://www.anp.gov.br/images/planos_desenvolvimento/Piranema.pdf>. Acesso em 06 de julho de 2018.

[2] Balanço Energético Nacional 2019 (BEN). Empresa de Pesquisa Energética (EPE). Relatório Síntese/Ana Base 2018. Rio de Janeiro/RJ. Maior de 2019.

[3] Brasil. Ministério do Meio Ambiente (MMA). Resolução CONAMA no 237, de 19 de Dezembro de 1997. Dispõe sobre a revisão e complementação dos procedimentos e critérios utilizados para o licenciamento ambiental. (83) 3322.3222 contato@conepetro.com.br www.conepetro.com.br

[4] Brasil. Ministério do Meio Ambiente (MMA). Portaria no 422, de 26 de outubro de 2011. Dispõe sobre procedimentos para o licenciamento ambiental federal de atividades e empreendimentos de exploração e produção de petróleo e gás natural no ambiente marinho e em zona de transição terra-mar.

[5] Godoy, A. V. de. A eficácia do licenciamento ambiental como um instrumento público de gestão do meio ambiente. Brasília: OAB Editora, 2005.

[6] Lima, G. G. A. A questão da natureza jurídica dos royalties na atividade de exploração e produção de petróleo e gás natural: expressão de responsabilidade civil e a condução da matéria pela justiça federal. Revista Jurídica da Seção Judiciaria de Pernambuco. 2011. Disponível em: < https://revista.jfpe.jus.br/index.php/RJSJPE/article/view/39>. Acesso em: 20 de Junho de 2018.

[7] Neta, M. da. S. C.; Moura, K. C. de. F.; Dias, N. da. S.; Souza, A. C. M.; Moura, K. H. S. Licenciamento ambiental: conflito de interesses. Revista Verde de Agroecologia e Desenvolvimento Sustentável. Pombal, vol.10, n5, p.76-80, 2015.

[8] Ramalho, J. P. Regulação Ambiental na Indústria do Petróleo: Uma Análise Comparativa entre o Brasil, os EUA e a Noruega. 2016. 103 f. Dissertação (Graduação em Engenharia de Petróleo), Departamento de Engenharia Química e de Petróleo, Universidade Federal Fluminense, Niterói. 


\section{Capítulo 2}

\section{Geomecânica e perfuração em formações Salinas}

\section{Vitor Gama Rodrigues}

\section{Fernanda Silva Calixto}

Resumo: A perfuração de poços sempre representou um cenário desafiador à engenharia, sobretudo quanto ao seu planejamento. Com as otimizações da tecnologia de exploração na última década, locais antes inacessíveis tornaram-se os principais alvos exploratórios. A descoberta de enormes reservatórios carbonáticos abaixo de espessas camadas de sal, realizada pela PETROBRAS em 2006 no litoral brasileiro, elevara a produção nacional à um patamar observado em grandes exportadores ao mesmo tempo que tornava a engenharia de poços ainda mais complexa. Geólogos, geofísicos e engenheiros têm se dedicado à identificação e mapeamento de estruturas salinas ao redor do mundo, uma vez que a presença deste tipo de rocha em uma bacia sedimentar aumenta as chances de sucesso exploratório. Os desafios inerentes a este tipo de rocha se dá às propriedades geomecânicas intrínsecas do sal, que muito difere das rochas siliciclásticas e carbonáticas convencionais, quando sob um estado de tensões e temperatura constantes, apresentando comportamento de fluxo plástico (creep). Atravessar trechos salinos exige muita expertise e a identificação destes através de levantamentos geofísicos e em real time é de fundamental importância para elaboração de estratégias e controle da perfuração, implementando o que há de mais sofisticado para este campo.

Palavras-chave: Perfuração, geomecânica, creep, rochas salinas. 


\section{INTRODUÇÃO}

O desenvolvimento tecnológico, principalmente tecnologia brasileira, permitiu que a exploração por novas reservas portadoras de excelentes acumulações de hidrocarbonetos se estendesse à lâminas de água profundas e ultraprofundas na última década. Assim, as interessantes descobertas em cenários do pré-sal fizeram a exploração de bacias sedimentares offshore contendo estruturas salinas torna-se o novo modelo exploratório em todo o mundo. Este novo modelo traz consigo grandes desafios para a engenharia, as propriedades geomecânicas das rochas salinas as diferem das demais formações, ocasionando potenciais problemas tanto dentro do corpo salino - instabilidade da parede do poço e colapso do revestimento por fluência - quanto próximas de sua estrutura - intervalos sobrepressurizados e severos kikcs (rubble zones). A fluência do sal dificulta também a perfuração quando próximo a estruturas dômicas salinas, pois a ascendência natural dos domos deforma as camadas acima e ao redor deste, resultando em tortuosidade acentuada na trajetória do poço e alterações das geopressões (FIRME, 2013).

Apesar dos riscos de se perfurar através de uma estrutura salina, estas rochas estão associadas a presença de potenciais reservatórios com óleo de boa qualidade. Estas estruturas, quando espessas, formam trapas estruturais bastante efetivas por possuírem porosidade funcionalmente nula, impedindo a migração do óleo que se acumula nas imediações de sua base. Devido a halocinese do sal, janelas são abertas e parte do óleo migra para a região pós- sal onde entra em contato com a água de subsuperfície que contém bactérias degradantes, tornando-o mais pesado e ácido, enquanto o óleo trapeado mantém suas características originas (FALCÃO, 2007).

Formações salinas representam um desafio por suas particularidades geomecânicas, porém, ressalta-se que nem todos os sais causam prejuízos à perfuração. A identificação prévia de zonas problemáticas é imprescindível ao planejamento da estratégia de perfuração, enquanto que a interpretação de alguns parâmetros durante a perfuração auxilia na detecção destas zonas em real time.

\section{METODOLOGIA}

Este artigo foi elaborado através de estudos da literatura técnica descritiva constituindo uma revisão que enfoca a análise geomecânica do sal e melhores estratégias de detecção e perfuração em formações salinas, estabelecendo um complemento aos artigos que abordam estratégias de perfuração nestas zonas, mas, não contam com os parâmetros de detecção, especialmente durante a perfuração.

O estudo de produções científicas acerca do tema foi realizado no período de março a junho de 2018, utilizando-se para a pesquisa livros técnicos e a base de dados das bibliotecas virtuais OnePetro, PB Publishing e do portal da PUC-Rio (Teses e Dissertações), reunindo os principais artigos publicados entre 2001 e 2017. O critério de seleção de artigos foi definido como: publicados pela Society Petroleum Engineers (SPE), Offshore Technology Conference (OTC) e American Rock Mechanics Association (ARMA). Durante o levantamento de dados, os materiais mais pertinentes ao tema foram publicados na língua inglesa, sendo as pesquisas ao OnePetro limitadas a este idioma e de onde foram adquiridos a maioria dos artigos científicos, sendo apenas um retirado do Boletim Técnico de Produção de Petróleo, na plataforma da PB Publishing. Os principais pontos observados durante o estudo foram coletados e abordados no presente artigo.

\section{RESULTADOS E DISCUSSÃO}

\subsection{GEMECÂNICA DO SAL}

Geologicamente o sal é uma estrutura evaporítica, possuindo porosidade funcionalmente nula, servindo como uma camada selante que aprisiona com maior efetividade os fluidos que chegam até a sua base ou que estão envoltos ao seu corpo, não havendo, idealmente, poropressão em seu interior, salve intercalações com formações permoporosas. Do ponto de vista geomecânico, o sal não sofre compactação, não variando (ou variando muito pouco) sua densidade com o contínuo soterramento, contrariando os princípios da geotecnia, gerando a hipótese de que o comportamento geomecânico do sal não depende do confinamento (ROCHA e AZEVEDO 2009).

A halocinese do sal é o que mais a diferencia das demais formações. Rochas salinas apresentam baixa resistência mecânica, deformando plástica e lentamente de modo progressivo ao longo do tempo quando submetidas a regimes de tensões cisalhantes ou axiais. A fluência ocorre, pela ascensão do corpo menos denso para áreas de menor resistência ao fluxo, induzindo inclinações e deformações nas rochas 
sobrejacentes e ao seu redor (rubble zones). Devido a esta mobilidade, muitas vezes, maiores tensões horizontais são esperadas dentro e ao redor do corpo salino, conferindo ao sal altos gradientes de fratura, em valores próximos ou superiores aos gradientes de sobrecarga. As descontinuidades e tricas geradas durante a fluência são naturalmente fechadas pelas deformações lentas do sal, processo conhecido por cura ou self-healing. Defeitos pontuais (vacância, auto-intersticial e impurezas) e lineares (discordância de aresta, espiral e mista) são as principais falhas que engatilham os mecanismos de fluência (DUSSEAULT et al, 2004; POIATE, 2012; FIRME, 2013).

A taxa de fluência varia com o tipo de sal predominante na estrutura salina, da temperatura e tensões atuantes e da sua espessura. Sais de cloreto apresentam as maiores variações de taxas de fluência, principalmente os sais hidratados. Assim, taquidritas $\left(\mathrm{CaMg}_{2} \mathrm{Cl}_{6} * 12 \mathrm{H}_{2} \mathrm{O}\right)$ e carnalitas $\left(\mathrm{MgKCl}_{3} * 6 \mathrm{H}_{2} \mathrm{O}\right)$ são classificados como sais mais móveis, enquanto halitas $(\mathrm{NaCl})$ apresenta uma menor mobilidade. Sais mais móveis são também mais solúveis em água, o que pode gerar problemas para perfuração caso fluidos inadequados sejam utilizados para tal. Outros evaporitos, como carbonatos e sulfatos, são essencialmente imóveis e menos solúveis. A profundidade afeta diretamente a fluência do sal, pois maiores tensões verticais - aplicadas pelo soterramento - e gradientes geotérmicos estarão atuando sobre estes corpos. A espessura do sal determina o seu comportamento halocinético. Seções menos espessas estão mais sujeitas ao movimento, ascendendo e formando estruturas dômicas conhecidas como diápiros, enquanto seções mais espessas não apresentam tanta mobilidade. Ótimas acumulações de óleo são encontradas abaixo de grandes estruturas salinas por não haver movimentos significativos que possam abrir janelas e permitam a migração do óleo para a região pós-sal (AMER et al, 2016; POIATE, 2012).

\subsection{PRINCIPAIS PARÂMETROS À DETECÇÃO DO SAL}

As abordagens realizadas por POIATE (2012) e FIRME (2013), como a sensibilidade e condutividade térmica, podem ser consideradas para deteç̧ão de trechos salinos durante a perfuração. ROCHA e AZEVEDO (2009) e FALCÃO et al (2007) destacam os principais parâmetros de detecção de rochas salinas antes e também durante a perfuração através da sísmicas e ferramentas de perfilagem que podem estar instaladas no LWD (Logging While Drilling) do BHA (Bottom Hole Assembly). Tais parâmetros podem ser considerados:

$>\quad$ Antes da perfuração:

- Levantamentos geofísicos através da sísmica (2, 3 e 4D, imageamento e geoprocessamento) para identificar o corpo salino e ter uma ideia de suas dimensões;

- Levantamento dos históricos de poços próximos para correlação. Informaç̧ões como a estratigrafia ajudam a identificar os principais sais que constituem a estrutura salina e dados de geopressões dão uma ideia das zonas que podem gerar perdas de circulação ou kicks.

$>\quad$ Durante a perfuração:

- $\quad$ Alterações bruscas no ROP. Um rápido aumento na taxa de penetração pode indicar a perfuração em zonas fraturadas próximos ao corpo salino (o que pode gerar consideráveis perdas de circulação, por isso, o material de combate a perda deve estar pronto para uso) ou através do próprio sal. Halitas apresentam altos valores de ROP $(>10 \mathrm{~m} / \mathrm{h})$. Quedas bruscas do ROP $(\sim 1 \mathrm{~m} / \mathrm{h})$ podem indicar a perfuração de anidritas ou dolomitas, rochas evaporíticas de maior dureza;

- Utilizar do VSP(Vertical Seismic Profile) ou SWD (Seismic While Drilling) na coluna de perfuração para prever a aproximação das rochas salinas;

- $\quad$ Perfis térmicos podem ser usados para determinação do topo e base do sal, pois as rochas salinas apresentam uma alta condutividade térmica, demonstrando menores valores geotérmicos do que as formações que estão acima e abaixo dela;

- $\quad$ Alteração dos dados de perfis elétricos: no perfil densidade, pode ser observado a leitura de valores menores, entre 1,5 e $2,2 \mathrm{~g} / \mathrm{cm}^{3}$. Sais, em geral, têm densidade menor do que as outras formações, que variam entre 2,5 e $2,8 \mathrm{~g} / \mathrm{cm}^{3}$. Sais mais duros, como anidritas, possuem os maiores valores para densidade, variando próximo a $2,97 \mathrm{~g} / \mathrm{cm}^{3}$. No perfil resistividade, há um aumento considerável dos valores lidos. Esta característica, contra intuitiva, se dá pelo fato deste perfil identificar a resistividade dos fluidos presentes nos poros das rochas e sabendo-se que sal possui porosidade desprezível, os valores obtidos são elevados. Uma alteração mais intuitiva ocorre no perfil caliper. A leitura do diâmetro do poço pode fornecer altos valores indicando um alargamento por dissolução ou valores mais baixos, indicando 
fechamento do trecho por fluência;

\subsection{PERFURAÇ̃̃O NO SAL}

A perfuração através do sal já ocorria em diversas partes do mundo (Mar do Norte, Golfo Pérsico, Golfo do México, Brasil, etc.), porém, em extensões que consistiam entre dezenas e centenas de metros, devido as dificuldades encontradas. FALCÃO et al (2007) relembra que até a década de 80, na Bacia de Campos, foram perfurados 22 poços que atravessavam mais de 10 metros de sais solúveis, onde, destes, 11 tiveram problemas com fechamento do poço, 1 teve o revestimento colapsado, 3 foram desviados e 3 foram perdidos.

Atualmente, descritos na literatura técnica, mais de 3 mil metros de halita foram perfurados com sucesso no Golfo do México e, aproximadamente, 2 mil metros de sais entre anidritas, halitas e taquidritas foram atravessados na Bacia de Santos. De fato, nem todos os sais causam problemas à perfuração e durante 0 planejamento do poço, simulações numéricas são utilizadas para prever o comportamento do sal medindo a sua taxa de fechamento. WHITSON et al (2001) ressalta que formações salinas de menor mobilidade, como halitas puras, são preferíveis à perfuração, principalmente se mais espessas. Por não conter poropressão e possuir altos gradientes de fratura, seções mais longas do que nas demais formações sedimentares poderão ser perfuradas, estendendo-se o comprimento das fases.

A estabilidade do poço frente a zona de sal depende da correta escolha do fluido de perfuração utilizado para atravessar tal seção. Existem basicamente dois tipos de fluidos para esta operação: fluidos aquosos saturados com $\mathrm{NaCl}$ e fluidos não-aquosos (também chamados de fluidos a base de óleo e, mais recentemente, fluidos sintéticos).

WHITFILL et al (2002), FALCÃO et al (2007) e AMER et al (2016) concordam que os fluidos sintéticos são os mais empregados para a perfuração em águas profundas e ultraprofundas, principalmente em formações salinas. Em maiores profundidades, fluidos aquosos são desconsiderados, pois tendem a formar hidratos próximos ao fundo do mar. Além disso, as maiores temperaturas aumentam sua solubilidade, necessitando cada vez mais de $\mathrm{NaCl}$ para mantê-lo saturado, não garantindo a dissolução de outros sais presentes na formação. Fluidos a base de óleo diesel foram amplamente utilizados, sendo recentemente substituídos pelos fluidos sintéticos. Estes fluidos são menos tóxicos (a base de n-Parafina), mais toleráveis a contaminação e mais estáveis termicamente. Também maximizam a taxa de penetração e diminuem a vibração da coluna. Principais desvantagens são quanto aos elevados custos e maior limitação do uso de produtos de combate a perda.

Quanto a cimentação de revestimentos, VALLEJO et al. (2017) realizou ensaios para determinar a concentração ideal dos sais mais utilizados nas misturas das pastas de cimento, cloreto de sódio $(\mathrm{NaCl})$ e cloreto de potássio ( $\mathrm{KCl}$ ), em poços no Golfo do México, região comumente utilizada como padrão na indústria petrolífera. Ao final, foi observado que as pastas contendo $\mathrm{KCl}$ apresentam maiores controles de perda de fluido, fluido livre, tempo de espessamento e quanto a sua reologia, sendo mais recomendada para pastas empregadas em zonas profundas e ultraprofundas por apresentar, também, maiores resistências a compressão e custos menores quando comparadas as pastas que contêm o $\mathrm{NaCl}$, pois para estas, maiores concentração do sal são necessários, enquanto que com $\mathrm{KCl}$, menores concentrações são necessárias para se atingir valores ótimos.

Para o planejamento da perfuração no sal, FALCÃO et al (2007) e WHITSON et al (2001) abordam estratégias construídas dos aprendizados na evolução da perfuração.

Utilizar de simuladores de fluência para prever o comportamento do sal e determinar os pesos ideias do fluido de perfuração a manter a estabilidade do poço. Sais de menor mobilidade (como halitas puras) são mais favoráveis à perfuração, pois apresentam carregamentos mais uniformes e, sendo homogêneas, inibem os problemas de controle de poço, permitindo que longas extensões destes sais possam ser perfuradas em uma única fase. Ferramentas analíticas como o LWD e o MWD (Measurement While Drilling) devem estar presentes na coluna de perfuração para prever regiões problemáticas, principalmente na saída do sal, onde os altos pesos utilizados para manter a estabilidade do sal acarretam em severas perdas de circulação ao atingir formações extremamente fragilizadas, acompanhando e corrigindo os ganhos de ângulo que possam ocorrer.

Para perfuração das rochas salinas, brocas PDC (Polycrystalline Diamond Compact) apresentam melhores resultados quando comparados às brocas de cones, sendo mais indicadas para esta operação. Existem também algumas variações destas brocas, tais como as brocas bicêntricas, que podem aumentar em até 
$20 \%$ o diâmetro nominal. Mais comumente, alargadores do tipo underreamer são utilizados nas operações junto a estabilizadores. Estes alargadores possuem de duas a três peças móveis que são acionados hidraulicamente quando há a necessidade de aumentar o diâmetro do poço, instaladas pouco acima da broca. Estas ferramentas permitem alagar de 20 a $40 \%$ o diâmetro nominal, ideal para formações com maior taxa de fluência, sendo muito utilizadas também para realizar repasses.

Boas práticas são estabelecidas como: acompanhar todos os parâmetros de perfuração metro a metro, realizar repasses a cada seção perfurada, realizar repasses de toda a seção caso seja detectado fechamento, realizar manobras curtas até a última sapata em intervalos de até 10 horas, circular o poço a cada 12 horas pelas linhas de kill e choke do BOP (Blowout Preventer) e do choke manifold, evitando obstruções por acúmulo de sal no fluido.

\section{CONCLUSÃO}

Formações salinas estão associadas a excelentes reservatórios petrolíferos, constituindo um novo cenário exploratório em todo o mundo. 0 comportamento mecânico das rochas salinas as diferem das rochas sedimentares convencionais, trazendo novos desafios à engenharia. Por vezes, estes corpos salinos se mostram mais vantajosos quanto a perfuração por não apresentarem os principais problemas observados nos carbonatos e siliciclásticos, contudo, regiões ao entorno destas estruturas merecem mais atenção. Zonas com sais de maior mobilidade devem ser evitadas, isolando-as rapidamente se intercaladas nos trechos perfurados, demonstrando a importância de se detectar regiões problemáticas a tempo de tomar as ações mitigadoras. Assim, um bom planejamento e as boas práticas operacionais irão garantir a integridade estrutural do poço.

\section{REFERÊNCIAS}

[1] Amer, A. et al. Drilling Through Salt Formations: A Drilling Fluids Review. Society of Petroleum Engineers (SPE), paper no-180326-MS, 2016.

[2] Dusseault, M. B. et al. Drilling Around Salt: Risks, Stresses and Uncertainties. American Rock Mechanics Association (ARMA), paper nำ04-647, 2004.

[3] Falcão, J. L. et al. Perfuração em Formações Salinas. PB Publishing, Petrobras, Rio de Janeiro, v. 2, n. 2, p. 261 - 286, 2007.

[4] Firme, P. A. L. P. Modelagem Constitutiva e Análise Probabilística Aplicadas a Poços em Zonas de Sal. 2013. Dissertação (Mestrado em Engenharia Civil) - Departamento de Engenharia Civil, PUC-Rio, Rio de Janeiro.

[5] Poiate Junior, E. Mecânica das Rochas e Mecânica Computacional para Projetos de Poços de Petróleo em Zonas de Sal. 2012. Tese (Doutorado em Engenharia Civil) - Departamento de Engenharia Civil, PUC-Rio, Rio de Janeiro.

[6] Rocha, L. A. S.; Azevedo, C. T. Projeto de Poços de Petróleo: Geopressões eAssentamento de Colunas de Revestimento. 2. Ed. Rio de Janeiro: Interciência: Petrobras, 2009.

[7] Vallejo, V. et al. Ultra Deepwater Salt Zones Cementing in Gulf of Mexico Wells. Offshore Technology

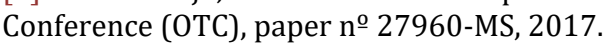

[8] Whitfill, D. et al. Drilling Salt: Effect of Drilling Fluid on Penetration Rate and Hole Size. Iadc/SPE Drilling Conference, paper no 74546, 2002.

[9] Whitson, C. D.; MCFADYEN, M. K. Lessons Learned in the Planning and Drilling of Deep Subsalt Wells in the Deepwater Gulf of Mexico. Society of Petroleum Engineers (SPE), peper no 71363, 2001. 


\section{Capítulo 3}

\section{Obtenção e estudo reológico de um fluido de perfuração à base de água}

\section{Mariana Martins do Vale \\ Alfredo Ismael Curbelo Garnica \\ Fabíola Dias da Silva Curbelo}

Resumo: A seleção de fluidos de perfuração de poços de petróleo e gás natural, bem como a avaliação do desempenho desses fluidos durante a operação é muito importante no desenvolvimento na área de campo, como também, na fase exploratória. Para garantir uma perfuração segura e eficiente, esses fluidos têm por funções principais carrear o cascalho gerado na perfuração, resfriamento da broca, manutenção da estabilidade do poço, bem como o controle da pressão para evitar e entrada de fluxo de óleo, gás ou água proveniente das rochas perfuradas. Nesse âmbito, com um vasto estudo realizado a respeito dos aditivos químicos utilizados na preparação do fluido de perfuração afim de formulá-lo, este trabalho teve como foco, preparar e estudar a reologia de um fluido de à base de água para perfuração de poços de petróleo. Os parâmetros reológicos determinados foram: viscosidade aparente, viscosidade plástica, limite de escoamento e força-gel. Os resultados obtidos para estes parâmetros estão de acordo com as normas da PETROBRÁS N-2604. Os dados de tensão vs taxa de cisalhamento indicam a tendência de um comportamento plástico real do fluido proposto, sendo o modelo de HerschellBuckley representativo dos dados experimentais. Observou-se também, uma diminuição da viscosidade aparente com o aumento da taxa de cisalhamento, aspecto característico do fluido proposto.

Palavras-chave: Fluido de perfuração, reologia, viscosidade aparente, Herschell- Buckley. 


\section{INTRODUÇÃO}

0 sucesso e conclusão de um poço de perfuração e o custo do projeto estão relacionados às propriedades dos fluidos de perfuração. Neste contexto, a escolha do fluido de perfuração e a preservação de suas propriedades impactam profundamente nos aspectos operacionais e econômicos do projeto.

Tecnicamente, a perfuração de poços consiste em um conjunto de operações necessárias para atravessar as

formações geológicas a fim de se conseguir a prospecção do hidrocarboneto. As rochas são perfuradas pela ação rotativa de uma broca existente na extremidade de uma coluna de perfuração e os fragmentos da rocha são removidos pela ação de um fluido de perfuração por bombeamento na coluna de perfuração. (THOMAS, 2004). 0 eficiente transporte dos cascalhos à superfície, bem como sua sustentação durante as paradas de circulação dependem significativamente do comportamento reológico do fluido. (MAHTO,2004).

Os fluidos à base de água apresentam vantagens em relação aos outros por apresentar baixo custo, boa biodegradabilidade e baixo impacto ambiental. (DARLEY e GRAY, 1988) Nesse âmbito com um vasto estudo realizado sobre os constituintes já utilizados na preparação e de suas respectivas funções nos fluidos de perfuração, este trabalho teve por foco formular um fluido de perfuração a base de água, a partir de seus constituintes (adensante, viscosificante, controlador de $\mathrm{pH}$, inibidor, redutor de filtrado) básicos e realizar o estudo reológico do mesmo.

\section{METODOLOGIA}

\subsection{PREPARAÇÃO DO FLUIDO DE PERFURAÇÃO À BASE DE ÁGUA}

0 fluido de perfuração foi preparado a partir da mistura dos aditivos (Tabela 1) que foram adicionados, um a um, sob agitação máxima (17000 rpm) em agitador Hamilton Beach(Figura 1), modelo 140, obedecendo a ordem descrita abaixo:

1.Pesa-se 0,5 g de goma xantana e 3,0 g de HP- amido com três casas decimais;

2.Adiciona-se $350 \mathrm{ml}$ de água industrial no copo metálico do aparelho de dispersão, Hamilton Beach- Fann, Modelo 140;

3.Com as quantidades de aditivos pré-estipuladas devidamente pesadas, adiciona-se lentamente a goma xantana no copo metálico e agita-se por $10 \mathrm{~min}$;

4.Em seguida, adicionam-se HP- amido e agita-se por $10 \mathrm{~min}$;

5.Por fim coloca-se 12 gotas de bactericida e agita-se por mais 5 minutos.

Tabela 1: Aditivos utilizados na preparação do fluido de perfuração.

\begin{tabular}{|c|c|c|}
\hline \multicolumn{3}{|c|}{ Concentração } \\
\hline Água industrial & 1 bbl-eq & Fase contínua \\
\hline Goma xantana & $0,5 \mathrm{ppb} / 1 \mathrm{ppb}$ & Viscosificante \\
\hline HP-amido & $3,0 \mathrm{ppb}$ & Redutor de filtrado \\
\hline $\mathrm{NaOH}$ & $0,5 \mathrm{ppb}$ & Alcalinizante \\
\hline Argila ativada & $10 \mathrm{ppb}$ & Viscosificante \\
\hline $\mathrm{NaCl}$ & $10 \mathrm{ppb}(28.000)$ & Eletrólito \\
\hline Triazina & $0,3 \mathrm{ppb}-12$ gotas & Bactericida \\
\hline Baritina & Peso 9,5 ppg & Adensante \\
\hline
\end{tabular}


Figura 1: Misturador Hamilton Beach Fann- Modelo 140

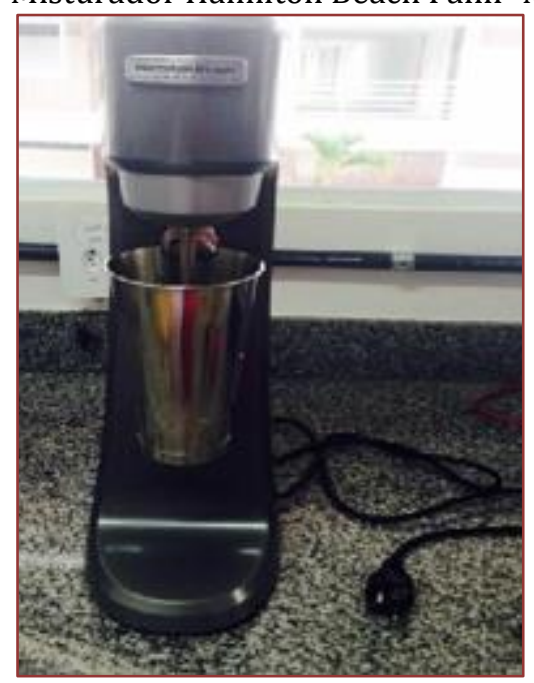

\subsection{DETERMINAÇÃO DA MASSA ESPECIFICA DO FLUIDO}

Para medida da massa específica do fluido de perfuração foi utilizada a balança de lama Fann modelo 140 (Figura 2). A metodologia de ensaio é simples, coloca-se o fluido ensaiado no recipiente (copinho) da balança. A medida de densidade é obtida através do ajuste de uma peça móvel. Esta peça é deslocada, a fim de equilibrar a balança, tendo como referência um nível de bolha. A medida de densidade é então obtida na marcação presente no braço da balança onde a peça móvel equilibrou o conjunto.

Figura 2. Balança de lama Fann- Modelo 140

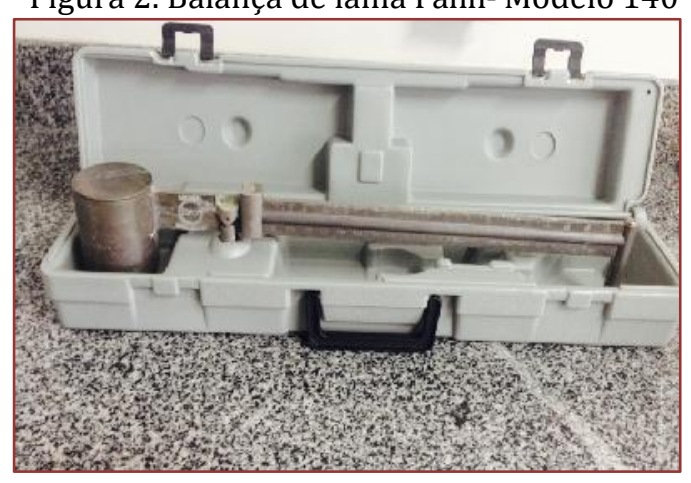

\subsection{ESTUDO REOLÓGICO DO FLUIDO DE PERFURAÇÃO}

Após 24 horas de repouso o fluido foi agitado durante 5 minutos em agitador mecânico Hamilton Beach, modelo 140 a velocidade de $17000 \mathrm{rpm}$. Em seguida o fluido foi transferido a um recipiente próprio para o armazenamento da amostra durante as medições. No viscosímetro Fann 35A, foram lidos seis valores do ângulo de deflexão (torque) com taxas de cisalhamento variando de 5,1 a 1021,8 s-1. A leitura das medidas foi realizada da seguinte forma, baseando-se na Norma PETROBRÁS N-2605 (1998):

1. Após 2 minutos a partir do ligamento do aparelho a velocidade de 600 rpm é lido o valor de $\theta_{600}$,isto é, a deflexão a $600 \mathrm{rpm}$.

2. Altera-se a velocidade de rotação para 300 rpm e após 15 segundos, é lido o valor de $\theta_{300}$;

3.A velocidade é então reduzida a $200 \mathrm{rpm}$ e espera-se estabilizar para efetuar a leitura de $\theta_{200} .0$ mesmo procedimento foi utilizado para as velocidades de $100 \mathrm{rpm}, 6 \mathrm{rpm}$ e $3 \mathrm{rpm}$ nas obtenções dos valores de $\theta_{100}, \theta_{6}, \theta_{3}$. 
A partir dos valores dos ângulos de deflexão lidos, é possível a determinação das viscosidades aparente (VA), viscosidades plásticas (VP) e o limite de escoamento (LE), de acordo com a mesma norma:

1.A viscosidade aparente, em cP, corresponde ao valor medido na leitura a 600 rpm dividido por 2;

2.A viscosidade plástica, em cP, é a diferença das leituras obtidas a 600 e a 300 rpm;

3.0 limite de escoamento, em $\mathrm{N} / \mathrm{m}^{2}$ é calculado como sendo a diferença entre a leitura a $300 \mathrm{rpm}$ e a viscosidade plástica.

Além das três grandezas, é possível a determinação dos valores de forças- géis conforme o seguinte procedimento:

1.Manter o fluido a velocidade de $600 \mathrm{rpm}$ durante 15 segundos;

2.Manter em repouso em 10 segundos;

3.Alterar a velocidade para $3 \mathrm{rpm}$ e realizar a leitura registrando a maior deflexão do indicador como gel inicial $\left(\mathrm{G}_{0}\right)$ em lbf/100pé2;

4.Manter o fluido em repouso em 10 segundos;

5.Alterar a velocidade para $3 \mathrm{rpm}$ e realizar a leitura registrando a maior deflexão do indicador como gel inicial $\left(\mathrm{G}_{10}\right)$ em lbf/100pé2;

A força gel é um parâmetro de natureza reológica, que indica o grau de gelificação. É calculada como sendo a diferença entre as forças final e inicial. (GRAY \& DARLEY, 1981). A força gel $G_{0}$ mede a resistência inicial para colocar o fluxo em fluido. Já a final, neste caso $\mathrm{G}_{10}$ mede a resistência do fluido para reiniciar o fluido quando este fica certo tempo em repouso. (MACHADO, 2002)

Através dos dados coletados, descritos neste item, é possível plotar as curvas de escoamento para o tratamento de dados de forma a caracterizar o comportamento reológico do fluido estudado.

A partir das deflexões lidas $(\theta$ ), pode- se calcular a tensão cisalhante (Equação

1) e utilizando os valores das velocidades de rotação, calcula-se a taxa de cisalhamento ( $\gamma$ ) (Equação 2). 0 valor da tensão de cisalhamento $(\tau)$, em Pascal, e o valor da taxa de cisalhamento $(\gamma)$, em $s^{-}{ }^{1}$, são: (SHIROMA, 2012).

$$
\tau=0,51 . \theta
$$

$\gamma=1,703 . \mathrm{N}$
[1]

[2]

Os valores de viscosidade referentes ao gráfico $\log (\mu$, viscosidade aparente) vs $\log (\gamma$, taxa de cisalhamento) são calculados a partir da Equação 3, utilizando os valores de deflexão e velocidade de rotação, obtidos do estudo reológico.(SHIROMA,2012)

$$
\mu=300 . \theta / \mathrm{N}
$$

\subsection{MODELO DE HERSCHELL- BUCKLEY}

O Modelo de Herschell- Buckley foi utilizado para representar os dados experimentais, obtidos no item 2.2. (BENNETT E MAYERS, 1982).

A equação que representa este modelo é descrita a seguir:

$$
\tau=K \gamma^{n}+\tau_{0}
$$

Em que, $\mathrm{K}=$ índice de consistência; $\mathrm{n}=$ índice de comportamento; $]_{0}$ = tensão de corte inicial. 
Os parâmetros K e n do modelo foram determinados a partir do intervalo convencional 300 e 600 rpm, nas medidas convencionais citadas na norma PETROBRÁS N-2605:

$$
\begin{array}{ll}
1 . & \begin{array}{r}
\text { Indice de comportamento, } \mathrm{n:} \\
\log \left(\tau_{600}-\tau_{300} / \tau_{300}-\tau_{0}\right)
\end{array} \\
2 . & \log \left(\frac{\gamma_{600}}{\gamma_{300}}\right) \\
& \begin{array}{c}
\text { Indice de consistência, } \mathrm{K}: \\
K=\frac{\tau-\tau_{0}}{\gamma^{n}}
\end{array}
\end{array}
$$

0 valor de $\tau_{0}$ ( tensão inicial de corte) foi determinado por extrapolação do gráfico tensão $v s$ taxa de cisalhamento.

\section{RESULTADOS E DISCUSSÃO}

\subsection{MASSA ESPECÍFICA}

Inicialmente, foi determinada a massa especifica do fluido, onde esta medida para o fluido obtida por meio da balança de lama, foi de 9,1lb/gal. Esse valor está de acordo com a Norma PETROBRÁS N-2604 (1998), visto que a massa especifica deveestar em um intervalo entre 8,34 a 16,68 lb/gal .

\subsection{PARÂMETROS REOLÓGICOS REFERENTES AO FLUIDO FORMULADO}

A tabela 2 representa os resultados dos parâmetros reológicos referentes ao fluido formulado.

Tabela 2-Resultados dos parâmetros referentes ao fluido formulado avaliados perante à norma PETROBRÁS N-2604.

\begin{tabular}{|c|c|c|}
\hline Parâmetros & Valores & Norma PETROBRÁS N-2604 \\
\hline Viscosidade aparente & $19,0 \mathrm{cP}$ & mínimo de $15,0 \mathrm{cP}$ \\
\hline Viscosidade plástica & $9,0 \mathrm{cP}$ & mínimo de 4,0 cP \\
\hline Limite de escoamento & 20,0lbf/100pé2 & valor máximo igual a $15^{*} \mathrm{VP}$ \\
\hline Gel inicial $\left(\mathrm{G}_{0}\right)$ & 9,0lbf/100pé2 & mínimo de 7lbf/100 pé2 \\
\hline Gel final ( $\mathrm{G}_{10}$ ) & 10,0lbf/100pé2 & entre 10 e 15 lbf/100 pé2 \\
\hline
\end{tabular}

De acordo com as normas especificadas já mencionadas no trabalho, os valores das viscosidades plásticas, das viscosidades aparentes e o limite de escoamento, gel inicial e gel final estão dentro da faixa dos padrões citados na norma.

\subsection{CURVAS DE TENSÃO E DEFORMAÇÃO}

Observando a Figura 3, percebe-se uma tensãode corte inicial e uma tendência a um comportamento plástico real do fluido (ou fluido pseudoplástico com tensão de corte inicial), o que é confirmado posteriormente pelo modelo de Herschell-Buckley(KELESSIDIS,2006). 
Figura 3: Gráfico (tensão de cisalhamento, $\tau$ versus taxa de deformação, $\gamma$ ) da curva de fluxo para o fluido.

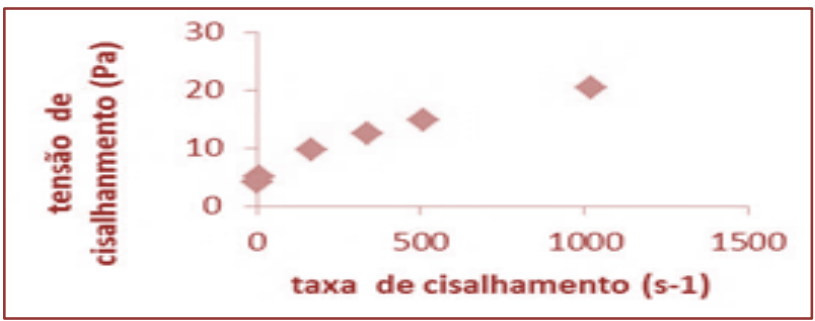

A Figura 4 mostra o gráfico referente ao modelo de Herschell-Buckley sobreposto à curva previamente elaborada por meio de dados experimentais.

Figura 4: Ajuste dos dados experimentais pelo modelo de Herschell - Buckley.

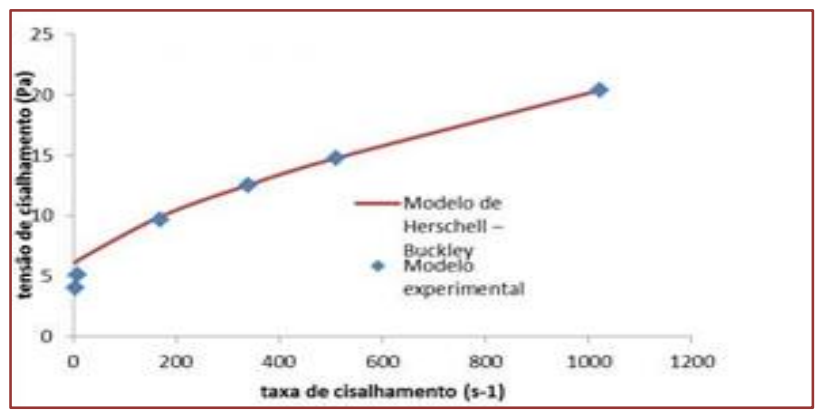

A tabela 3 mostra os valores dos parâmetros obtidos para o modelo de Herschell- Buckley.

Tabela 3: Parâmetros do modelo de Herschell-Buckley.

\begin{tabular}{cc|c|r} 
& \multicolumn{3}{c}{ Parâmetros reológicos } \\
Fluido de & $\mathrm{n}$ & $\mathrm{K}\left(\mathrm{Pa} . \mathrm{S}^{\mathrm{n}}\right)$ & $\tau_{0}(\mathrm{~Pa})$ \\
Perfuração & 0,6976 & 0,1164 & 5,7672 \\
\hline
\end{tabular}

A partir da Figura 5, pode-se observar que os valores teóricos da tensão obtidos pelo modelo de HerschellBuckley representam significativamente os resultados das tensões de cisalhamento obtidas experimentalmente.

Figura 5- Gráfico referente ao [experimental versus ? teórico.

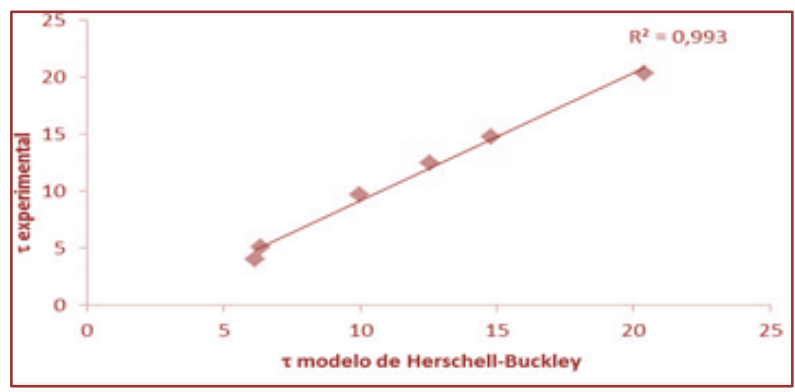

A Figura 6 mostra um decréscimo de viscosidade quando a taxa de cisalhamento é aumentada, exibindo assim, a pseudoplasticidade do fluido. 
Figura 6- Gráfico da Log $\mu$ (viscosidade) versus Log ?(taxa de cisalhamento).

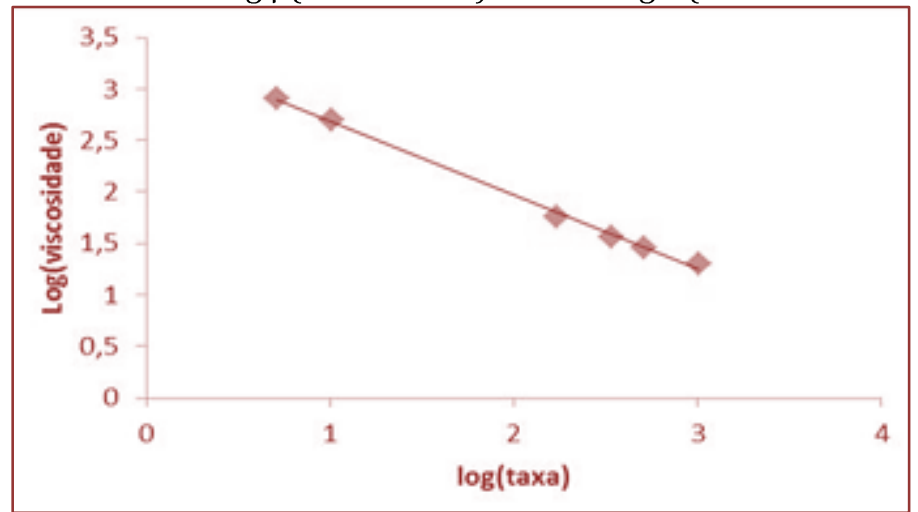

Este comportamento é importante para o fluido de perfuração, visto que com o aumento da velocidade de escoamento do fluido dentro da coluna de perfuração, tem-se um aumento da taxa de cisalhamento, e consequentemente uma diminuição da viscosidade deste fluido, pois dentro da coluna necessita-se de uma certa facilidade do fluido escoar. Quando o fluido de perfuração atinge a formação, na região situada na ponta da broca, ocorre uma redução brusca de velocidade e, portanto, da taxa de cisalhamento, levando a um aumento da viscosidade do fluido, que por sua vez atende a exigência de transportar os cascalhos até a superfície, liberados pela broca durante a perfuração.

\section{CONCLUSÕES}

1)Os parâmetros reológicos obtidos ( viscosidade aparente, viscosidade plástica, limite de escoamento, gel inicial e final) para o fluido de perfuração formulado estão dentro dos padrões da norma PETROBRÁS N2604.

2)0 fluido de perfuração obtido foi classificado como plástico real e o modelo de Herschell - Buckley mostrou-se satisfatório na representação dos dados experimentais do estudo reológico deste fluido.

\section{AGRADECIMENTOS}

Ao apoio financeiro da Agência Nacional do Petróleo, Gás Natural e Biocombustíveis - ANP -, da Financiadora de Estudos e Projetos - FINEP - e do Ministério da Ciência, Tecnologia e Inovação - MCTI por meio do Programa de Recursos Humanos da ANP para o Setor Petróleo e Gás - PRH-ANP/MCTI e ao Laboratório de Cimentos-LABCIM/UFRNpelo fornecimento dos aditivos estudados.

\section{REFERÊNCIAS}

[1] Alberto, J.T.A. Análisis de los fluidos de perforación em la indústria petrolera.2010,109p.Tese de Doutorado. Universidade de Vera Cruz, Vera Cruz.

[2] Bennett, C. O.; Meyers, J.E. -Fenômenos de Transporte: quantidade de movimento, calor e massa- McGrawHill do Brasil- São Paulo, 1982.

[3] Darley, H.C. H \& Gray, G.R.Composition and Properties of oil well drilling fluids,p.509,1985.

[4] Kelessidis, V.C.; Maglione, R.; Tsamantaki, C.;Aspirtakis, Y. -Optimal determination of rheological parameters for Herschel-Bulkley drilling fluids and impact on pressure drop, velocity profiles and penetration rates during drilling- Journal of Petroleum Science and Engineering 53: 203-224, 2006.

[5] Machado, J. C. Fundamentos e Classificação de Fluidos Viscosos. Reologia e Escoamento de Fluidos- Ênfase na indústria do petróleo. Editora Interciência. Rio de Janeiro, 2002. pg 1- 40.

[6] Mahto, V.; Sharma, V. P. -Rheological study of water based oil well drilling fluid - Journal of Petroleum Science Engineering 45: 123-128 2004.

[7] Petrobras - Ensaio de viscosificante para fluido de perfuração à base de água na exploração e produção de petróleo- Especificação, N-2604, 1998.

[8] Petrobras - Ensaio de viscosificante para fluido de perfuração à base de água na exploração e produção de 
petróleo- Especificação, N-2605, 1998.

[9] Shiroma, H.P. Estudo do comportamento reológico de suspensões aquosas de bentonita e cmc: influência da concentração de NaCl.2012, 114p. Dissertação (mestrado de Engenharia química).Universidade de São Paulo, São Paulo.

[10] Thomas, J. E. Fundamentos de Engenharia de Petróleo. Interciência, 2004. 


\section{Capítulo 4}

Análise da influência da goma xantana e do tween 80 na viscosidade e no volume de filtrado de fluidos de perfuração hidroargilosos

\section{Allison Ruan de Morais Silva}

\section{Francisco Klebson Gomes dos Santos}

Geraldine Angélica Silva da Nóbrega

Diego Angelo de Araújo Gomes

Resumo: Os fluidos de perfuração devem ser desenvolvidos de forma a favorecer uma perfuração rápida e segura, sendo assim, deve-se garantir o controle de suas propriedades físicas e químicas. Dentre estas propriedades, estão: parâmetros reológicos, força gel, parâmetros de filtração, alcalinidade, teor de bentonita ou de sólidos ativos, etc. A falta de controle de algumas destas propriedades pode ocasionar diversos problemas durante a perfuração de poços. Por exemplo, tem-se o inchamento de argilas hidratáveis da formação geológica, causando a instabilidade do poço e podendo ser evitada a partir da formação de uma película fina e impermeável conhecida como reboco (filter-cake). Deste modo, o presente trabalho teve como objetivo avaliar a influência de aditivos tensoativo e polímero nas propriedades reológicas e no volume de filtrado de fluidos hidroargilosos. Para tanto, foram estudados um tipo de argila bentonita, um tensoativo não iônico (Tween 80) e o polímero goma xantana (GX). A preparação dos fluidos e a sua análise foram realizadas segundo as normas da Petrobras, sendo determinadas as viscosidades aparente e plástica e o volume de filtrado. Os resultados mostraram que a aditivação dos fluidos e o acréscimo de Tween 80 conduziram a um aumento das viscosidades. Os resultados também evidenciaram o benefício da goma xantana, aliada ao Tween 80 , nas viscosidades e no volume de filtrado dos fluidos de perfuração.

Palavras-chave: Fluidos de Perfuração, Goma Xantana, Tween 80. 


\section{INTRODUÇÃO}

Fluidos de perfuração, também conhecidos como lamas de perfuração, são uma complexa mistura de sólidos, líquidos e, em alguns casos, até gases; podendo assumir, do ponto de vista químico, aspectos de suspensão, dispersão coloidal ou emulsão, dependendo do estado físico dos componentes. 0 American Petroleum Institute - API os define como fluidos de circulação usados em perfurações rotativas para o desempenho de determinadas funções durante a operação de perfuração, tornando-se o fluido de circulação um componente indispensável na perfuração de poços [THOMAS, 2001; LUMMUS e AZAR, 1986].

Segundo Darley e Gray [1988], para obter sucesso na perfuração é necessário que os fluidos apresentem um bom desempenho, que por sua vez é determinado de acordo com as funções exercidas pelo fluido, essas funções são: estabilizar as paredes do poço; resfriar, limpar e lubrificar a broca; reduzir o atrito entre a broca e as paredes do poço; transportar os detritos de perfuração; formar uma película de baixa permeabilidade denominada reboco (filter-cake), entre outras.

\subsection{FLUIDOS HIDROARGILOSOS}

São fluidos que possuem como fase líquida contínua e dispersante a água. Considera-se, principalmente, a natureza da água e os aditivos químicos empregados no preparo do fluido, pois qualquer alteração nos componentes básicos poderá provocar sensíveis mudanças em suas propriedades [THOMAS, 2001].

Basicamente, os fluidos são constituídos por três componentes: água, que é a sua fase contínua e dispersante; a fase dos sólidos reativos, constituída por argilas e folhetos hidratáveis provenientes das formações geológicas; e a fase dos sólidos inertes como, por exemplo, o calcário ou areia. A água possui como principal função prover o meio de dispersão para os materiais coloidais [THOMAS, 2001; AMORIM, 2003].

\subsection{PROPRIEDADES DOS FLUIDOS DE PERFURAÇÃO}

Segundo Thomas [2001], as propriedades de controle de fluidos de perfuração podem ser físicas ou químicas. As físicas são genéricas e podem ser medidas em qualquer tipo de fluido, enquanto que as químicas são específicas e utilizadas para distinguir alguns tipos de fluidos. Os parâmetros reológicos e os parâmetros de filtração são exemplos de propriedades físicas.

\subsubsection{VISCOSIDADE APARENTE (VA) E VISCOSIDADE PLÁSTICA (VP)}

De acordo com Thomas [2001], o comportamento de um fluido é definido pelos parâmetros reológicos. Considera-se que o fluido segue um modelo reológico, cujos parâmetros influenciam diretamente no cálculo de perdas de carga na tubulação e na velocidade de transporte dos cascalhos.

De acordo com Amorim [2003], a viscosidade plástica é definida como a medida da resistência interna do fluido ao escoamento, que resulta da interação dos sólidos presentes.

Stefan [1966], define a viscosidade aparente como a viscosidade de um fluido não-newtoniano apresentando comportamento newtoniano, à determinada taxa de cisalhamento.

Os fluidos de perfuração hidroargilosos comportam-se como fluidos plásticos. Uma vez que a viscosidade depende da tensão de cisalhamento aplicada, suas características reológicas se diferem das dos fluidos newtonianos. Os fluidos à base de água e bentonita podem ser descritos como plásticos de Bingham, que são fluidos que requerem a aplicação de uma tensão de cisalhamento mínima inicial denominada de limite de escoamento para que haja alguma deformação cisalhante, e suas propriedades reológicas são definidas através dos parâmetros de viscosidade plástica e limite de escoamento [LUMMUS e AZAR, 1986; SHIROMA, 2012; STEFAN, 1966].

\subsubsection{PARÂMETROS DE FILTRAÇÃO}

Os fluidos de perfuração possuem a capacidade de formar uma camada de partículas sólida e úmida denominada de reboco sobre as rochas permeáveis que estão sendo expostas pela broca. Esta propriedade é de fundamental importância para o sucesso da perfuração e da completação do poço. Para que o reboco 
seja formado, deve haver o influxo da fase líquida do fluido do poço para a formação, conhecido como processo de filtração. 0 fluido deve ter uma fração razoável de partículas com dimensões ligeiramente menores que as dimensões dos poros das rochas expostas, pois existindo partículas com dimensões adequadas, a obstrução dos poros é rápida e somente a fase líquida do fluido (filtrado) invade a rocha [THOMAS, 2001].

Se o reboco formado é impermeável sua espessura irá aumentar, o que implica no decréscimo do diâmetro do poço, e no aumento da pressão do mesmo. Consequentemente, a perfuração será prejudicada. Uma perda excessiva de água livre torna o sistema, constituído por água mais argila, não só mais viscoso como também pobre em partículas coloidais, provocando o acúmulo de partículas na parede do poço, diminuindo o espaço de circulação entre a haste e as paredes, dificultando as manobras de perfuração. Quando a permeabilidade é adequada, ou seja, existem partículas sólidas com dimensões adequadas, a obstrução dos poros é rápida e somente a fase líquida do fluido, o filtrado, invade a rocha [BENNA, KBIRARIGUIB e BERGAYA, 2001; SANTOS, 2002].

Além das viscosidades aparente e plástica, a determinação do volume de filtrado permite obter conclusões sobre a qualidade coloidal da argila. Quanto maior a proporção de partículas coloidais, menor a percentagem de água livre no sistema e, como consequência, menor a perda de filtrado [AMORIM, 2003; STEFAN, 1966].

\subsection{ARGILAS BENTONÍTICAS}

É uma argila largamente utilizada na indústria, em setores tais como perfuração de poços de petróleo e de água, fundições diversas, pelotização de minério de ferro, indústria química e farmacêutica, entre outros. Caracteriza-se pela predominância dos argilominerais do grupo da esmectita, ilita e caulinita, sendo constituída por duas folhas tetraédricas de silicatos separadas por uma folha octaédrica de alumina, unidas entre si por oxigênios comuns às folhas. Encontra-se, no espaço entre as camadas, moléculas de água adsorvidas e os chamados cátions trocáveis, que podem ser $\mathrm{Ca}^{2+}, \mathrm{Mg}^{2+} \mathrm{e} \mathrm{Na}^{+}$. Quando encontrados os três cátions, as argilas bentoníticas são conhecidas como policatiônicas [AMORIM, 2003; GOPINATH, SCHUSTER e SCHUCKMANN, 1981; SCHUSTER e SCHUCKMANN, 1988].

\subsubsection{HIDRATAÇÃO}

Quando as folhas individuais de montmorilonita são expostas à água, as moléculas de água são adsorvidas na superfície das camadas de sílica, que são então separadas umas das outras. Este comportamento é chamado de inchamento interlamelar e é controlado pelo cátion associado à estrutura da argila. Como a adsorção de água interlamelar avança, tem-se como resultado a separação das camadas de argila, expondo uma maior área para hidratação [AMORIM, 2003; LUMMUS \& AZAR, 1986].

Segundo Lummus \& Azar [1986], a hidratação de argilas também é resultante das forças de cisalhamento aplicadas às dispersões, que promovem a quebra das ligações químicas das estruturas das argilas, resultando na exposição de valências positivas dos átomos de sílica, negativas dos átomos de oxigênio, ou ambas, dependendo de onde ocorra a quebra. Estes íons adsorvem maior quantidade de água, promovendo assim uma maior delaminação das camadas de argila. Esta água adsorvida é chamada de "água de ligação quebrada" e promove diminuição da água livre disponível. Este fenômeno justifica a aplicação de elevadas taxas de cisalhamento quando do preparo de lamas de bentonita e explica o aumento da viscosidade destas lamas quando o cisalhamento é aplicado.

\subsection{ADITIVOS}

Frequentemente adota-se a prática de aditivação do fluido na tentativa de melhorar a qualidade dos fluidos de perfuração compostos por argilas bentoníticas, sendo comumente utilizados aditivos poliméricos. 0 processo de aditivação é feito durante a sua preparação nos tanques de lama ou mesmo durante a operação de perfuração quando for necessária a adequação das suas propriedades [BARBOSA, AMORIM e FERREIRA, 2007]. 


\subsubsection{GOMA XANTANA (GX)}

A goma xantana $\left(\mathrm{C}_{35} \mathrm{H}_{49} \mathrm{O}_{29}\right)$ é um polissacarídeo de elevado peso molecular produzido durante a fermentação realizada pela bactéria Xanthomonas Campestris. Tem sido usada extensivamente como viscosificante para fluidos de perfuração na indústria do petróleo, para completação e estimulação de poços e mesmo para aplicações envolvendo métodos especiais para recuperação de óleo devido à suas características reológicas únicas [ORENTAS, SLONEKER e JEANES, 1963].

De acordo com KHAN et al. [2003], as moléculas da goma xantana possuem a capacidade de se adsorverem, ficando retidas na superfície das rochas, reduzindo a permeabilidade das mesmas. Segundo XU et al. [2013], as soluções que contém goma xantana apresentam um comportamento pseudoplástico, ou seja, a viscosidade diminui com o aumento da taxa de deformação do fluido. Contudo, recuperam rapidamente a viscosidade na remoção da tensão de cisalhamento. A associação das cadeias de goma xantana existe quando em repouso ou em baixas taxas de cisalhamento, sendo estabilizadas pelas ligações de hidrogênio. No cisalhamento, a extensão da agregação é reduzida pelo alinhamento das cadeias, resultando em uma baixa viscosidade [NASCIMENTO, 2013].

\subsubsection{TWEEN 80}

Os tensoativos são substâncias naturais ou sintéticas que possuem em sua estrutura uma parte hidrofóbica (apolar), e uma parte hidrofílica (polar). De acordo com suas características iônica ou não iônica, são adicionados ao sistema bentonita-água, interagindo com as mesmas [FARIAS et al., 2006; ROSSI et al., 2006].

Segundo a Oxiteno, 0 Tween 80 é um tensoativo não iônico compõe a linha ALKEST® TW, que é composta por ésteres de sorbitan etoxilados. Os produtos da linha ALKEST® TW são hidrofílicos, apresentando altos valores de HLB. A presença da cadeia de polioxietileno torna os produtos da linha ALKEST® TW solúveis ou dispersíveis em água, favorecendo a sua aplicação em emulsões óleo em água (O/A). Devido ao alto grau de etoxilação, os produtos da linha ALKEST $®$ TW também atuam como umectantes e agentes antiestática.

Ainda de acordo com a Oxiteno, o Tween 80 se mantém em estado líquido a temperatura ambiente, apresentando porcentagem em peso de água de no máximo 3,0\% e HLB calculado igual a 15, conferindolhe a função de dispersante de sólido em água. Além disso, possui baixa toxicidade e é considerado facilmente biodegradável.

\section{METODOLOGIA}

A pesquisa foi desenvolvida no Laboratório de Engenharia de Petróleo do Departamento de Ciências Ambientais e Tecnológicas (DCAT) da UFERSA, campus Mossoró, Rio Grande do Norte.

Para a execução deste trabalho, utilizou-se dos seguintes reagentes: água deionizada; argila bentonita não tratada, fornecida gentilmente pela ARMIL-MINERAÇÃO DO NORDESTE, localizado na cidade de ParelhasRN; polímero goma xantana (GX), fornecidos gentilmente pela PETROBRAS; tensoativo não iônico, comercial, Tween 80, fornecido pela Vetec Química Fina Ltda.

Para a análise do comportamento de aditivos nas propriedades reológicas e no volume de filtrado de fluidos de perfuração hidroargilosos, utilizou-se os seguintes equipamentos: balança analítica de precisão, modelo AY220 - MARTE, para a medição precisa de quantidades de bentonita e dos aditivos utilizados; agitador mecânico Hamilton Beach, modelo HMD200CE, utilizado para o preparo de fluidos de perfuração; viscosímetro FANN, modelo 35A, para a realização do estudo reológico do fluido; estufa FANN, modelo roller oven, para o envelhecimento dos fluidos; filtro prensa API, FANN SERIES 300, para a determinação do volume de filtrado do fluido.

\subsection{PREPARAÇÃO DOS FLUIDOS}

Em todas as amostras de fluidos preparados foram utilizadas 4,86\% em massa de argila bentonita, seguindo de acordo com a norma N-2605 (Petrobras, 1998 Apud FARIAS et al., 2006), sendo adicionado $17,01 \mathrm{~g}$ de argila à $350 \mathrm{~mL}$ de água deionizada e agitada durante $15 \mathrm{~min}$ a uma velocidade entre 15.000 rpm e $18.000 \mathrm{rpm}$ em agitador mecânico. Em seguida, para a formulação não aditivada, o fluido foi envelhecido durante $16 \mathrm{~h}$ à $90^{\circ} \mathrm{C}$ em uma estufa roller oven. 


\subsection{ADITIVAÇÃO}

A aditivação dos fluidos foi realizada em duas etapas. Em cada uma das etapas foram formulados quatro fluidos contendo, respectivamente, $1 \mathrm{~g}$ e $3 \mathrm{~g}$ de goma xantana (GX). A GX foi adicionada durante agitação entre $15.000 \mathrm{rpm}$ e $18.000 \mathrm{rpm}$ por um agitador mecânico. Após 5 min de agitação, foram adicionadas as seguintes quantidades em massa de tensoativo: 0,0291 g, 0,2037 g, 0,4365 g e 0,6111 g. A massa correspondente a uma gota foi realizada com a média aritmética das massas obtidas em balança analítica. Após mais cinco minutos de agitação, os fluidos já aditivados, foram envelhecidos durante $16 \mathrm{~h}$ à $90^{\circ} \mathrm{C}$ em uma estufa roller oven.

\subsection{VISCOSIDADES}

VA e VP foram determinados em viscosímetro Fann 35A. Utilizou-se as Equações 1 e 2:

$$
\mathrm{VA}=\frac{\mathrm{L} 600}{2}(\mathrm{cP})
$$

Sendo VA a viscosidade aparente, dada em centipoise (cP), e L600 a leitura no viscosímetro a 600 rpm.

$$
\mathrm{VP}=L 600-L 300(\mathrm{cP})
$$

Sendo VP a viscosidade plástica, dada em centipoise (cP), e L300 a leitura no viscosímetro a $300 \mathrm{rpm}$.

\subsection{VOLUME DE FILTRADO}

Para a determinação do volume de filtrado, os fluidos foram agitados durante 1 min no agitador mecânico entre $15.000 \mathrm{rpm}$ e $18.000 \mathrm{rpm}$. Logo após, o fluido foi transferido para a célula do filtro prensa API, e durante $30 \mathrm{~min}$ foi aplicada uma pressão de $100 \mathrm{psi}\left(7,0 \mathrm{kgf} / \mathrm{cm}^{2}\right)$. Em seguida, o filtrado presente na proveta foi lido e obteve-se a medida do volume do filtrado, expresso em $\mathrm{mL}$.

\section{RESULTADOS E DISCUSSÃO}

Os resultados obtidos com os valores de massa fixados em $1 \mathrm{~g}$ e $3 \mathrm{~g}$ para GX e variações do Tween 80 estão expressos nas Tabelas 1 e 2.

Tabela 1: Fluidos aditivados com $1 \mathrm{~g}$ de GX e variações de Tween 80.

\begin{tabular}{|c|c|c|c|}
\hline Tween $80(\mathrm{~g})$ & \multicolumn{1}{c|}{ VA (cP) } & \multicolumn{1}{c|}{ VP (cP) } & VF (mL) \\
\hline 0,0291 & 11,5 & 6,0 & 12,4 \\
\hline 0,2037 & 11,5 & 6,0 & 12,8 \\
\hline 0,4365 & 13,0 & 7,0 & 16,0 \\
\hline 0,6111 & 18,0 & 8,0 & 16,0 \\
\hline
\end{tabular}

Tabela 2: Fluidos aditivados com $3 \mathrm{~g}$ de GX e variações de Tween 80.

\begin{tabular}{|c|c|c|c|}
\hline Tween $80(\mathrm{~g})$ & \multicolumn{1}{|c|}{ VA (cP) } & VP (cP) & VF (mL) \\
\hline 0,0291 & 30,0 & 6,0 & 6,5 \\
\hline 0,2037 & 30,5 & 7,0 & 7,6 \\
\hline 0,4365 & 30,5 & 7,0 & 8,0 \\
\hline 0,6111 & 31,0 & 8,0 & 8,0 \\
\hline
\end{tabular}


Observam-se, a partir dos resultados obtidos, variações positivas nos valores de VA, VP e VF ao decorrer do acréscimo de Tween 80.

A GX é um agente viscosificante, pois possui alto peso molecular. Além disso, as soluções que contém GX apresentam um comportamento pseudoplástico, explicando seus altos valores de VA e valores de VP mais baixos, pois sua viscosidade diminui com o aumento da taxa de deformação, recuperando rapidamente a viscosidade na remoção da tensão de cisalhamento. Outro fator que contribui para os altos valores de VA é que a associação das cadeias de GX existe quando em repouso ou em baixas taxas de cisalhamento, sendo estabilizadas pelas ligações de hidrogênio, enquanto que no cisalhamento a extensão da agregação é reduzida pelo alinhamento das cadeias, resultando em menores valores de VP. 0 Tween 80 age como dispersante de sólido em água. As variações positivas das viscosidades com o acréscimo do Tween 80 aconteceram devido ao aumento da molhabilidade e da redução da tensão superficial, o que contribuiu para o aumento da área de contato com o substrato. Porém, as variações nas viscosidades foram pequenas e o tensoativo apresentou pouca influência. Todos os fluidos contendo $3 \mathrm{~g}$ de GX e o fluido contendo $1 \mathrm{~g}$ de GX e 0,6111 g de Tween 80 satisfizeram as especificações da N-2604 da Petrobras [1998] para o uso em perfuração de poços (VP $\leq 4,0 \mathrm{cP}$ e VA $\leq 15,0 \mathrm{~mL})$.

Devido às moléculas de GX possuírem a capacidade de se adsorverem, retendo-se na superfície das rochas observa-se baixos valores de VF. 0 efeito dispersivo causado pelo Tween 80 causou um aumento no VF ao decorrer do seu acréscimo, indicando a diminuição das partículas coloidais e aumentando a percentagem de água livre no sistema. Porém, todos os fluidos se mantiveram dentro da especificação N-2604 da Petrobras [1998], que especifica $u m$ VF $\leq 18,0 \mathrm{~mL}$.

\section{CONCLUSÕES}

Ao analisar a influência da GX aliada ao Tween 80 nas propriedades reológicas e no volume de filtrado conclui-se que, os fluidos aditivados com GX apresentaram bom desempenho, obtendo-se altos valores de viscosidade e principalmente valores elevados de VA, e melhores desempenhos em relação às viscosidades ao decorrer do acréscimo do Tween 80. Para o VF, os fluidos aditivados com $3 \mathrm{~g}$ de GX apresentaram os melhores resultados dentre todos os fluidos, porém, a dispersão, de certo modo, prejudicou a desenvoltura do VF de modo a aumentar a sua permeabilidade ao acrescentar maiores quantidades de Tween 80. Todas as formulações contendo $3 \mathrm{~g}$ de GX e a contendo $1 \mathrm{~g}$ de GX e 0,6111 g de Tween 80 satisfizeram as especificações.

\section{AGRADECIMENTOS}

Ao CNPq/UFERSA pelo apoio financeiro; à ARMIL-MINERAÇÃO DO NORDESTE, pelo fornecimento da argila; e à PETROBRAS pelo fornecimento do aditivo polimérico.

\section{REFERÊNCIAS}

[1] Amorim, L. V. Melhoria, proteção e recuperação da reologia de fluidos hidroargilosos para uso na perfuração de poços de petróleo. 2003, 290p. Tese de Doutorado, Universidade Federal de Campina Grande, Programa de Pós Graduação em Engenharia de Processos. Campina Grande-PB.

[2] Barbosa, M. I. R.; Amorim, L. V.; Ferreira, H. C. Compostos poliméricos como aditivos de argilas bentoníticas. Cerâmica, v. 53, p. 354-360, 2007.

[3] Benna, M.; Kbir-Ariguib, N.; Bergaya, F. Static filtration of purified sodiumbentonite clay suspensions: effect of clay contente. Apllied Clay Science, v. 19, p. 103-120, 2001.

[4] Darley, H. C. H.; Gray, G. R. Composition and Properties of Drilling and Completion Fluids. Gulf Publishing Company, 1988.

[5] Farias, K. V.; Amorim, L. V.; Ferreira, HC.; Pereira, E. Estudo da reologia e espessura do reboco de fluidos de perfuração: influência de dispersantes e umectante aniônicos. Cerâmica, v. 52, p. 307-314, 2006.

[6] Gopinath, T.R., Schuster, H.D. \& Schuckmann, W.K. Clay Mineralogy and Geochemistry of Continental Bentonite and Their Geological Implications. Revista Brasileira de Geociências, v. 18, p. 345-352, 1988.

[7] Gopinath, T.R., Schuster, H.D. \& Schuckmann, W.K. Modelo de Ocorrência e Gênese da Argila Bentonítica de Boa Vista, Campina Grande, Paraíba Revista Brasileira de Geociências, v. 11, p. 185-192, 1981. 
[8] Khan, R., Kuru, E., Themblay, B., Saasen, A. An Investigation of Formation Damage Characteristics of Xanthan Gum Solutions Used for Drilling, Drill-In, Spacer Fluids, and Coiled Tubing Applications. Petroleun Society's Canadian International Petroleum Conference, Calgary, Alberta, Canada, 2003.

[9] Lummus, J. L.; Azar, J. J. Drilling Fluids Optimization a Practical Field Approach. Pennwell Corp, 1986.

[10] Nascimento, R. C. A. M.; Magalhães, J.; Pereira, E.; Amorim, L. V. Degradação térmica de fluidos de perfuração argilosos aditivados com polímeros e lubrificante. Revista Matéria, v. 18, p. 1329-1339, 2013.

[11] Orentas, D. G.; Sloneker, J. H.; Jeanes, A. Pyruvic acid content and constituent sugars of exocellular polysaccharides from different species of the genus Xanthomonas. Canadian Journal of Microbiology, v. 9, p. 427-430, 1963.

[12] Rossi, C. G. F. T.; Dantas, T. N. de C.; Neto, A. A. D.; Maciel, M. A.M. Tensoativos: uma abordagem básica e perspectivas para aplicabilidade industrial. Revista Universidade Rural: Série Ciências Exatas e da Terra, v. 25, n.1-2, p. 73-85, 2006.

[13] Santos, P. S. Ciência e Tecnologia de Argilas. Edgard Blücher, 2002.

[14] Shiroma, P. H. Estudo do comportamento reológico de suspensões aquosas de bentonita e CMC: influência da concentração do NaCL. 2012, 130p. Dissertação de Mestrado, Universidade de São Paulo, Programa de Pós Graduação em Engenharia Química. São Paulo-SP.

[15] Silva, A. L. C.; Ponzetto, E.; Rosa, A. Tensoativos: Conceitos Gerais e Suas Aplicações em Tintas. Disponível em:<http://www.oxiteno.com.br/>. 20/09/2014.

[16] Thomas, J. E. Fundamentos de Engenharia de Petróleo. Interciência, 2001.

[17] Xu,L.; Xu,G.; Liu,T.; Chen,Y.; Gong,H. The comparison of rheological properties of aqueos welan gum and xanthan gum solutions. Carbohydrate Polymers, v. 92, p. 516-522, 2013. 


\section{Capítulo 5}

Variação das propriedades de um fluído de perfuração com biodiesel com o tempo e a temperatura

\section{Elba Gomes dos Santos Leal \\ Rui Carlos de Sousa Mota \\ Ricardo Guilherme Kuentzer \\ Ricardo Matos Santos \\ Pedro Luis Araujo dos Santos \\ Caio Ramos Valverde}

Resumo: A perfuração de poços de petróleo é realizada por uma soda de perfuração utilizando um fluido ou lama de perfuração. A escolha do fluido de perfuração a ser utilizado e a manutenção de suas propriedades durante a perfuração é de grande importância pois influenciam diretamente no processo. Dentre as propriedades do fluido tem-se a massa específica ou densidade da lama, e os parâmetros reológicos, os quais são responsáveis pela pressão hidrostática no interior do poço e propriedades do escoamento do fluido, respectivamente. A redução do valor da densidade da lama pode trazer como principal problema a ocorrência de um "kick" ou "Blowout", o qual deverá ser evitado. 0 presente trabalho tem como objetivo verificar as variações da densidade e parâmetros reológicos de um fluido de perfuração com biodiesel com o tempo e a temperatura de perfuração. Os resultados obtidos ilustram as diminuição nos valores de densidade do fluido à medida que aumentam o tempo e a temperatura de perfuração.

Palavras-chave: densidade, viscosidade aparente, viscosidade plástica e limite de escoamento. 


\section{INTRODUÇÃO}

Durante os processos de perfuração de poços de petróleo, a escolha e seleção do fluido de perfuração adequado e a manutenção de suas propriedades ao longo do processo se torna fundamental para a segurança e operação de perfuração durante toda essa etapa.

A perfuração de poços demanda da utilização de produtos que melhorem o desempenho da perfuração em condições de altas temperaturas e pressões. Além disso, os requisitos ambientais exigidos necessitam que os mesmos possuam maior biodegradabilidade e menor toxidade, condições estas que elevam os valores dos fluídos de perfuração de base parafínica utilizados atualmente.

Segundo Thomas (2001), os fluídos de perfuração são misturas complexas de sólidos, líquidos, produtos químicos e, por vezes, até gases. São indispensáveis durante toda a perfuração do poço, pois deve apresentar características que garantem a integridade das formações do poço, a segurança dos profissionais envolvidos e a integridade do meio ambiente. Facilitar as interpretações geológicas do material retirado do poço.

Várias são as propriedades dos fluidos de perfuração utilizados e os mesmos possuem composições variadas, dependendo dos parâmetros de perfuração a serem seguidos. Historicamente, o propósito primordial dos fluídos de perfuração era servir como veículo para a remoção dos cascalhos do poço, mas atualmente, as suas diversas aplicações dificultam a atribuição de funções específicas.

Dentre algumas funções dos fluídos de perfuração tem-se que o mesmo não deve: ser danoso nem prejudicial ao meio ambiente e a equipe de trabalho; não pode interferir na produtividade do poço nem contaminar as formações rochosas; corroer ou desgastar os equipamentos de perfuração e, possuir custo acessível a sua produção.

Uma das propriedades dos fluidos de perfuração é a massa específica ou densidade. Esta pode ser definida como o peso da lama por unidade de volume, podendo ser expressa em libras/galão (lb/gal); libras por pé cúbico $\left(\mathrm{lb} / \mathrm{ft}^{3}\right)$ e quilograma por metro cúbico $\left(\mathrm{Kg} / \mathrm{m}^{3}\right)$.

A densidade do fluido de perfuração utilizado nas operações é responsável pela manutenção das propriedades hidrostáticas do poço, e a mesma se altera com o aumento da profundidade do poço. Segundo Kirschner, (2008), o fluido de perfuração a ser utilizado dever fornece a pressão hidrostática necessária para evitar o colapso das paredes do poço. 0 controle das pressões no interior do poço é feito pelo fluido através da geração de uma pressão hidrostática superior à pressão dos fluidos das formações (aqueles contidos nos poros das formações) cortadas pela broca. Quando esta pressão hidrostática se torna menor do que a das formações, e em presença de meios porosos, pode ocorrer o fluxo de fluido da formação para o interior do poço (kick), que se não devidamente controlado pode se transformar numa erupção (blowout).

Já o comportamento de fluxo de um fluido é definido pelos parâmetros reológicos, que vão influenciar diretamente no cálculo de perdas de carga na tubulação e velocidade de transporte dos cascalhos. Fazendo certas medidas reológicas do fluido, é possível determinar como o fluido escoará em condições variadas de temperatura, pressão e taxa de cisalhamento. Em termos reológicos, a viscosidade é o parâmetro mais conhecido, sendo definida como a resistência que uma substância apresenta ao fluxo. No campo, as principais propriedades reológicas de interesse, que se encontram vinculadas ao desempenho do fluido são: índice de comportamento; índice de consistência; viscosidade aparente; viscosidade plástica; limite de escoamento e força gel. Thomas, 2001. É importante controlar as propriedades reológicas do fluido visando aperfeiçoar a operação de perfuração, através da maximização da limpeza do poço, minimização da pressão de bombas, evitando o influxo da formação e prevenindo perda de circulação para a formação perfurada segundo Guimarães e Rossi, (2007).

De acordo com Guimarães e Rossi, (2007), diversos fatores afetam os fluidos de perfuração durante uma operação. Entre estes tem-se: variações de profundidade, interação com a formação rochosa do poço, variações de pressão e temperatura. Portanto, um fluido de perfuração além de ter de realizar suas funções primordiais, que são a suspensão, o controle de pressão, a estabilização das formações, apresentar poder de flutuação e de resfriamento da broca, devem apresentar características adequadas para que possam ser utilizados nas diversas formações. Sendo assim, um fluido de perfuração deve ser estável quimicamente, facilitar a separação dos cascalhos na superfície, ser inerte (não reagir) com as rochas produtoras, ser capaz de aceitar tratamento físico e/ou químico, ser passível de bombeamento, e ainda deve apresentar baixo grau de corrosão e abrasão (esfoliamento) em relação à coluna de perfuração e a outros equipamentos da coluna de perfuração, além de não ser agressivo ao meio ambiente (Thomas et al., 2001). 
Para impedir o influxo de fluidos da formação rochosa para dentro do poço e gerar um reboco fino e de baixa permeabilidade nas paredes do poço, a pressão hidrostática exercida pelo fluido de perfuração deverá ser maior que a pressão do poro. E a pressão do poro das rochas depende da profundidade do poço. Desta forma, os valores de densidade de um fluido de perfuração devem ser determinados ao longo de toda a operação de perfuração, de forma a garantir a manutenção de suas propriedades.

Desta forma, a presente pesquisa teve como objetivo principal ilustrar as alterações da massa especifica e dos parâmetros reológicos de um fluido de perfuração, utilizando biodiesel em sua composição, com o tempo e a temperatura de perfuração.

\section{METODOLOGIA}

Para análise da influência da temperatura e do tempo de perfuração sobre a densidade sobre as propriedades de um fluido de perfuração com biodiesel em sua composição, foi formulado 1,0 litro de fluido que possuía em sua composição $100 \mathrm{~mL}$ de biodiesel e bentonita.

A preparação do fluído de perfuração ocorreu de acordo com a prática de campo, que consiste em adicionar os aditivos, um a um, sob agitação a uma velocidade constante de $13.000 \mathrm{rpm}$ em agitador Hamilton Beach, modelo 936, ilustrado na Figura 1 (a), e permanecendo 5 min sob agitação a cada acréscimo de aditivo.

Para determinação da massa específica ou densidade do fluído de perfuração obtido foi utilizado o equipamento balança dessimétrica modelo Fann 140, ilustrado na Figura 1 (b) a seguir. A metodologia para obtenção dos resultados foi a do teste padrão: API-13B-2 2005, e recomendações do Manual de Fluidos de Perfuração, o qual consiste em colocar uma amostra de fluído dentro do recipiente até transbordar e colocar a tampa.

Figura 1 - (a) Equipamento Hamilton Beach Mixer, modelo 936. (b) Balança densimétrica Fann Modelo 140. Fonte: Laboratório de fluídos do IFBA, 2016.

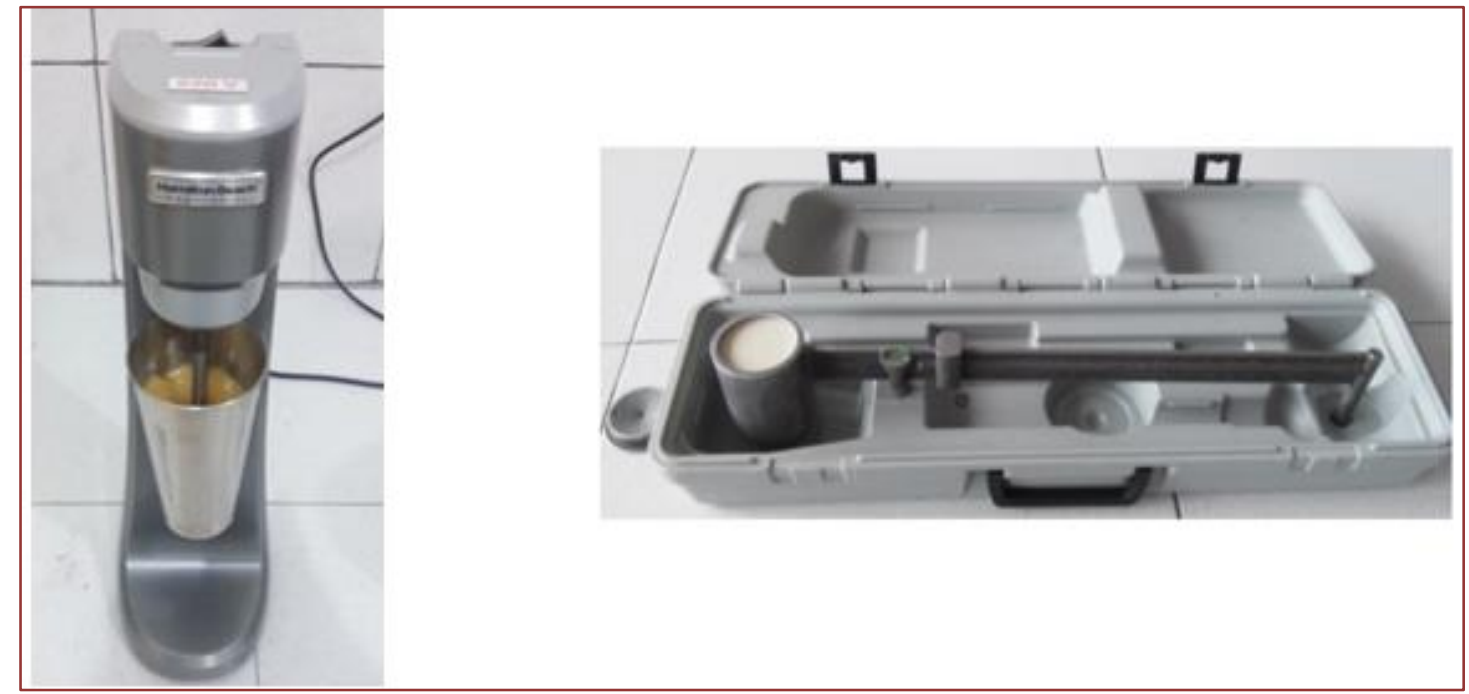

Para o estudo reológico (determinação das viscosidades aparente, plástica e limite de escoamento), o fluido era agitado durante 5 min no agitador mecânico Hamilton Beach, anteriormente descrito. Em seguida o fluido era transferido para o recipiente apropriado do viscosímetro Fann 35A, ilustrado na Figura 2, o qual possui seis valores de torque, que foram lidos com taxas de cisalhamento variando de 5,1 a $1022 \mathrm{~s}^{-1}$.

Com os dados das leituras obtidas no viscosímetro, calculou-se a viscosidade aparente (VA), a viscosidade plástica (VP) e o limite de escoamento (LE) segundo a norma N-2605, 1998, utilizando as equações abaixo. 
Figura 2 - Viscosímetro Fann, modelo 35 A. Fonte: Laboratório de fluídos do IFBA, 2016.

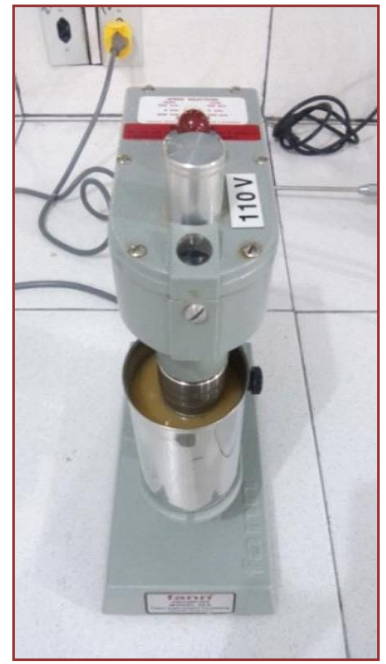

Após a preparação do fluido de perfuração, a sua densidade e os parâmetros reológicos de VA, VP e LE eram determinados. Anotadas os valores das propriedades, o fluido foi transferido para uma célula de pressão de aço inoxidável com capacidade para $260 \mathrm{~mL}$ de fluido, ilustrada na Figura 3 (a)

Para simular o efeito do envelhecimento do fluido de perfuração enquanto este circula no poço, a célula de envelhecimento foi colocada em uma estufa rotativa, como ilustrada na figura 3 (b). A estufa de rolagem em que foi configurado com a temperatura correspondente para o fluido e o tempo de permanência no forno. A estufa de rolagem tem a função de simular as condições temperatura e circulação do fluido dentro do poço, este movimento ocorre através de rolos motorizados que giram a célula dentro do forno, conforme a figura 6. Após ser retirado do forno, foram realizadas novamente as medições de densidade do fluido.

Figura 3 - (a) Célula de envelhecimento, (b) Equipamento Fann Estufa Rotativa Roller Oven.Fonte: Laboratório de fluidos do IFBA, 2016

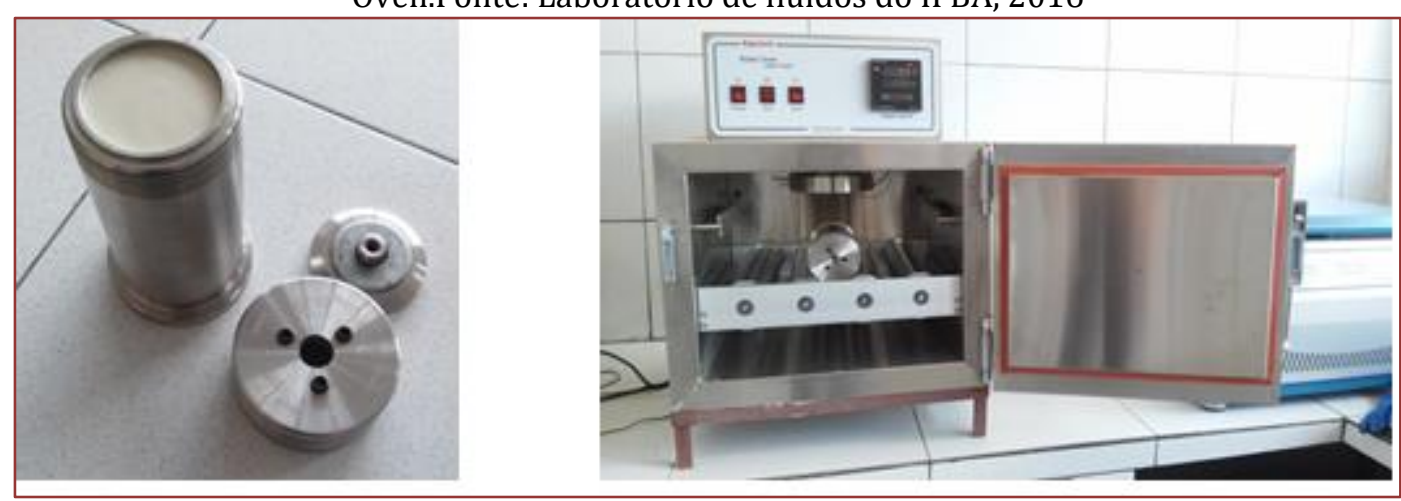




\section{RESULTADOS}

Os resultados obtidos neste trabalho ilustram a influencia da temperatura e do tempo de contato sobre o envelhecimento do fluido de perfuração utilizando biodiesel em sua composição.

Foi preparado um fluido de perfuração com massa específica inicial de 12,53 Lb/Gal e valores de VA, VP e LE respectivamente de: $50 \mathrm{cP}, 33 \mathrm{cP}$ e $45 \mathrm{~N} / \mathrm{m}^{2}$. Esses valores foram determinados logo após a preparação do fluido.

Em seguida o fluido foi colocado na célula de aço inoxidável e inserido no forno de rolagem, com a finalidade de verificar os efeitos da temperatura e do tempo de forno sobre a massa especifica do fluido de perfuração.

As temperaturas utilizadas para a realização deste trabalho foram de $30^{\circ} \mathrm{C}, 50^{\circ} \mathrm{C}$ e $70^{\circ} \mathrm{C}$. 0 tempo de contato variou de 0 a 6 horas de forno.

0 resultado obtido para variações da densidade podem ser observados na Figura 4, onde verificou-se que a medida que a temperatura aumenta de $30^{\circ} \mathrm{C}$ para $70^{\circ} \mathrm{C}$, ocorreu uma diminuição dos valores de massa específica do fluido estudado.

Verificou-se que o valor da massa específica também diminui com o aumento do tempo de forno do fluido. A diminuição ocorreu de 12,53 Lb/Gal no instante inicial, tempo 0 minuto, para 5,0 Lib/Gal após 6 horas de forno com temperatura de $70^{\circ} \mathrm{C}$.

Os valores obtidos para variações de VA, VP e LE são ilustrados nas Figuras 5, 6 e 7 respectivamente. Estes resultados foram obtidos após o envelhecimento do fluido nos tempos definidos.

De forma geral, verificou-se que os valores de VA, VP e LE diminuem com o tempo e o aumento da temperatura de forno de $30^{\circ} \mathrm{C}$ para $70^{\circ} \mathrm{C}$.

Os valores de viscosidade aparente (VA), sofreram variações de $50 \mathrm{cP}$ para $33 \mathrm{cP}$ nas temperaturas de $50^{\circ} \mathrm{C}$ e $70^{\circ} \mathrm{C}$ após um tempo de forno de 300 minutos

Figura 4 - Variação da densidade com alterações da temperatura e tempo de forno.

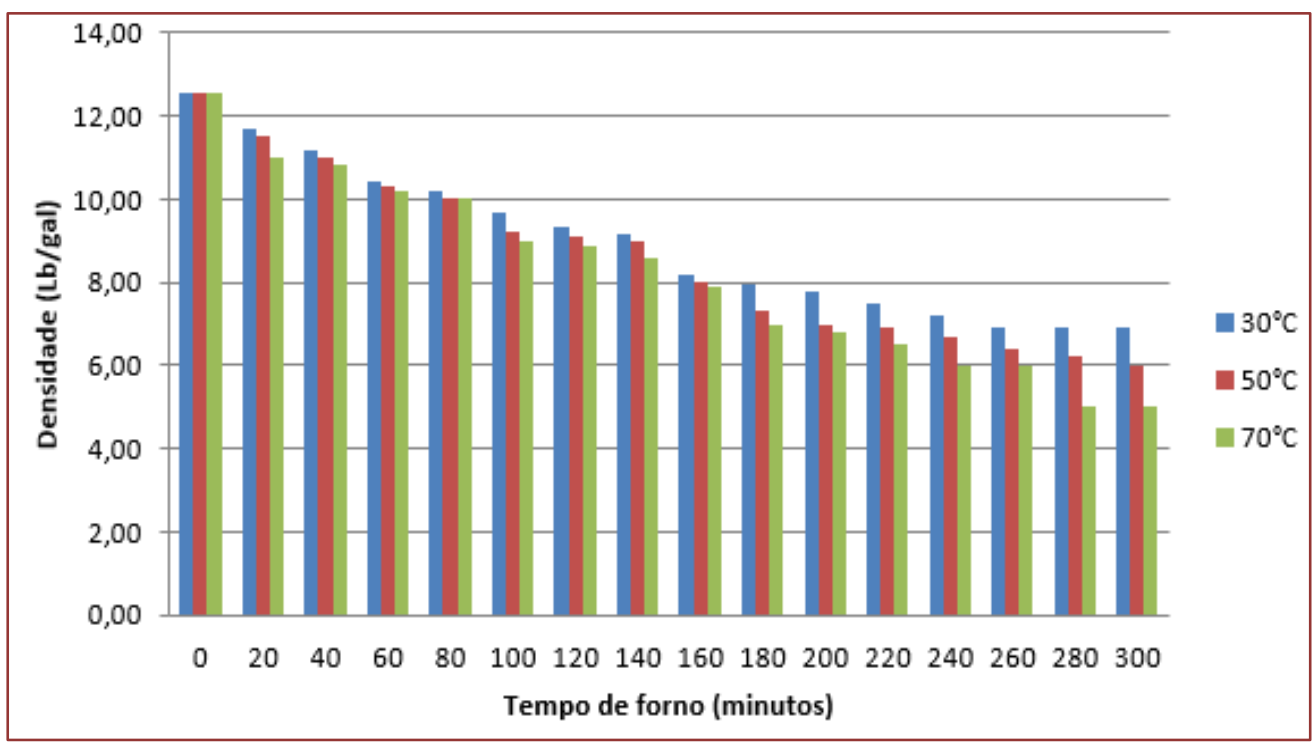


Figura 5 - Variação da viscosidade aparente com alterações da temperatura e tempo de forno.

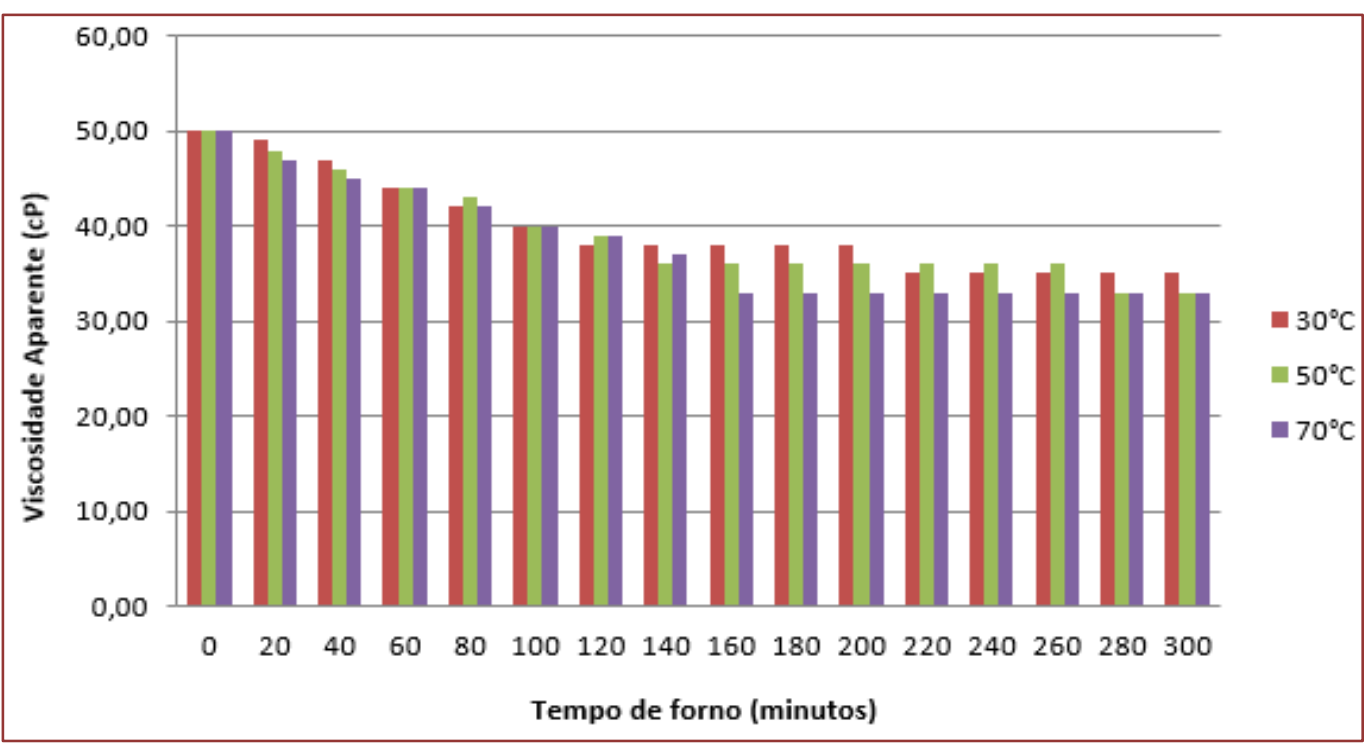

Esse mesmo comportamento foi observado nas figuras 6 e 7, onde os valores de viscosidade plástica e limite de escoamento diminuíram de $33 \mathrm{cP}$ para $22 \mathrm{cP}$ para VA e de $45 \mathrm{~N} / \mathrm{m}^{2}$ para $29 \mathrm{~N} / \mathrm{m}^{2}$.

Os valores finais de VA, VP e LE com as alterações de tempo e temperatura, ficaram foram dos padrões recomendados para fluidos de perfuração, segundo a Norma N 2605 de 1998.

Figura 6 - Variação da viscosidade plástica com alterações da temperatura e tempo de forno.

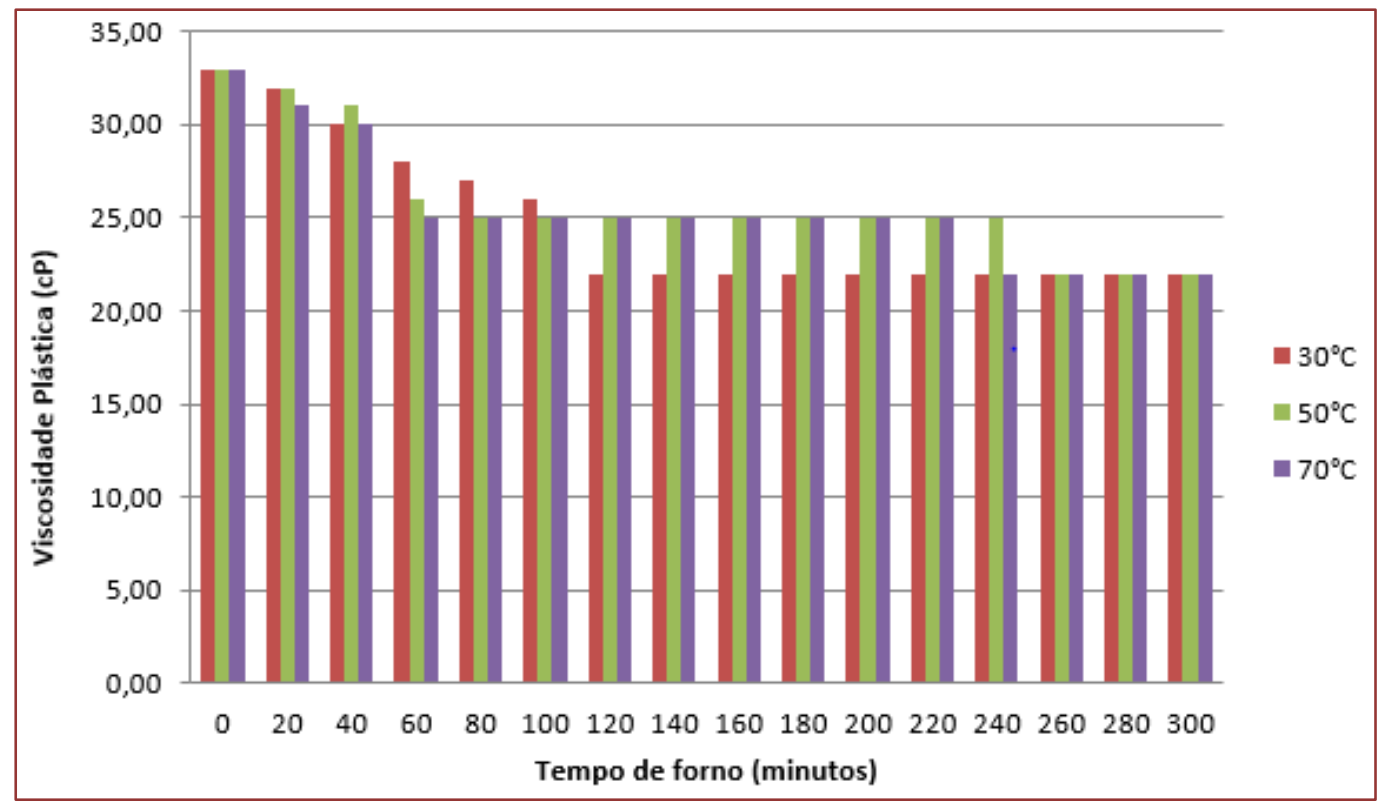


Figura 7 - Variação da viscosidade plástica com alterações da temperatura e tempo de forno.

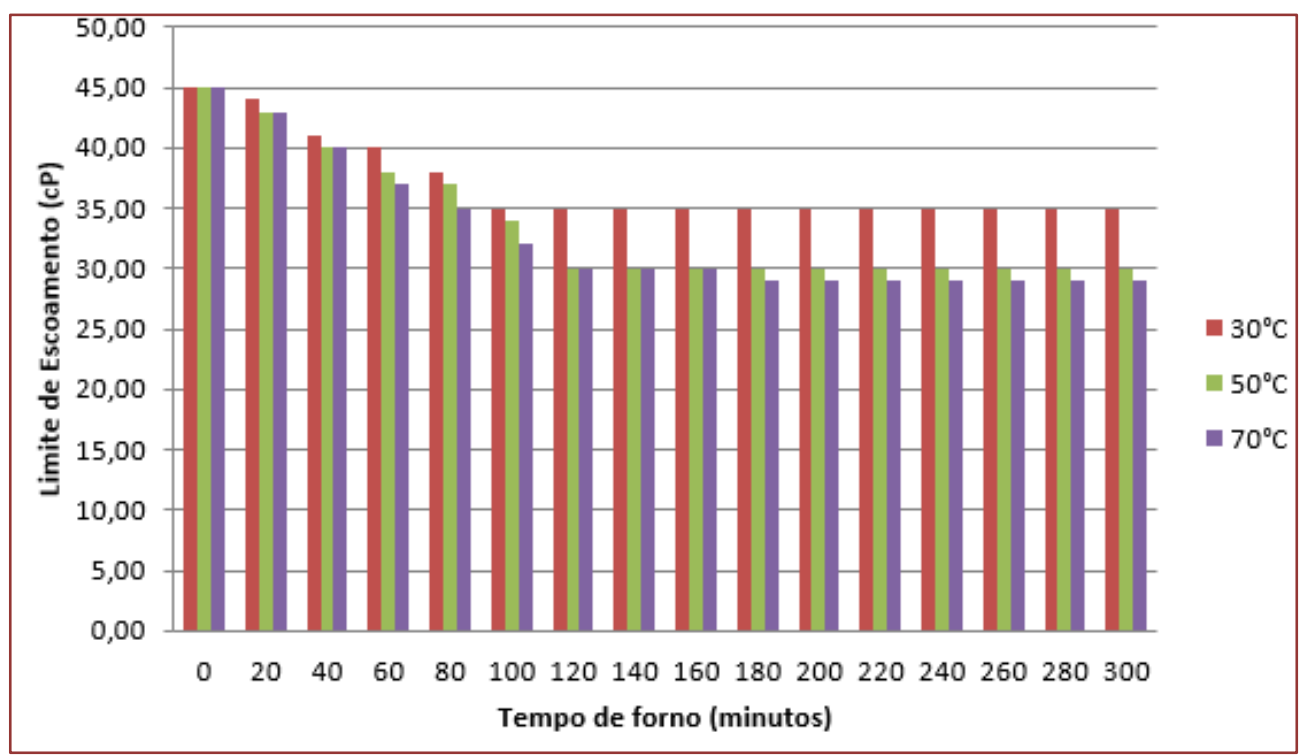

\section{CONCLUSÃO}

A partir dos resultados obtidos pode-se concluir que um aumento da temperatura e do tempo de forno provocaram alterações nos valores de densidade, viscosidade aparente, viscosidade plástica e limite de escoamento para o fluído de perfuração obtido utilizando biodiesel em sua composição.

A diminuição da densidade do fluído e perfuração provoca a diminuição da pressão hidrostática do poço, favorecendo a ocorrência de Kicks ou Blowout, que é o influxo indesejado de fluídos no poço.

Variações da temperatura e do tempo de forno nos fluidos de perfuração diminuíram os valores da viscosidade aparente (VA), viscosidade plástica (VP) e do limite de escoamento, os quais influenciam nos parâmetros reológicos do fluído de perfuração. Os resultados ilustraram que os valores obtidos nas temperaturas de $30^{\circ} \mathrm{C}, 50^{\circ} \mathrm{C}$ e $70^{\circ} \mathrm{C}$ para um tempo de 300 minutos de forno deixaram os valores dos parâmetros reológicos abaixo dos valores recomendados para fluidos de perfuração.

Assim, o monitoramento e manutenção de propriedades do fluído, como a densidade, durante a perfuração é de suma importância para garantir a integridade física dos profissionais envolvidos, a segurança do poço e do meio ambiente.

\section{REFERÊNCIAS}

[1] Guimarães, I, B.; Rossi, L. F. S.; Estudo dos Constituintes dos fluidos de perfuração: proposta de uma formulação otimizada e ambientalmente correta. $4^{\circ}$ Pdpetro, Campinas, SP, 2007.

[2] Kirschner, B. D.; Avaliação da estabilidade de fluidos de perfuração base água. Universidade Federal do Rio Grande do Norte, Nupeg, Prh-Anp 14. 2008

[3] Petrobras, Ensaio de Viscosificante para Fluido de Perfuração Base de Água na Exploração e Produção de Petróleo, Método, N-2605, 1998.

[4] Thomas, J. E. Fundamentos de engenharia de petróleo. 2. ed. Rio de Janeiro: Interciência: Petrobras, 2001. 


\section{Capítulo 6}

Um estudo sobre função porosidade da região de compactação no movimento gravitacional de uma suspensão particulada em proveta

Antônio Santos Silva

Hariel Udi Santana Mendes

Edilson de Jesus Santos

Paulo Victor Vieira Cunha

Victor Hugo dos Santos Ramos

Resumo: 0 movimento de suspensões particuladas é um grande objeto de estudo nas diversas áreas da Engenharia. Diversas aplicações são encontradas para este estudo, como, por exemplo, no escoamento em meios porosos e na sedimentação. Neste trabalho, com base nos testes de proveta para a sedimentação gravitacional, consideram-se as regiões de sedimentação livre, de transição e de compactação, ocupadas pela suspensão durante o processo. Na região de compactação, a suspensão será modelada por um meio poroso com restrição de incompressibilidade que, sob certas condições, permite o estabelecimento de uma equação diferencial para a função porosidade. Com isso, formula-se um modelo matemático cuja solução fornece diretamente a função porosidade para a região de estudo. $\mathrm{Na}$ equação que define a função porosidade surgem parâmetros constantes que precisam ser determinados, os quais também aparecem nas equações que descrevem as alturas das interfaces superior descendente e inferior ascendente e a porosidade média da suspensão. Foram determinados resultados numéricos que mostraram que o comportamento da curva obtida para a interface superior ascendente e porosidade média com o tempo são compatíveis com formas da literatura.

Palavras-chave: Função porosidade; região de compactação; meios porosos; sedimentação. 


\section{INTRODUÇÃO}

O estudo dos fenômenos de transportes em meios porosos é relevante tanto do ponto de vista teórico, como em diversas situações práticas que podem ser aplicadas nas diversas áreas da Engenharia, como por exemplo, na Engenharia de Processos Químicos, com ênfase nas operações unitárias que envolvem esta aplicação [1]. Na Engenharia de Petróleo, uma grande aplicação para o escoamento em meios porosos seriam os métodos de recuperação de petróleo, que consistem em injeção de fluido no reservatório, na maioria das vezes água ou gás, para aumentar a recuperação do óleo in place no reservatório [2].

Baseada na mecânica do contínuo para uma partícula sólida, é importante destacar que o movimento de queda acelerada de uma partícula num fluido é considerado o ponto de partida para se obter informações para a análise de parâmetros de uma suspensão particulada [3]. Do ponto de vista de um meio poroso saturado com fluido, modelado pela Teoria Contínua de Misturas Sólido-Fluido sem reações químicas, considerando que a densidade do sólido e do fluido puros são constantes, ou seja, com restrição de incompressibilidade, a formulação teórica, como apresentada em [4], fornece equações de balanço generalizadas, envolvendo grandezas constitutivas e arbitrárias.

Para um problema unidimensional, pode ser utilizada modelagem matemática do movimento gravitacional de suspensões particuladas em proveta, que não é simplesmente um problema puro de sedimentação. A modelagem envolvida é mais complexa, visto que, são envolvidas sub-regiões que variam com o tempo e são delimitadas por interfaces em movimento, sendo que em cada região a porosidade e as velocidades satisfazem um sistema de equações diferenciais parciais [5]. Além disso, é necessário estabelecer condições de contorno e iniciais para a resolução das equações diferenciais, considerar as condições de salto através da interface em movimento para caracterizar o problema que será modelado [5].

Este trabalho tem como objetivo realizar um estudo acerca da função porosidade na região de compactação do movimento gravitacional de uma suspensão particulada em proveta, através de modelagem matemática.

\section{METODOLOGIA}

\subsection{MODELAGEM MATEMÁTICA}

De acordo com o modelo matemático proposto por [5], o movimento de queda das partículas sólidas em proveta (início do movimento de queda das partículas sólidas até o término) é possível de ser caracterizado por meio de uma curva Altura x Tempo. Esta curva é dividida em sub-regiões, as quais podem ser caracterizadas de acordo com a Figura 1.

No gráfico da Figura 1, HPQR até a altura H corresponde à região de líquido puro, OPHO corresponde à região de sedimentação livre (SL), OPQO corresponde à região de transição (RT) e a região limitada por $\mathrm{OQR}$ e o eixo dos tempos corresponde à região de compactação (RC). As curvas $\mathrm{HPQR}, \mathrm{OP}$ e $\mathrm{OQ}$ correspondem, respectivamente, às alturas da interface superior descendente, da onda de aceleração e da face inferior ascendente.

Figura 1: Gráfico representativo do processo de sedimentação em proveta.

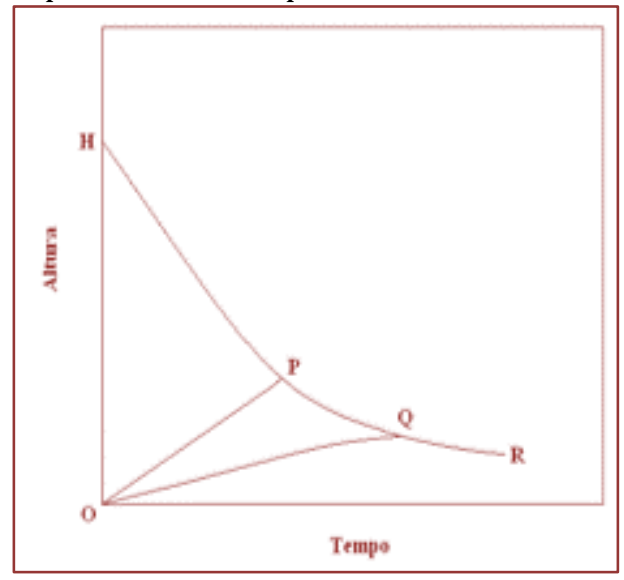


As seguintes relações podem ser escritas de cada uma das curvas da Figura (1):

$$
x(t), 0 \leq t \leq \infty \quad \bar{x}(t), 0 \leq t \leq t_{0} \quad z(t), 0 \leq t \leq t_{c}
$$

sendo $t$ a variável tempo, $x(t)$ a altura da interface superior descendente, $\bar{x}(t)$ a altura da onda de aceleração e $z(t)$ a altura da interface inferior ascendente. 0 tempo $t_{0}$ indica o instante de encontro da interface superior descendente com a onda de aceleração e o tempo $t_{c}$ indica o instante de encontro das duas interfaces. As alturas satisfazem as condições iniciais (equação 2) e as condições de contorno (equação 3).

$$
\begin{aligned}
& x(0)=H \quad \bar{x}(0)=0 \quad z(0)=0 \\
& \bar{x}\left(t_{0}\right)=x\left(t_{0}\right) \equiv x_{0} \quad x\left(t_{c}\right)=z\left(t_{c}\right) \equiv x_{c}
\end{aligned}
$$

onde $H$ é a altura inicial da suspensão na proveta. Além disso, considera-se $y$ como a coordenada espacial (posição) orientada para cima de tal modo que $y=0$ representa o fundo da proveta ou o eixo dos tempos na Figura 1. A função porosidade da suspensão na proveta é definida através da Equação 4.

$$
\varepsilon(y, t) \quad 0 \leq y \leq x(t) \quad 0 \leq t<\infty
$$

A função porosidade satisfaz a condição inicial:

$$
\varepsilon(y, 0)=\varepsilon_{0}=\text { constante } \quad 0 \leq y \leq H
$$

Com a seguinte notação no fundo da proveta:

$$
\varepsilon(0, t)=\varepsilon_{m}(t) \quad 0 \leq t \leq \infty \quad \varepsilon_{m f}=\lim _{t \rightarrow \infty} \varepsilon_{m}(t)
$$

As velocidades do fluido e do sólido, são definidas, respectivamente, por:

$$
V_{1}(y, t) \text { e } V_{2}(y, t) \quad 0 \leq y \leq x(t) \quad 0 \leq t<\infty
$$

E são nulas no fundo da proveta, expressando as condições de contorno:

$$
V_{1}(0, t)=V_{2}(0, t)=0 \quad 0 \leq t<\infty
$$

Modelando a suspensão na proveta por um meio poroso com restrição de incompressibilidade, da teoria de [4], os balanços de massa e quantidade de movimento linear podem ser escritos como segue.

\subsection{BALANÇOS BÁSICOS}

- Balanços de massa

$$
\frac{\partial \varepsilon}{\partial t}+\frac{\partial}{\partial y}\left(\varepsilon V_{1}\right)=0 \quad \frac{\partial \varepsilon}{\partial t}-\frac{\partial}{\partial y}\left((1-\varepsilon) V_{2}\right)=0
$$


Balanços de quantidade de movimento linear

$$
\begin{gathered}
\rho_{1} a_{1}=-\varepsilon \frac{\partial P_{f}}{\partial y}+\frac{\partial \sigma_{1}}{\partial y}+m+\rho_{1} g_{1} \quad \rho_{2} a_{2}=-(1-\varepsilon) \frac{\partial P_{s}}{\partial y}+\frac{\partial \sigma_{2}}{\partial y}-m+\rho_{2} g_{2} \\
\frac{\partial \varepsilon}{\partial t} \frac{\partial \Pi_{s f}}{\partial y}=\frac{\partial \varepsilon}{\partial y} \frac{\partial \Pi_{s f}}{\partial t} \quad, \quad \Pi_{s f}=P_{s}-P_{f} \\
g_{1}=g_{2}=-g \\
\rho_{1}=\varepsilon \rho_{f} \quad \rho_{2}=(1-\varepsilon) \rho_{s} \\
a_{\alpha}=\frac{\partial V_{\alpha}}{\partial t}+V_{\alpha} \frac{\partial V_{\alpha}}{\partial y} \quad \alpha=1,2
\end{gathered}
$$

sendo $P_{f}(y, t)$ e $P_{s}(y, t)$ pressões arbitrárias, $a_{\alpha}$ a aceleração, $\sigma_{1}$ e $\sigma_{2}$ a parte constitutiva do tensor tensão, $m(y, t)$ a força difusiva ou resistiva, $\rho_{f}$ e $\rho_{s}$ as massas específicas do fluido e do sólido, respectivamente e $g$ a aceleração da gravidade.

Como, das equações (8), tem-se que a função $\varepsilon V_{1}+(1-\varepsilon) V_{2}$ não depende de $y$, a partir da equação (7), nota-se que:

$$
\varepsilon V_{1}+(1-\varepsilon) V_{2} \quad 0 \leq y \leq x(t) \quad 0 \leq t<\infty
$$

\subsection{POROSIDADE NA REGIÃO DE COMPACTAÇÃO}

A região de compactação é limitada pela proveta e por:

$$
\begin{gathered}
0 \leq y \leq z(t) \quad 0 \leq t \leq t_{c} \\
0 \leq y \leq x(t) \quad t_{c} \leq t \leq \infty
\end{gathered}
$$

Por serem $P_{f}(y, t)$ e $P_{s}(y, t)$ arbitrárias, estas pressões podem ser escolhidas de modo adequado, de tal maneira que do sistema (10) pode ser escrita a equação de interseção:

$$
\begin{aligned}
\beta_{0} \frac{\partial \varepsilon}{\partial y}= & \varepsilon(1-\varepsilon)\left(V_{2}-V_{1}\right)+V_{0}\left(\varepsilon-\varepsilon^{*}\right) \\
\varepsilon^{*}(t)= & \varepsilon_{\infty}+\frac{3}{4}\left(\varepsilon_{m}(t)-\varepsilon_{m f}\right) \\
& \varepsilon_{\infty}=\lim _{t \rightarrow \infty} \varepsilon^{*}(t)
\end{aligned}
$$

sendo $V_{0}$ uma velocidade constante, $\varepsilon_{\infty}$ uma porosidade crítica e, com base em (6), $\varepsilon_{m f}$ é a porosidade final no fundo da proveta.

Com isso, a partir das equações de balanço de massa (9) e das equações (11) e (13), obtém-se a equação diferencial parcial a seguir:

$$
\beta_{0} \frac{\partial^{2} \varepsilon}{\partial y^{2}}=\frac{\partial \varepsilon}{\partial t}+V_{0} \frac{\partial \varepsilon}{\partial y}
$$

Pelas equações (6), (8) e (13) tem-se a condição de contorno:

$$
\beta_{0} \frac{\partial \varepsilon}{\partial y}(0, t)=V_{0}\left(\varepsilon_{m}(t)-\varepsilon^{*}(t)\right)
$$

Além disso, adota-se outra condição de contorno: 


$$
\frac{\partial \varepsilon}{\partial t}(0, t)=-3 k\left(\varepsilon_{m}(t)-\varepsilon_{m f}\right), \quad k=\frac{V_{0}^{2}}{16 \beta_{0}}
$$

Baseado na solução estática de (13), introduz-se a função:

$$
\epsilon(y)=\varepsilon_{\infty}+\left(\varepsilon_{m f}-\varepsilon_{\infty}\right) \exp \left(\frac{4 y}{L_{0}}\right), \quad L_{0}=\frac{V_{0}}{4 k}
$$

Para a obtenção da condição final:

$$
\lim _{t \rightarrow \infty} \varepsilon(y, t)=\in(y)
$$

Assim, as condições representadas pelas equações (2), (5), (15), (17) e (18) e a equação diferencial (14) formam um problema para a função porosidade, cuja solução exata é dada por:

$$
\varepsilon(y, t)=\left(\varepsilon_{m}(t)-\varepsilon_{m f}\right) \exp \left(\frac{y}{L_{0}}\right)+\in(y)
$$

Produzindo, pelas equações (6) e (8), a relação para a porosidade no fundo da proveta:

$$
\varepsilon_{m}(t)=\varepsilon_{m f}+\left(\varepsilon_{0}-\varepsilon_{m f}\right) \exp (-3 k t)
$$

Para a localização da interface superior ascendente, adota-se a condição:

$$
\frac{d \xi_{1}}{d t}=k\left(\frac{2}{k t+1}-3\right) \xi_{1} \quad \xi_{1}(t) \equiv \varepsilon(z(t), t)-\in(z(t)) \quad 0 \leq t \leq t_{c}
$$

Então, pelas equações (2), (16), (17), (19), (20) e (21), a altura da interface inferior ascendente é dada por:

$$
z(t)=\frac{V_{0}}{2 k} \ln (k t+1) \quad 0 \leq t \leq t_{c}
$$

Para o cálculo de $k$ e $V_{0}$, utiliza-se o encontro das interfaces, que fornece as relações:

$$
V_{0}=2 \omega_{0} \quad k x_{c}=\omega_{0} \ln \left(k t_{c}+1\right) \quad \omega_{0} t_{c}>x_{c}
$$

sendo $\omega_{0}$ a velocidade inicial da interface inferior ascendente.

Para encontrar a altura da interface superior descendente após o encontro das interfaces pode-se utilizar como base a equação (19). Para isso, como ponto de partida, considera-se a porosidade média da região de compactação após o encontro das interfaces, expressa por:

$$
\bar{\varepsilon}(t)=\frac{1}{x(t)} \int_{0}^{x(t)} \varepsilon(y, t) d y \quad t_{c} \leq t \leq \infty
$$


Logo, das equações (19), (20) e (24) temos:

$$
\bar{\varepsilon}(t)=\varepsilon_{\infty}+\left(\varepsilon_{0}-\varepsilon_{m f}\right) \frac{H}{x(t)} \mathrm{E}_{1}+\left(\varepsilon_{m f}-\varepsilon_{\infty}\right) \frac{H}{x(t)} \mathrm{E}_{2} \quad t_{c} \leq t \leq \infty
$$

onde

$$
\begin{aligned}
& \mathrm{E}_{1}=r_{0}(\exp (-3 k t))\left(\exp \left(\frac{x(t)}{L_{0}}\right)-1\right) \\
& \mathrm{E}_{2}=\frac{r_{0}}{4}\left(\exp \left(\frac{4 x(t)}{L_{0}}\right)-1\right) \quad, \quad r_{0}=\frac{L_{0}}{H}
\end{aligned}
$$

Usando o balanço de massa, tem-se que:

$$
(1-\bar{\varepsilon}(t)) x(t)=\left(1-\varepsilon_{0}\right) H \quad t_{c} \leq t \leq \infty
$$

Assim, a partir das equações (24), (25), (26), (27) e (28) chega-se à expressão:

$$
\frac{x(t)}{H}=\mathrm{A}_{0}+\left(\mathrm{A}_{f}-\mathrm{A}_{0}\right) \mathrm{E}_{1}+\left(1-\mathrm{A}_{f}\right) \mathrm{E}_{2} \quad t_{c} \leq t \leq \infty
$$

A qual, com base em (23), (26) e (27), fornecem de forma implícita, a altura da interface superior descendente após o encontro das interfaces, sendo que:

$$
\mathrm{A}_{0}=\frac{1-\varepsilon_{0}}{1-\varepsilon_{\infty}} \quad \text { e } \quad \mathrm{A}_{f}=\frac{1-\varepsilon_{m f}}{1-\varepsilon_{\infty}}
$$

Por (3) e (29) no ponto de encontro das interfaces tem-se:

$$
\frac{\mathrm{x}_{C}}{H}=\mathrm{A}_{0}+\left(\mathrm{A}_{f}-\mathrm{A}_{0}\right) \mathrm{E}_{1 C}+\left(1-\mathrm{A}_{f}\right) \mathrm{E}_{2 C}
$$

onde

$$
\mathrm{E}_{1 C}=\mathrm{E}_{1} \quad \text { e } \mathrm{E}_{2 C}=\mathrm{E}_{2} \text { para } x=x_{c} \text { e } t=t_{c}
$$

Além disso, considerando-se o sedimento final $(t \rightarrow \infty)$ :

$$
\frac{x_{f}}{H}=\mathrm{A}_{0}+\left(1-\mathrm{A}_{f}\right) \mathrm{E}_{2 f}, \mathrm{E}_{2 f}=\mathrm{E}_{2} \quad \text { para } x=x_{f}
$$

sendo $x_{f}$ a altura final da interface superior descendente.

Com isso, das equações (31), (32) e (33), obtêm-se:

$$
\begin{aligned}
& \mathrm{A}_{f}=\frac{r_{C}-\mathrm{E}_{2 C}+\left(\mathrm{E}_{2 f}-r_{f}\right)\left(1-\mathrm{E}_{1 C}\right)}{\mathrm{E}_{1 C}-\mathrm{E}_{2 C}+\mathrm{E}_{2 f}\left(1-\mathrm{E}_{1 C}\right)} \\
& \mathrm{A}_{0}=r_{f}-\left(1-\mathrm{A}_{f}\right) \mathrm{E}_{2 f}, r_{C}=\frac{x_{c}}{H}, \quad r_{f}=\frac{x_{f}}{H}
\end{aligned}
$$


As quais fornecem, por (30), os resultados:

$$
\begin{array}{r}
\varepsilon_{\infty}=1-\frac{1-\varepsilon_{0}}{\mathrm{~A}_{0}} \\
\varepsilon_{m f}=1-\left(1-\varepsilon_{0}\right) \frac{\mathrm{A}_{f}}{\mathrm{~A}_{0}}
\end{array}
$$

Assim, por (17), (19), (20), (22), (36) e (37), a porosidade para a região de compactação fica completamente estabelecida.

\section{RESULTADOS E DISCUSSÃO}

Os resultados para a função porosidade dependem, por (17), (19) e (20), dos valores de $V_{0}, k, \varepsilon_{m f}$ e $\varepsilon_{\infty}$. De acordo com [5], para definir o ponto de encontro das interfaces $\left(x_{c}, t_{c}\right)$, deve-se obter o ponto mínimo de:

$$
W=\frac{u_{0} x}{2(H-x)-u_{0} t}
$$

Onde $u_{0}$ é a velocidade de sedimentação livre.

As relações (23) formam a base inicial para o cálculo de $\omega_{0}$ e $k$, começando com $\omega_{0}$, o qual já tem um limitante inferior.

Para a suspensão aquosa de atapulgita com porosidade inicial 0,97 e altura inicial da suspensão na proveta de $40 \mathrm{~cm}$ [6], o valor de $\omega_{0}$ compatível com (29) foi de $0,098 \mathrm{~cm} / \mathrm{min}$, resultado em $k$ igual a $0,006 \mathrm{~min}^{-1}$. Para esta suspensão são mostrados resultados nas Tabelas 1 e 2.

A Tabela 1 mostra que a função porosidade da região de compactação, antes do instante de encontro das interfaces, comporta-se de acordo com dados da literatura, representativos do fenômeno, ou seja, para cada instante a porosidade aumenta do fundo da proveta até a interface superior descendente, diminuindo com o tempo em cada posição.

A Tabela 2 mostra que a função porosidade da região de compactação, após o instante de encontro das interfaces, também se comporta como esperado, ou seja, para cada instante a porosidade aumenta do

\begin{tabular}{|c|c|c|c|c|}
\hline $\begin{array}{c}y \\
(\mathrm{~cm})\end{array}$ & $40 \mathrm{~min}$ & $\begin{array}{c}\varepsilon(y, t), \\
80 \mathrm{~min}\end{array}$ & $\begin{array}{l}0 \leq y \leq z(t \\
120 \mathrm{~min}\end{array}$ & $160 \mathrm{~min}$ \\
\hline $\mathbf{0}$ & 0,9249 & 0,9039 & 0,8941 & 0,8896 \\
\hline 1,0 & 0,9305 & 0,9066 & 0,8954 & 0,8902 \\
\hline 2,0 & 0,9368 & 0,9096 & 0,8969 & 0,8910 \\
\hline 3,0 & 0,9442 & 0,9132 & 0,8987 & 0,8920 \\
\hline 4,0 & & 0,9173 & 0,9009 & 0,8932 \\
\hline 5,0 & & 0,9223 & 0,9036 & 0,8949 \\
\hline 6,0 & & 0,9284 & 0,9071 & 0,8972 \\
\hline 7,0 & & & 0,9117 & 0,9004 \\
\hline 8,0 & & & 0,9181 & 0,9052 \\
\hline 9,0 & & & & 0,9126 \\
\hline \multirow[t]{3}{*}{10,0} & & & & 0,9242 \\
\hline & \multicolumn{4}{|c|}{$\mathrm{z}(\mathrm{t}), \mathrm{cm}$} \\
\hline & 3,49 & 6,34 & 8,74 & 10,81 \\
\hline
\end{tabular}
fundo da proveta até a interface superior descendente, diminuindo com o tempo em cada posição.

Tabela 1: Valores da porosidade da região de compactação antes do encontro das interfaces. 
Tabela 2: Valores da porosidade da região de compactação após o encontro das interfaces.

\begin{tabular}{|c|c|c|c|c|}
\hline & \multicolumn{4}{c}{$\varepsilon(y, t), \quad 0 \leq y \leq x_{f}$} \\
$\mathbf{y}(\mathbf{c m})$ & $200 \mathrm{~min}$ & $220 \mathrm{~min}$ & $240 \mathrm{~min}$ & $260 \mathrm{~min}$ \\
\hline & 0,8874 & 0,8869 & 0,8865 & 0,8862 \\
\hline $\mathbf{0}$ & 0,8878 & 0,8871 & 0,8867 & 0,8864 \\
\hline 1,0 & 0,8882 & 0,8875 & 0,8870 & 0,8866 \\
\hline 2,0 & 0,8888 & 0,8880 & 0,8874 & 0,8870 \\
\hline 3,0 & 0,8896 & 0,8887 & 0,8880 & 0,8875 \\
\hline 4,0 & 0,8908 & 0,8897 & 0,8889 & 0,8884 \\
\hline 5,0 & 0,8925 & 0,8912 & 0,8904 & 0,8898 \\
\hline 6,0 & 0,8951 & 0,8937 & 0,8927 & 0,8920 \\
\hline 7,0 & 0,8992 & 0,8976 & 0,8964 & 0,8957 \\
\hline 8,0 & 0,9058 & 0,9039 & 0,9026 & 0,9017 \\
\hline 9,0 & 0,9164 & 0,9142 & 0,9127 & 0,9117 \\
\hline 10,0 & & & &
\end{tabular}

A Figura 2 ilustra que a forma da curva da interface inferior ascendente com o tempo resultante do modelo apresenta o comportamento esperado [7].

Figura 2: Altura da interface inferior ascendente versus tempo.

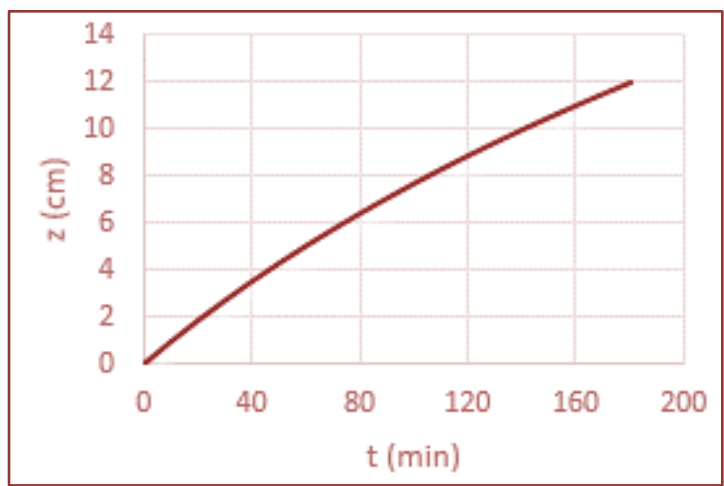

\section{CONCLUSÕES}

0 modelo matemático apresentado fornece a função porosidade em termos de parâmetros, os quais podem ser determinados conhecendo-se os movimentos das interfaces, principalmente o da interface superior descendente, relacionada à porosidade média da suspensão. Assim, dados experimentais mostrando as alturas das interfaces e a porosidade média podem ser facilmente empregados para a determinação de parâmetros de sedimentação. Para a suspensão testada, verificou-se o comportamento compatível da função porosidade e da interface inferior ascendente com a literatura.

\section{REFERÊNCIAS}

[1] Cremasco, M.A. Operações unitárias em sistemas particulados e fluidodinâmicos - 2ª edição. São Paulo: Blutcher, 2014.

[2] Rosa, A. J. R. S. Carvalho e J. A. D. Xavier: Engenharia de Reservatórios de Petróleo. Rio de Janeiro: Interciência, 2006.

[3] Basset, A. B. Dynamic simulation of sheared suspensions. Philosophical Transactions of the Royal Society A, v. 179 , p. 43-63, 1888.

[4] Silva, A. S.; Jesus, e.; Pagano, R. L.; Meneses, L. D. M.; Rocha C. P. S. Equações do movimento de suspensões particuladas com restrição de incompressibilidade. Scientia Plena, v. 9, n. 11, p. 114201-1, 2013.

[5] Libório, D. O. Construção de uma Base de Informações para a Diferença de Pressões Arbitrárias em uma Suspensão Particulada. 2016, 74f, Dissertação de Mestrado - Programa de Pós-Graduação em Engenharia Química da Universidade Federal de Sergipe, UFS, 2016.

[6] Tiller, F. M.; D’avila, J.S. Zona de compressão em sedimentação. Anais do VIII Enemp, Vol. 2, p. 269-297. Curitiba-PR. 1980.

[7] Font, R. Compression Zone Effect in Batch Sedimentation. AIChE Journal, Vol. 34, n. 2, p. 229-252. 1988. 


\section{Capítulo 7}

Comparação do uso do método térmico de recuperação para oléos de diferentes graus API a partir de simulação computacional

\section{Bianca Gabriel de Souza}

Karolline Dewanele Santana Rocha

Hariel Udi Santana Mendes

Acto de Lima Cunha

Resumo: Os métodos de recuperação secundários foram desenvolvidos para complementar a energia do reservatório, quando esta não é suficiente par trazer o óleo até a superfície. Devido a relativa simplicidade, baixo custo e disponibilidade do fluido, a injeção de água é o método mais utilizado no mundo. Para o caso de reservatórios de óleos pesados os métodos térmicos são mais utilizados pois agem principalmente reduzindo a viscosidade do óleo, melhorando sua mobilidade e, consequentemente, sua recuperação. Esse trabalho busca comparar a injeção de água aquecida em reservatórios de óleos com diferentes ${ }^{\circ} \mathrm{API}$, a partir da análise de fatores como eficiência de varrido, fração recuperada e volume acumulado de produção, através de simulação computacional usando como ferramenta o software comercial ANSYS CFX 18.1@. Foi gerada uma malha em linha direta contendo dois poços produtores e dois poços injetores e simulada a injeção contínua de água aquecida em um período de 4 anos. Segundo a literatura a eficiência do método é inversamente proporcional ao grau API do petróleo, o que pode ser corroborado, visto que a eficiência de varrido e fração recuperada apresentaram valores maiores para o caso de menor grau API.

Palavras-chave: simulação computacional, métodos de recuperação, processo térmico, eficiência de varrido, fração recuperada. 


\section{INTRODUÇÃO}

A energia natural de um reservatório de petróleo nem sempre é suficiente para elevá-lo até a superfície, e mesmo quando é, essa energia vai se esgotando à medida que o óleo vai sendo produzido, fazendo-se necessária a implementação de uma forma suplementar de energia. Os métodos de recuperação secundária de petróleo visam incrementar a energia do reservatório ou tornar mais eficiente a energia natural (primária) deste e podem tornar viáveis campos maduros.

Rosa (2006) divide os métodos de recuperação secundária em métodos convencionais e especiais. Como método dito convencional tem-se a injeção de água e de gás, que apenas deslocam os fluidos presentes nos poros. Já os métodos especiais agem no próprio fluido alterando suas características ou a interação fluidorocha, dentre eles destacam-se os métodos térmico, químico, miscível e microbiológico, entre outros.

A injeção de água é o método mais amplamente utilizado devido ao seu baixo custo quando comparado a outros métodos, pela abundância da fonte, principalmente em cenários offshore, boa eficiência e operação relativamente fácil. Nesse método, não há mistura entre o fluido injetado e o óleo, a água desloca o óleo em direção ao(s) poço(s) produtor(es).

Entretanto, no caso de reservatórios de óleos viscosos, os métodos convencionais podem não ser tão eficientes, pois a alta viscosidade dificulta a movimentação do óleo. Além disso, a maior mobilidade do gás e da água em relação ao óleo reduz a eficiência de varrido. A alternativa mais indicada para esses casos é o uso método de recuperação especial térmico.

0 método térmico consiste no aquecimento do reservatório através de combustão in-situ ou injeção de um fluido quente, normalmente faz-se injeção de água (líquida ou na forma de vapor). A adição de temperatura traz alguns benefícios como diminuição da viscosidade, dilatação térmica e formação de solvente, que acarreta em aumento das eficiências de varrido e deslocamento, melhorando o fator de recuperação. Segundo a literatura, a redução da viscosidade é mais acentuada em óleo de baixo ${ }^{\circ} \mathrm{API}$, que normalmente também são mais viscosos. Assim, quanto mais pesado o óleo, mais eficiente o método.

Dessa forma esse trabalho visa a comparação de duas situações de injeção de água aquecida como método de recuperação especial para diferentes ${ }^{\circ} \mathrm{API}$ para análise da influência desse parâmetro na recuperação do óleo.

\section{METODOLOGIA}

\subsection{MODELO FÍSICO}

Para desenvolver esse trabalho foi utilizada a ferramenta computacional ICEM-CFD 18.1 da plataforma ANSYS®, onde foi modelado um reservatório com dimensões quadráticas de $300 \mathrm{~m} \times 300 \mathrm{~m} \times 5 \mathrm{~m}$. No reservatório, quatro poços foram distribuídos da seguinte forma: dois poços produtores espaçados $240 \mathrm{~m}$ entre si e dois poços injetores espaçados também $240 \mathrm{~m}$ entre si. Cada poço tem $20 \mathrm{~cm}$ de diâmetro e a geometria da malha é linha direta com $240 \mathrm{~m}$ de distância entre os poços produtores e injetores, como ilustrado na Figura 1(a). Sendo feita a simulação de 35040 horas de injeção, correspondente a 4 anos, para dois casos: óleo do reservatório com 17 e $30^{\circ} \mathrm{API}$.

Analisando a Figura 1(b), pode-se perceber que foi realizado um refinamento da malha nas proximidades dos poços, aumentando a confiabilidade e precisão dos resultados do modelo, pois a pressão e a velocidade do fluxo são maiores nessa área, geralmente provocando erros. A malha é constituída por 268.800 nós que deram origem a 300.115 elementos de malha. 
Figura 1 - (a): Ilustração do esquema de poços e dimensões do modelo utilizado; (b): Malha representativa do reservatório. Próprio autor.

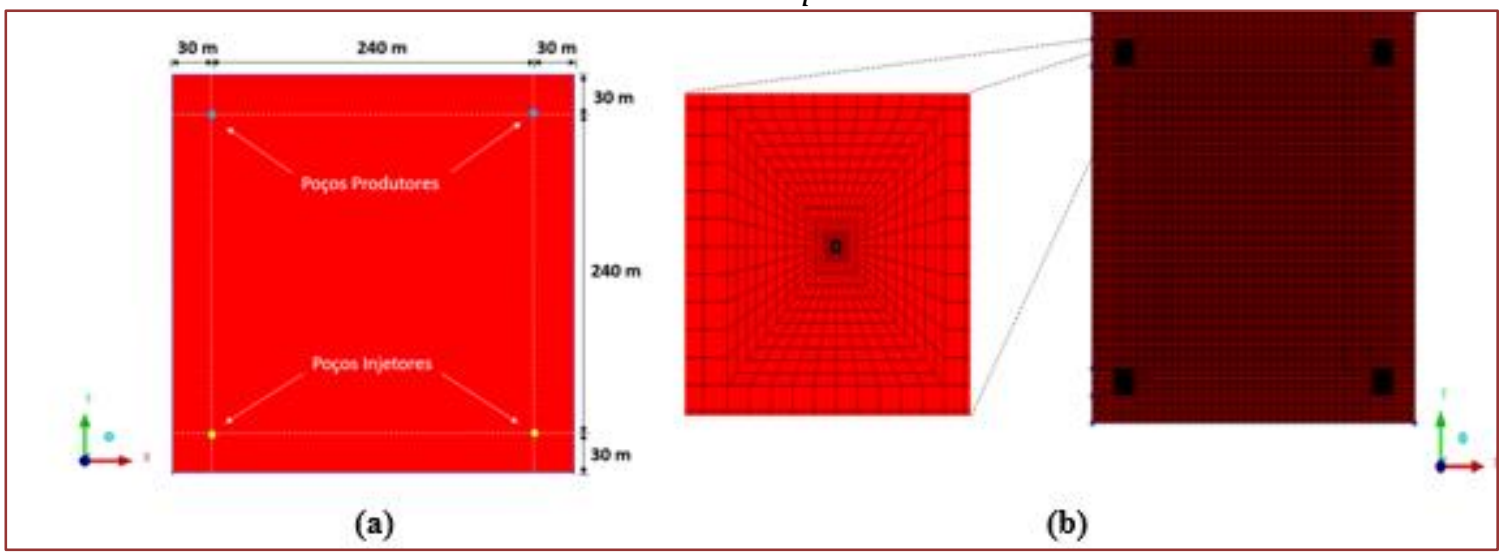

\subsection{MODELAGEM MATEMÁTICA}

Para descrição do modelo matemático de escoamento em meios poroso foi utilizada uma generalização das equações de conservação de massa (2.1), quantidade de movimento (2.2) e de energia (2.4) e a lei de Darcy generalizada (2.5). As equações de Navier-Stokes, são equações diferenciais que descrevem o movimento de fluidos e estabelecem que as mudanças no momento linear e aceleração de uma partícula fluida são o produto das mudanças na pressão e forças viscosas dissispativas que atuam dentro do fluido.

$$
\begin{gathered}
\frac{\partial}{\partial t}(\phi \rho)+\nabla \cdot(\rho \mathbf{K} \cdot \vec{U})=0 \\
\frac{\partial(\rho \phi \vec{U})}{\partial t}+\nabla \bullet(\rho \phi(\mathbf{K} \vec{U}) \otimes \vec{U})=-\nabla \cdot\left(\mu_{c} \mathbf{K}\left(\nabla \vec{U}+\nabla \vec{U}^{T}\right)+S_{i}^{M}\right.
\end{gathered}
$$

Onde $t$ é o tempo, $\varphi$ é a porosidade volumétrica, $\rho$ é a densidade volumétrica, $K$ é o tensor porosidade de área, $\mu_{\mathrm{e}}$ é a viscosidade efetiva e $S_{i}^{M}$ a fonte de quantidade de movimento linear, que no ANSYS CFX 18 é dado pela equação (2.3), onde $\mathrm{C}^{\mathrm{R} 1}$ é o coeficiente linear de resistência, $\mathrm{C}^{\mathrm{R} 2}$ é o coeficiente de resistência quadrática, $S_{i}^{s p e c}$ representa outras fontes de quantidade de movimento relacionadas com as espécies presentes e $\mathrm{U}$ e $\mathrm{U}_{\mathrm{i}}$, velocidades superficiais.

$$
\begin{gathered}
S_{i}^{M}=-C^{R 1} U_{l}-C^{R 2}|\vec{U}| \vec{U}_{l}+S_{i}^{\text {spec }} \\
\frac{\partial}{\partial t}(\phi \rho H)+\nabla \cdot(\rho \mathbf{K} \cdot \vec{U} H)-\nabla \cdot\left(\Gamma_{e} \mathbf{K} \cdot \nabla H\right)=\phi S^{H} \\
-\frac{\partial P}{\partial x_{l}}=\frac{\mu}{\mathbf{K}} U_{t}+K_{l \text { tos } \rho} \rho|\vec{U}| U_{l}
\end{gathered}
$$

Sendo P a pressão, $\mu$ a viscosidade dinâmica do fluido e $\vec{U}$ a velocidade de Darcy - definida como uma velocidade superficial considerando um meio contínuo e poros interconectados e desprezando os detalhes de estruturas porosas -, $\mathrm{K}_{\text {loss }}$ o coeficiente empírico de perda, que no ANSYS CFX 18 tem valor nulo, já $\frac{\mu}{K}$ não pode ser igual a zero.

Os coeficientes $\mathrm{C}^{\mathrm{R} 1}$ (2.6) e $\mathrm{C}^{\mathrm{R} 2}$ (2.7) podem ser obtidos a partir da comparação das equações (2.3) e (2.5) e utilização das velocidades reais no lugar de velocidades superficiais e são expressos por

$$
C^{p_{1}}=\frac{\mu}{\mathbf{K}}
$$

$$
C^{R_{2}}=K_{\text {loss }} \rho
$$




\subsection{CARACTERÍSTICAS DO RESERVATÓRIO}

As condições iniciais do meio poroso e fluidos nele contidos são apresentadas nas tabelas 1 e 2.

Tabela 1: Propriedades dos fluidos.

\begin{tabular}{|l|c|}
\multicolumn{1}{|c|}{ Propriedades físicas } & Meio poroso \\
\hline Permeabilidade $\left(\mathrm{m}^{2}\right)$ & $1 \times 10^{-13}$ \\
\hline Porosidade & 0,2 \\
\hline Coeficiente de perda de resistência - Kloss & 0 \\
\hline
\end{tabular}

Tabela 2: Propriedades do meio.Propriedades físicas

\begin{tabular}{|c|c|c|c|}
\hline & \multicolumn{2}{|c|}{ Petróleo } & \multirow{2}{*}{ Água } \\
\hline & ${ }^{\circ}$ API 17 & ${ }^{\circ} \mathrm{API} 30$ & \\
\hline Densidade $\left(\mathrm{kg} / \mathrm{m}^{3}\right)$ & 952,86 & 876,16 & 997,0 \\
\hline Calor específico (J/kg.K) & \multicolumn{2}{|c|}{2092} & 418407 \\
\hline Condutividade térmica $(\mathrm{W} / \mathrm{m} . \mathrm{K})$ & \multicolumn{2}{|c|}{0,143} & 0,6069 \\
\hline Viscosidade dinâmica (cP) & \multicolumn{2}{|c|}{2} & 0,000252964 \\
\hline Massa molar (kg/kmol) & \multicolumn{2}{|c|}{105,47} & 18,02 \\
\hline
\end{tabular}

A definição das condições de contorno adotadas nas fronteiras do reservatório é necessária para que seja possível a aplicação das equações mostradas anteriormente.

I. Nas faces superior, inferior e lateral, representativas das fronteiras do reservatório foi adotada a condição de superfície impermeável. Para as paredes dos poços utilizou-se a condição de paredes adiabáticas.

II. Nos poços produtores foi considerada uma condição de pressão estática igual 2000 psi.

III. Na seção de entrada de cada poço de injeção foi admitida uma vazão mássica de água constante igual a $0,289 \mathrm{~kg} / \mathrm{s}$ e fração volumétrica igual a 1,0 para água e 0,0 para o óleo. E temperatura de $300^{\circ} \mathrm{F}$ para a água injetada.

IV. No que se refere ao reservatório, admitiu-se como condição inicial que o reservatório estava a uma pressão de 3441,9 psi e fração volumétrica igual a 0,0 para água e 1,0 para o óleo leve e temperatura de $233,24^{\circ} \mathrm{F}$ para o óleo no reservatório.

\section{RESULTADOS E DISCUSSÃO}

Para analisar a frente de avanço da água, utilizou-se um plano no meio do reservatório $(\mathrm{z}=2,5 \mathrm{~m})$, determinando a fração volumétrica de água e óleo nesse plano. Observa-se que a injeção de água se dá de forma radial. Isso se deve à homogeneidade do reservatório (porosidade e permeabilidade). Como pode se observar pelas Figura 2 e 3, houve queda da fração volumétrica de óleo ao longo do tempo de injeção, o que demonstra que a água realizou uma boa eficiência de varrido no espaço entre os poços.

Foi escolhido o meio do reservatório pois a água segue um caminho preferencial para a base do reservatório, isso acontece por causa da diferença de densidade entre os fluidos e do efeito da gravidade. Assim, no meio do reservatório encontram-se os valores médios de saturação.

Figura 2: Saturação de óleo nos respectivos tempos de injeção para API 17. Próprio autor.

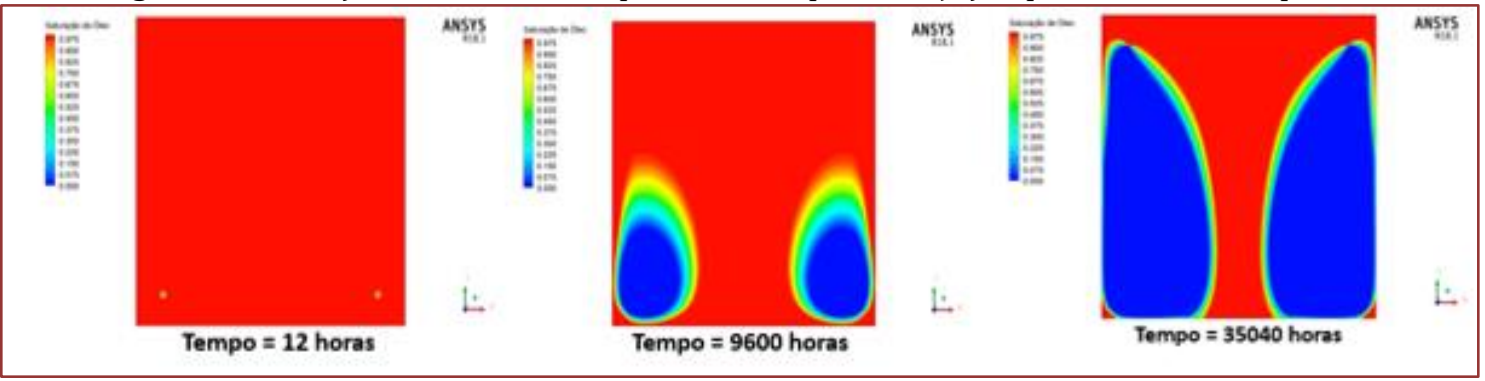


Figura 3: Saturação de óleo nos respectivos tempos de injeção para ${ }^{\circ}$ API 30. Próprio autor.

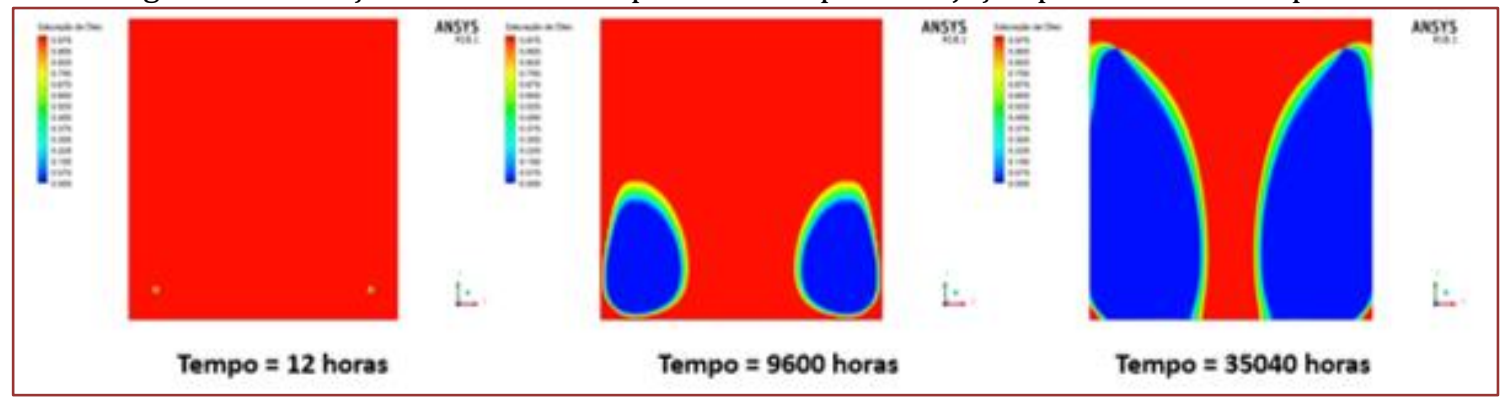

A eficiência de varrido é dada pela razão entre o volume poroso invadido pela água e o volume poroso total, dando assim uma boa perspectiva da eficiência do método: quanto maior for esse valor, maior a área do reservatório que foi afetada pelo método de recuperação e, consequentemente, maior a quantidade de óleo produzido. No Gráfico 1 podemos observar que a eficiência de varrido é maior para o óleo com $17^{\circ} \mathrm{API}$, mantendo aproximadamente $6 \%$ maior que parar o óleo com $30^{\circ} \mathrm{API}$ para um mesmo volume de água injetado durante toda a simulação.

Também pode ser observado o melhor desempenho para a o caso do óleo com ${ }^{\circ}$ API 17 ao analisar o comportamento da fração de óleo recuperada, ilustrada no Gráfico 2, chegando a 65,6\%, enquanto para o ${ }^{\circ}$ API 30 o máximo valor alcançado foi de $59,9 \%$

Gráfico 1: Comportamento da eficiência de varrido com a variação do volume de água injetado.

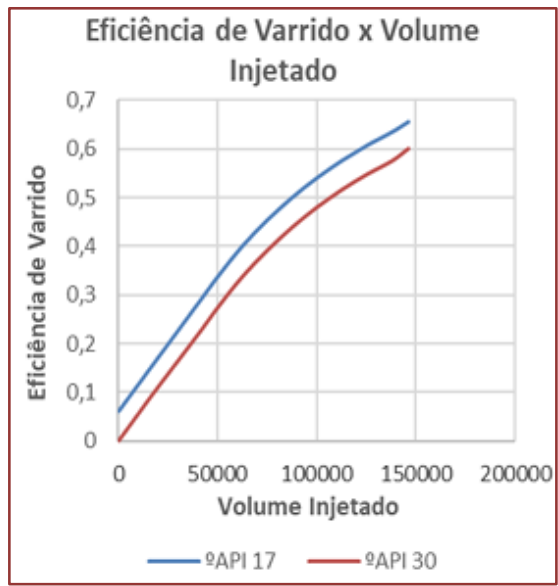

Gráfico 2: Comportamento do fator de recuperação com o tempo para cada caso.

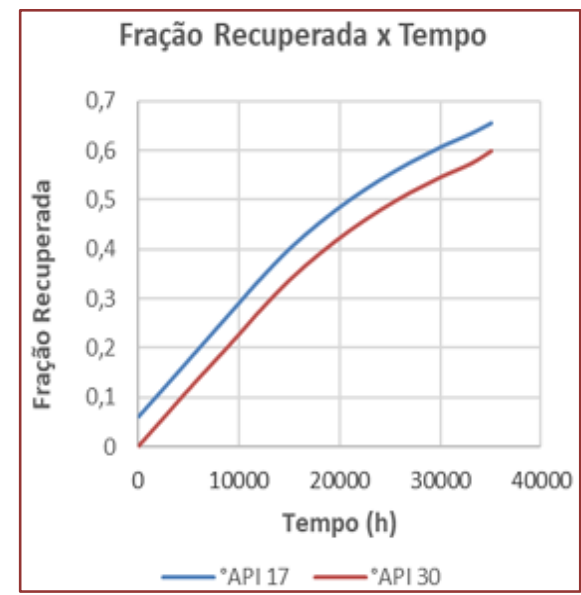

As vazões de água e óleo produzidas para cada tempo são mostradas no Gráfico 3 para os dois casos. Como esperado, a vazão de água é nula até quando ocorre o breakthrough, que é quando a frente de avanço da água atinge o poço produtor. A partir desse instante, água começará a ser produzida e sua vazão aumentará gradativamente, enquanto a produção de óleo diminui, o que pode ser observado no Gráfico 4. Também se nota que o volume de água produzido é maior para o óleo mais leve, assim como sua produção começa mais cedo, isso se dá pela maior razão de mobilidade desse caso.

Não é possível saber o tempo exato em que ocorreu o breakthrough, apenas que, em ambos os casos, ocorre entre 4800 e $9600 \mathrm{~h}$. Entretanto, ao se observar o comportamento da curva de volume de água produzido é possível notar que para o grau API 30 é maior para um mesmo tempo. 
Gráfico 3: Comportamento das vazões de água e óleo produzido por tempo

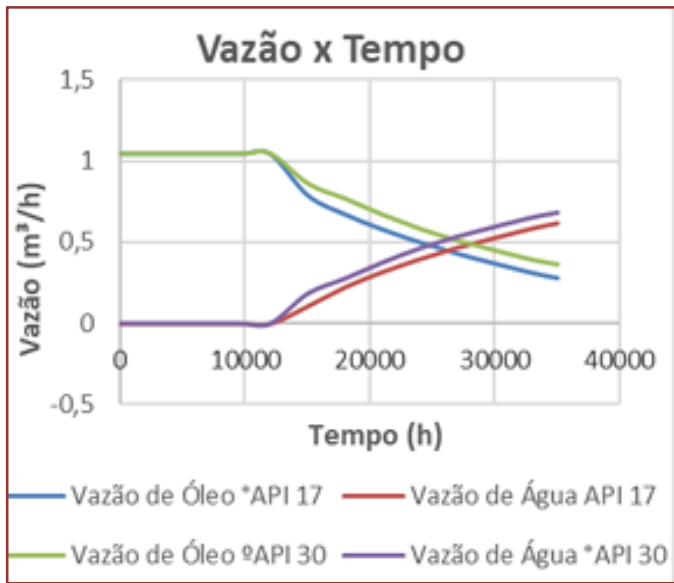

Gráfico 4: Comportamento dos volumes de água e óleo produzidos com o tempo

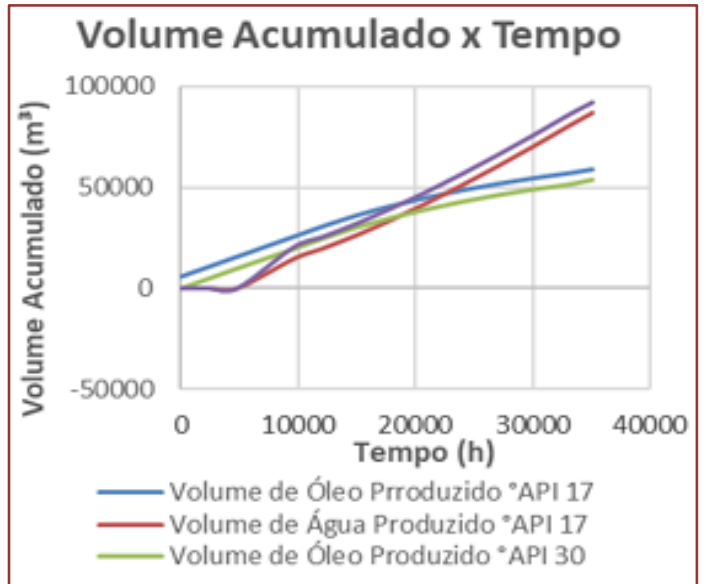

\section{CONCLUSÕES}

Os resultados obtidos foram condizentes com o esperado, uma vez que o método foi desenvolvido para óleos viscosos, logo é mais eficiente para reservatórios de óleos de menor ${ }^{\circ} \mathrm{API}$, que normalmente possuem maiores valores de viscosidade.

- $\quad 0$ caso do reservatório com ${ }^{\circ}$ API 17 apresentou menor volume de água produzido, 86919,6 m³ enquanto para o ${ }^{\circ}$ API 30 o volume foi $92089,28 \mathrm{~m}^{3}$;

- $\quad$ óleo mais pesado levou mais tempo para atingir o breakthrough, o que tem efeito positivo sobre a eficiência de varrido e, consequentemente, na recuperação do óleo;

- $\quad$ A eficiência de varrido manteve aproximadamente 6\% maior para o grau API 30.

\section{REFERÊNCIAS}

[1] Cunha, A. L. Recuperação avançada não-isotérmica de óleo pesados em reservatórios de petróleo via simulação numérica. Programa de Pós-Graduação em Engenharia Química, Dissertação de Mestrado, Campina Grande, Paraíba, 2010.

[2] Felipe, I. A. S., Estudo Da Injeção Cíclica De Vapor Seguida Da Injeção Contínua, Aplicado Em Reservatórios De Óleo Extra-Pesado. UFRN, nov de 2017.

[3] Marinho, J. L. G., Oliveira, L. M. T. de, Pimentel, R. de O, Simulação Numérica Da Recuperação Térmica De Petróleo Utilizando Injeção De Água Quente, I Conepetro, 2015.

[4] Neto, V. R. R. Análise Da Recuperação De Óleo De Um Reservatório Com Características Do Pré-Sal Brasileiro Com Injeção De Água E Co2, Ufrn, nov de 2017.

[5] Oliveira, M. T. de M., Modelagem E Simulação Da Recuperação Secundária Em Reservatórios De Petróleo Utilizando Configuração Five-Spots. Dissertação de Mestrado, Ufal, 2015.

[6] Rosa, A. J.; Carvalho, R. S.; Xavier, J. A. D. Engenharia de reservatórios de petróleo. Editora Interciência. Rio de Janeiro, RJ. 2011. 


\section{Capítulo 8}

Influência da redução do teor de enxofre sobre as propriedades físico-químicas e na estabilidade oxidativa do óleo diesel

\section{Camila Gisele Damasceno Peixoto Morais \\ Josué Santiago de Almeida \\ Amanda Duarte Gondim \\ Antonio Souza de Araujo \\ Valter José Fernandes Junior}

Resumo: Um dos principais problemas relacionados à utilização do óleo diesel como combustível é a presença de enxofre (S) que provoca poluição no meio ambiente e corrosão nos motores. Para atender às exigências da legislação brasileira, o óleo diesel com concentração máxima de enxofre igual a $10 \mathrm{mg} / \mathrm{kg}$ (S10) vem sendo amplamente comercializado no país. Entretanto, a redução no teor de enxofre pode acarretar mudanças nas propriedades físico-químicas do combustível, as quais são essenciais para o desempenho dos veículos. Este trabalho tem como objetivo a identificação das principais mudanças nas propriedades físico-químicas do óleo diesel e como elas estão relacionadas à redução do teor de enxofre. A massa específica, o ponto de fulgor e a curva de destilação foram determinadas para amostras de óleo diesel dos tipos S10, S500 e S1800. Os óleos também foram caracterizados por Calorimetria Exploratória Diferencial sob Pressão (PDSC). Os resultados da caracterização físico-química mostraram que a redução do enxofre tornou os combustíveis mais leves e fluidos, permitindo uma maior aplicabilidade a ambientes com baixas temperaturas e uma maior segurança para o transporte e armazenamento. Os dados de PDSC apontaram para uma diminuição da estabilidade oxidativa com a redução do teor de enxofre.

Palavras-chave: diesel, teor de enxofre, propriedades físico-químicas, estabilidade oxidativa, PDSC. 


\section{INTRODUÇÃO}

Dentre os derivados do petróleo, o diesel tem uma função essencial na economia brasileira devido ao seu uso nos setores agrícola e industrial, já que é o derivado de petróleo mais consumido do país [Empresa de Pesquisa Energética, 2018]. Entretanto, a utilização de produtos derivados do petróleo tem sido uma das principais causas de danos ao meio ambiente. A queima de combustíveis fósseis gera impactos ambientais através da liberação de poluentes atmosféricos, como o dióxido de carbono (CO2), o monóxido de carbono (CO), os óxidos de nitrogênio (NOx), os óxidos de enxofre (SOx) e material particulado (MP) [Braun et al., 2003].

Com os impactos ambientais somados ao crescimento da frota automobilística no país, o Governo Federal estabeleceu em 1986, o Programa de Controle da Poluição do Ar por veículos Automotores - PROCONVE. Esse programa foi formatado em fases, nas quais ficaram definidos os limites de emissão para veículos leves e pesados. Por outro lado, os combustíveis nacionais devem se adequar a requisitos de qualidade definidos em legislação, a fim de maximizar a vida útil dos motores e manter as emissões de poluentes em níveis aceitáveis. Paralelamente ao desenvolvimento das etapas do PROCONVE, a Agência Nacional do Petróleo, Gás Natural e Biocombustíveis (ANP) promoveu entre 2001 e 2013 uma redução expressiva na concentração de enxofre nos combustíveis. Desde então a quantidade de enxofre no óleo diesel vem diminuindo gradativamente de $3500 \mathrm{mg} / \mathrm{kg}$ para $500 \mathrm{mg} / \mathrm{kg}$ em 2013 e em 2014 a concentração desse material chegou a marca de $10 \mathrm{mg} / \mathrm{kg}$.

0 enxofre presente no petróleo e seus derivados pode ser encontrado nas seguintes formas: tióis (ou mercaptanos); sulfetos; polissulfetos; tiofenos, benzotiofenos e derivados; moléculas policíclicas contendo outros heteroátomos ( $\mathrm{N}$ e O); sulfeto de hidrogênio $\left(\mathrm{H}_{2} \mathrm{~S}\right)$ ou enxofre elementar [Brasil et al., 2012].

Os compostos de enxofre presentes nos combustíveis dão origem, no processo da queima, aos óxidos de enxofre (SOx), importantes poluentes atmosféricos, causadores da chuva ácida e responsáveis por problemas pulmonares na população. Os compostos sulfurados também provocam corrosão e envenenamento de catalisadores de diversos processos de refino e de catalisadores automotivos, existentes nos escapamentos dos veículos. Por esse motivo, a redução do teor de enxofre é um dos pontos mais importantes na evolução das especificações dos derivados de petróleo, uma vez que as legislações ambientais vêm buscando adaptar a produção de derivados de petróleo com teores de enxofre cada vez mais baixos [Peixoto et al., 2018].

No entanto, concentrações mínimas desse elemento podem acarretar mudanças nas propriedades intrínsecas do combustível, visto que a remoção do enxofre implica em uma diminuição da polaridade dos hidrocarbonetos do combustível. Conhecer as características físico-químicas, tais como, massa específica, ponto de fulgor e temperaturas de destilação é essencial para a determinação da qualidade do óleo diesel. Os métodos térmicos (DSC, DTA, TGA) também encontraram ampla aplicação para o estudo de várias propriedades físico-químicas dos derivados de petróleo. A Calorimetria Exploratória Diferencial sob Pressão (PDSC) tem se mostrado uma ferramenta eficaz na medição da estabilidade oxidativa em lubrificantes e no controle de qualidade de polímeros [Gondim, 2009].

o objetivo deste trabalho foi identificar as principais mudanças nas propriedades físico-químicas do óleo diesel e como elas estão relacionadas a redução do teor de enxofre, através de metodologias propostas pela ANP e de PDSC.

\section{METODOLOGIA}

As amostras de óleo diesel, isentos de biodiesel, foram fornecidas pela Refinaria Potiguar Clara Camarão (RPCC), localizada em Guamaré, no estado do Rio Grande do Norte. Foram disponibilizados dois lotes de diesel dos tipos S10 e S500, e um lote de S1800. As amostras foram identificadas como S10 (1), S10 (2), S500 (1), S500 (2) e S1800. As cinco amostras foram primeiramente submetidas à caracterização físicoquímica e, em seguida, à análise de PDSC. Os ensaios de caracterização físico-química foram realizados de acordo com as normas da ASTM (Tabela 1). 
Tabela 1: Métodos utilizados na caracterização físico-química das amostras de óleo diesel.

\begin{tabular}{|c|c|}
\hline \multicolumn{1}{|c|}{ Método } & Análise \\
\hline ASTM D 86 & Destilação Atmosférica \\
\hline ASTM D 93 & Ponto de Fulgor \\
\hline ASTM D 4052 & Massa Específica \\
\hline ASTM D 4294 & Teor de enxofre (S1800) \\
\hline ASTM D 5453 & Enxofre Total (S500 e S10) \\
\hline
\end{tabular}

Na determinação do teor de enxofre da amostra S1800 foi utilizado o Analisador de Raios X por Energia Dispersiva (FRX), modelo EDX-800, fabricado pela Shimadzu. Para as amostras de S10 e S500 foi empregado o Analisador de Enxofre Total por Fluorescência de Ultravioleta (FUV), modelo TS 3000, marca Thermo Scientific. A massa específica foi realizada em um densímetro digital Anton Paar D4500M. A determinação do ponto de fulgor foi realizada com o equipamento automático de vaso fechado PenskyMartens, marca TANAKA, modelo APM-7. Por fim, a destilação atmosférica foi realizada em um destilador automático Optidist, marca PAC.

A análise de PDSC foi realizada em calorímetro NETZSCH DSC 204, sob pressão constante de $1100 \mathrm{kPa}$, em atmosfera de ar sintético, pelo método dinâmico. 0 aquecimento foi de $30{ }^{\circ} \mathrm{C}$ a $330{ }^{\circ} \mathrm{C}$ a uma rampa de $20{ }^{\circ} \mathrm{C} \mathrm{min}^{-1}$. A análise foi realizada com cadinho de alumina aberto e massa de amostra de aproximadamente $10 \mathrm{mg}$.

\section{RESULTADOS E DISCUSSÃO}

\subsection{CARACTERIZAÇÃO FÍSICO-QUÍMICA}

Os lotes de óleo diesel dos tipos S10, S500 e S1800 foram submetidos a uma caracterização físico-química. Os resultados estão apresentados na Tabela 2.

Tabela 2: Resultados da caracterização físico-química do S1800, S500 e S10.

\begin{tabular}{|c|c|c|c|} 
Diesel & \multicolumn{1}{c}{$\begin{array}{c}\text { Enxofre } \\
(\mathrm{mg} / \mathrm{kg})\end{array}$} & $\begin{array}{c}\text { Massa } \\
\text { específica } \\
\left(\mathrm{kg} / \mathrm{m}^{3}\right)\end{array}$ & $\begin{array}{c}\text { Ponto de } \\
\text { Fulgor } \\
\left({ }^{\circ} \mathrm{C}\right)\end{array}$ \\
\hline S10 (1) & 12 & 826,9 & 62,0 \\
\hline S10 (2) & 35 & 824,6 & 62,0 \\
\hline S500 (1) & 430 & 831,5 & 52,0 \\
\hline S500 (2) & 465 & 829,7 & 48,0 \\
\hline S1800 & 1210 & 836,5 & 40,0 \\
\hline
\end{tabular}

As amostras de S500 e S1800 apresentaram teor de enxofre abaixo do limite máximo especificado pela ANP. Já o S10 (2) teve valor acima do esperado. O S10 chega até a Refinaria Potiguar Clara Camarão através de navio e fica armazenado em tanques, sendo utilizado apenas como matéria-prima para formulação do S500 (através de mistura com S1800). Uma vez que a RPCC não está fazendo a comercialização de S10 no estado do Rio Grande do Norte, não é obrigada a manter o teor de enxofre inferior a $10 \mathrm{mg} / \mathrm{kg}$.

A redução na concentração de enxofre provocou uma diminuição na massa específica. Essa constatação está relacionada à composição e ao tamanho das cadeias dos hidrocarbonetos e afeta a propriedade de volatilidade. O S1800 apresentou frações finais mais pesadas do que S500 e S10 conforme os dados de destilação, e a sua massa específica foi mais elevada. Assim, esse diesel é o que potencialmente apresenta maior conteúdo energético por volume. As amostras de S500 e S10, por sua vez, apresentaram massas específicas menores, o que pode estar relacionado a um maior teor de parafinas e cadeias carbônicas mais curtas.

0 ponto de fulgor está relacionado à inflamabilidade e varia em função do teor de hidrocarbonetos leves existentes no diesel, limitando os pontos iniciais de ebulição do produto. Como pode ser visto nos dados da destilação, o S10 e o S500 apresentaram temperaturas iniciais mais elevadas que o S1800, sendo um indicativo da presença de hidrocarbonetos menos voláteis. Uma vez que a inflamabilidade aumenta com uma maior quantidade de hidrocarbonetos leves, essa característica confere temperaturas de ponto de fulgor mais altas para os combustíveis com menores concentrações de enxofre. 


\subsection{DESTILAÇÃO ATMOSFÉRICA (D86)}

O comportamento da destilação das amostras mostrou pontos de ebulição iniciais mais elevados para o S500 e S10. Em contrapartida, as frações destiladas médias e pesadas tiveram temperaturas mais baixas para combustíveis com menor teor de enxofre. Na Figura 1, observa-se que em aproximadamente $20 \%$ de recuperado, a curva de S1800 assume temperaturas mais elevadas que as curvas referentes aos lotes de S500 e S10.

Figura 1: Curvas de destilação atmosférica.

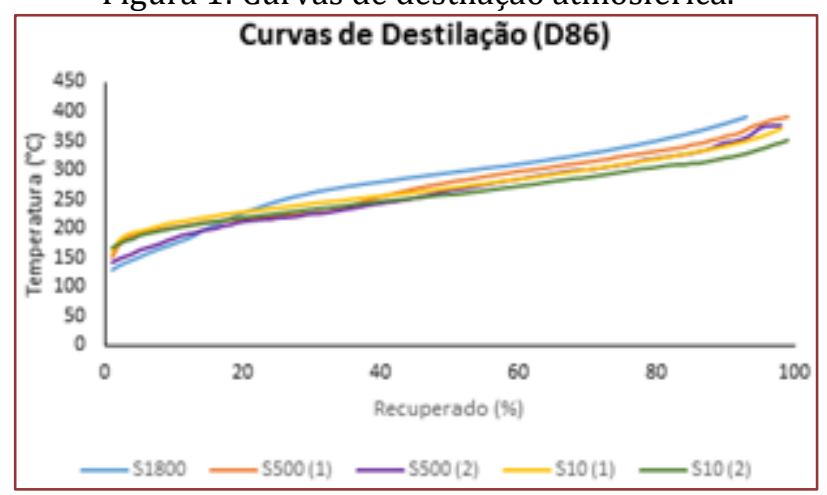

Essas observações corroboram os dados de ponto de fulgor, que também apontaram para a ausência de compostos voláteis. Até $17 \%$ de recuperado, o S500 (1) apresentou temperaturas em média $5,3{ }^{\circ} \mathrm{C}$ mais elevadas que o S1800, enquanto o S500 (2) teve temperaturas em média $2,0{ }^{\circ} \mathrm{C}$ mais baixas que as do S1800 até $10 \%$ de recuperado. Comparando os resultados do S10 e do S1800, a diferença entre as temperaturas de destilação foi de $13,2{ }^{\circ} \mathrm{C}$ para o lote 1 e $4,1{ }^{\circ} \mathrm{C}$ para o lote 2 , correspondendo a $18 \%$ e $12 \%$ de recuperado, respectivamente. Por sua vez, até os $20 \%$ de recuperado, o S500 (1) apresentou temperaturas em média $8,4^{\circ} \mathrm{C}$ mais baixas que o $\mathrm{S} 10$ (1), enquanto o $\mathrm{S} 500$ (2) teve temperaturas em média de $2,0^{\circ} \mathrm{C}$ mais baixas que o $\mathrm{S} 10(2)$.

A segunda mudança observada foi a diminuição das temperaturas de ebulição do S500 e S10 em relação ao S1800 a partir de 20\% de recuperado. Se as curvas de S500 e S10 também forem comparadas, observa-se que as amostras de S500 tem temperaturas mais elevadas que as amostras de S10 nesta faixa.

Sabe-se também que os compostos de enxofre presentes no diesel são polares. Sua interação intermolecular é dipolo permanente, difícil de ser rompida. Com a diminuição da quantidade desses compostos no combustível, a maior parte das interações passa a ser do tipo dipolo induzido, que é a interação intermolecular mais fraca que existe. Sendo assim, torna-se mais fácil o seu rompimento, o que proporciona temperaturas de ebulição menores.

A diminuição das temperaturas das frações finais (85\%, 90\%, 95\%) está relacionada ao tamanho das cadeias carbônicas, devido a modificações nos cortes de destilação (tanto na destilação atmosférica e a vácuo, quanto nas torres fracionadoras que acompanham as unidades de craqueamento e coque) que dão origem ao diesel. Essa alteração é feita para que as correntes de carga do processo HDS tenham teor de enxofre um pouco menor. Assim, reduz-se a necessidade de severidade em termos de pressão, temperatura e quantidade de hidrogênio usadas na hidrodessulfurização.

Essas observações também ratificam as diferenças encontradas nas massas específicas. Uma vez que o S1800 tem cadeias carbônicas mais longas, sua massa específica é maior. Já as amostras de S500 e S10 tem cadeias carbônicas mais curtas, logo apresentam massas específicas menores que os do S1800.

\subsection{CALORIMETRIA EXPLORATÓRIA DIFERENCIAL SOB PRESSÃO (PDSC)}

A análise de PDSC foi realizada com o intuito de estudar a estabilidade oxidativa dos diferentes tipos de diesel. Através da curva PDSC dinâmica foi possível obter a temperatura inicial da oxidação (OT) e a temperatura de pico da oxidação (Tp). A figura 2 apresenta as curvas PDSC sobrepostas para as cinco amostras de diesel. 
Figura 2: Curvas PDSC sobrepostas.

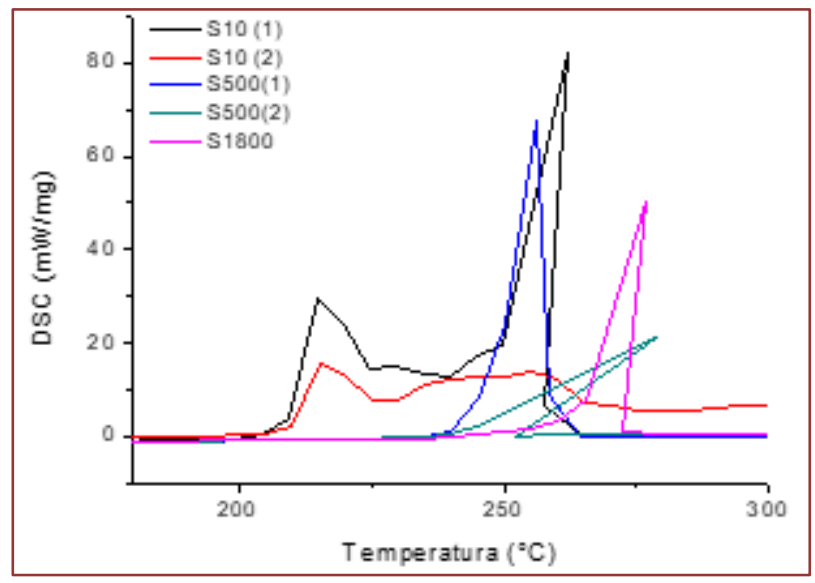

Os dados obtidos através desta análise estão listados na Tabela 3. De acordo com os dados apresentados, o S1800 teve as maiores temperaturas inicial e de pico de oxidação. As amostras de diesel com menor concentração de enxofre apresentaram as menores temperaturas de oxidação. Os dieseis com concentração intermediária de enxofre, tiveram temperaturas de oxidação entre o S10 e o S500.

Tabela 3: Valores de OT e Tp obtidos pela análise de PDSC dinâmico.

\begin{tabular}{|c|c|c|}
\hline DIESEL & OT $\left({ }^{\circ} \mathrm{C}\right)$ & $\mathrm{T}_{\mathrm{p}}\left({ }^{\circ} \mathrm{C}\right)$ \\
\hline $\mathrm{S} 10(1)$ & 210 & 215 \\
\hline $\mathrm{S} 10(2)$ & 205 & 215 \\
\hline $\mathrm{S} 500(1)$ & 239 & 257 \\
\hline $\mathrm{S} 500(2)$ & 230 & 258 \\
\hline S1800 & 248 & 277 \\
\hline
\end{tabular}

Na amostra S10 (1) observou-se ainda um segundo evento referente a combustão, iniciando à temperatura de $245{ }^{\circ} \mathrm{C}$ e com valor de Tp igual a $262{ }^{\circ} \mathrm{C}$. Por fim, foi perceptível que o diesel apresentou comportamento linear relacionado o aumento da concentração de enxofre e a temperatura de início da oxidação.

\section{CONCLUSÕES}

Este trabalho procurou avaliar as principais alterações nas propriedades físico-químicas do óleo diesel do estado do Rio Grande do Norte, com a diminuição do teor de enxofre.

Todas as amostras analisadas apresentaram resultados em conformidade com as especificações vigentes, exceto a amostra de S10 (2), cujo teor de enxofre estava acima do especificado.

Os parâmetros de destilação física e ponto de fulgor apontaram para a ausência de compostos voláteis nas amostras de S10 e S500. Os valores da massa específica indicaram que o S1800 é mais pesado e potencialmente apresenta maior conteúdo energético por volume, que o $S 500$ e o S10, sendo este último o que apresenta menor massa específica, o que pode estar relacionado a presença de cadeias carbônicas mais curtas.

Quanto a temperatura de início da oxidação através do PDSC dinâmico, foi observado um comportamento linear com o aumento da concentração de enxofre.

Em suma, constatou-se que a redução no teor de enxofre do óleo diesel provoca alterações nas características físico-químicas do produto, tornando-o mais leve e fluido, com uma maior aplicabilidade a ambientes com temperaturas baixas, e com maior segurança para o transporte e armazenamento. Além disso, proporciona menores temperatura de oxidação. 


\section{AGRADECIMENTOS}

Os autores agradecem à Refinaria Potiguar Clara Camarão pelo fornecimento das amostras e aos Laboratórios de Combustíveis e de Catálise e Petroquímica da UFRN pela execução das análises.

\section{REFERÊNCIAS}

[1] Brasil, N. I.; Araújo, M. A. S.; Sousa, E. C. M. Processamento de Petróleo e Gás: petróleo e seus derivados, processamento primário, processos de refino, petroquímica, meio ambiente. Rio de Janeiro: LTC, 2012.

[2] Braun, S.; Appel, L. G.; Schmal, M. A poluição gerada por máquinas de combustão interna movidas à diesel - a questão dos particulados. Estratégias atuais para a redução e controle das emissões e tendências futuras. Quim. Nova, v.27, p. 472-482, 2003.

[3] Conselho Nacional do Meio Ambiente. Resolução Conama no 005, de 15 de junho de 1989. Dispõe sobre o Programa Nacional de Controle da Poluição do Ar - Pronar. Diário oficial [da] República do Brasil. Brasília, DF, 25 ago. 1989.

[4] _. Resolução Conama no 018, de 06 de maio de 1986. Dispõe sobre a criação do Programa de Controle de Poluição do Ar por Veículos. Diário oficial [da] República do Brasil. Brasília, DF, 17 jun.1986.

[5] Empresa de Pesquisa Energética. Balanço Energético Nacional 2018 - Ano Base 2017: Relatório Síntese. Rio de Janeiro: EPE, 2018.

[6] Gondim, A. D. Avaliação da estabilidade térmica e oxidativa do biodiesel de algodão e do efeito da adição de antioxidantes. 2014, 247p. Tese de Doutorado, Universidade Federal do Rio Grande do Norte, Programa de Pós Graduação em Química. Natal-RN.

[7] Peixoto, C. G. D.; Fernandes JR., V. J.; Coriolano, A. C. F.; Araujo, R. R.; Fernandes, G. J. T.; Araujo, A. S. Evaluation of the thermal properties of diesel oil with low sulfur content. Journal of thermal analysis and calorimetry. v. 131, p. 697-704. 


\section{Capítulo 9}

\section{Avaliação da perovsquita $\mathrm{BaCeO}_{3}$ como catalisador na}

conversão de óleo de soja em biodiesel via rota etílica

\section{Alexsandro Rocha da Silva}

Gustavo Fernandes Quixadá

Paulo Eduardo da Costa Santos

Andarair Gomes dos Santos

Resumo: Este trabalho tem por finalidade testar a atividade catalítica da perovsquita $\mathrm{BaCeO}_{3}$ para conversão de triglicerídeos em biodiesel a partir da reação de transesterificação do óleo de soja comercial. Para isso utilizou-se razão molar óleo-álcool de 1:6, temperatura controlada de $60^{\circ} \mathrm{C}, 1 \%$ em massa de catalisador em relação à massa do óleo durante 3 horas de reação e agitação mecânica de 350 rpm. Após a reação as fases foram separadas e o biocombustível preparado para sua caracterização onde a partir da mesma analisou-se a conversão a partir da análise termogravimétrica (TGA/DTA). Através dos resultados obtidos percebeu-se que a perovsquita testada nas condições reacionais estabelecidas apresentou uma pequena atividade catalítica gerando uma conversão em biodiesel de apenas 1,93\%.

Palavras-chave: Biodiesel, Catálise Heterogênea, Perovsquita $\mathrm{BaCeO}_{3}$, Transesterificação etílica. 


\section{INTRODUÇÃO}

O mercado de combustíveis a partir de fontes renováveis tem crescido bastante nos últimos anos, principalmente em virtude da instabilidade político econômica do mercado do petróleo, e, além disso, a necessidade que se tem para reduzir as emissões de poluentes gasosos na atmosfera provenientes da queima de fontes não renováveis de energia. 0 biodiesel tem características e potencialidade para substituir o diesel derivado do petróleo [BAIL, et al., 2007].

A Sociedade Americana de Testes e Materiais (ASTM) definiu biodiesel como um combustível constituído de ésteres de monoalquila de ácidos graxos de cadeias longas derivados de óleos vegetais ou gordura animal, que satisfaçam os requerimentos da norma ASTM D 6751. O biodiesel apresenta diversas vantagens quando comparado ao diesel derivado de petróleo: é derivado de fontes renováveis, biodegradável, não tóxico, apresenta baixa emissão de poluentes, alto ponto de fulgor, excelente lubricidade e pode ser usado puro ou misturado com diesel derivado do petróleo [MA; HANNA, 1999].

0 biodiesel pode ser produzido pela transesterificação, também conhecida como alcoólise, de óleos vegetais e/ou gorduras animais, ou pela esterificação de ácidos graxos livres, mediante a utilização de um catalisador ácido, básico ou enzimático, que pode ser homogêneo ou heterogêneo [ZHANG et al., 2003].

Uma grande quantidade de resíduos indesejáveis é produzida durante o processo de conversão do óleo em biodiesel devido ao uso de catalisadores homogêneos [ALMERINDO, 2007]. Logo, é necessária a realização de um processo secundário de extração líquido-líquido, que por sua vez produzem quantidades excessivas de resíduos que demandam projetos, construção e instalação de estações de tratamento de efluentes, acopladas as unidades de produção de biodiesel [PINTO et al., 2005; CASTILHO, et al., 2009 apud COLOMBO \& BARROS, 2009].

A síntese do biodiesel também pode ser realizada por catálise heterogênea. Tal estratégia oferece vantagens técnicas e ambientais em relação à catálise homogênea, pois facilita a purificação dos monoésteres alquilícos, permite a reciclagem do catalisador sólido ao longo de sua vida útil e minimiza a geração de efluentes. Além disso, facilita consideravelmente a recuperação e a purificação da glicerina. Vários sólidos têm sido propostos como catalisadores em potencial para a síntese do biodiesel. 0 desempenho destes materiais como catalisadores está naturalmente relacionado com a natureza dos sítios ácidos ou básicos encontrados nestes materiais [DI SERIO et al., 2008]. Os catalisadores CaO, $\mathrm{Sr}\left(\mathrm{NO}_{3}\right)_{2} / \mathrm{ZnO}, \mathrm{KI} / \mathrm{Al}_{2} \mathrm{O}_{3}, \mathrm{Na} / \mathrm{NaOH} / \mathrm{Al}_{2} \mathrm{O}_{3}, \mathrm{KF} / \mathrm{MgO}$, resinas de troca iônica são exemplos capazes de conduzir a reação de transesterificação [ZABETI et al., 2009].

Os óxidos com estrutura do tipo perovsquita apresentam a fórmula geral $\mathrm{ABO}_{3}$ (sendo o cátion $\mathrm{A}$ maior que B) e demonstram alta atividade catalítica e boa estabilidade térmica até temperaturas da ordem de $1000{ }^{\circ} \mathrm{C}$ [TEJUCA et al., 1989]. Tais perovsquitas são de especial interesse por também apresentar condutividade elétrica e iônica, com excelente estabilidade química em uma ampla faixa de temperatura. Todavia, somente uma pequena fração de materiais com estrutura perovsquita tem sido explorada como catalisadores [SANTOS et al., 2014; LIMA et al., 2012; STORTI et al., 2014; SANTIAGO et al., 2013].

Para uma transesterificação estequiometricamente completa, uma proporção molar 3:1 de álcool por triacilglicerídeos é necessária. Entretanto, devido ao caráter reversível da reação, o agente transesterificante geralmente é adicionado em excesso contribuindo, assim, para aumentar o rendimento do éster, bem como permitir a sua separação do glicerol formado [MEHER et al., 2006; http://journeytoforever.org/biodiesel_make.html, 2015.] NAKATANI et al. [2009] utilizaram o óxido de cálcio, oriundo da calcinação do carbonato de cálcio a $700 \stackrel{\circ}{\circ} \mathrm{C}$, como catalisador para a metanólise do óleo de soja. Foram obtidas amostras de monoésteres com pureza da ordem de $99 \%$, utilizando $20 \%$ de catalisador e RM de $6: 1$ por $4 \mathrm{~h}$ a $65^{\circ} \mathrm{C}$.

STORTI et al. [2014] testou a perovsquita $\mathrm{SrTiO}_{3}$ como catalisador para transesterificação etílica do óleo de soja utilizando $15 \%$ em massa de catalisador, 8 horas de reação e temperatura de $78^{\circ} \mathrm{C}$ sob refluxo obtendo conversão de 99,44\% em ésteres etílicos considerando-se assim o processo eficiente.

0 objetivo principal deste trabalho foi testar o potencial catalítico da perovsquita $\mathrm{BaCeO}_{3}$ na reação de transesterificação do óleo de soja comercial para obtenção de biodiesel.

\section{METODOLOGIA}

Para a produção do biodiesel utilizou-se como reagente o óleo de soja comercial, álcool etílico P. A. $(99,6 \%)$ e o material cerâmico do tipo perovsquita de composição $\mathrm{BaCeO}_{3}$ como catalisador. 


\subsection{PRODUÇÃO DE CATALISADOR}

0 material $\mathrm{BaCeO}_{3}$ foi sintetizado segundo metodologia proposta por SANTOS et al., [2014] 0 método consiste na diluição do EDTA ácido em hidróxido de amônia (1g: 10mL), sob agitação e aquecimento $\left(40^{\circ} \mathrm{C}\right)$, com posterior introdução dos respectivos metais; adição do ácido cítrico seguido do aumento da temperatura até $80^{\circ} \mathrm{C}$. As proporções definidas estequiometricamente e razão molar de EDTA ácido, ácido cítrico e íons metálicos totais de 1,0:1,5:1,0. Posteriormente, ajuste do pH 11 com adição de hidróxido de amônia $\left(\mathrm{NH}_{4} \mathrm{OH}\right)$, permanecendo sob agitação e aquecimento até a formação do gel, o qual foi tratado termicamente, a $1100^{\circ} \mathrm{C}$ por 5 horas.

\subsection{REAÇÃO DE TRANSESTERIFICAÇÃO ETÍLICA}

A reação ocorreu-se por 3 horas a $60^{\circ} \mathrm{C}$ com razão molar (RM) de álcool-óleo 6:1 segundo a metodologia de MACLEOD et al. [2008]. Utilizou-se $1 \%$ de catalisador de acordo com a metodologia de RASHTIZADEH [2013] e a rota etílica sob agitação de 350 rpm.

Após a reação, o catalisador foi separado por centrifugação durante 10 minutos à 2500 rpm e logo depois realizada extração líquido-líquido utilizando solução a $10 \%$ de cloreto de sódio para que todo o excesso de álcool. A fim da eliminação de possíveis outros subprodutos oriundos da reação de transesterificação etílica presentes no óleo pudessem ser removidos do mesmo foram ainda realizadas 5 lavagens sucessivas com água destilada à $25^{\circ} \mathrm{C}$ medindo-se o $\mathrm{pH}$ da água de lavagem do biocombustível.

\subsection{ANÁLISES DE CONVERSÃO}

Realizou-se a análise do óleo de soja comercial e do biodiesel formado a fim de verificar a conversão da oleaginosa em ésteres etílicos de cadeia curta através de Termogravimetria e Análise Térmica Diferencial (TGA/DTA) em equipamento NETZSCH STA 449F3 com razão de aquecimento de $10{ }^{\circ} \mathrm{C} / \mathrm{min}$ sob atmosfera inerte utilizando nitrogênio como gás de arraste com vazão de $25 \mathrm{~mL} / \mathrm{min}$.

Utilizou-se cadinhos de platina para medição e as massas das amostras pesadas foram de 4,295 mg de óleo de soja e 4,099 mg de biodiesel etílico para a realização do teste. Iniciou-se a análise termogravimétrica utilizando o equipamento operando inicialmente a uma temperatura de $25^{\circ} \mathrm{C}$ e finalizando o mesmo a $800^{\circ} \mathrm{C}$.

\section{RESULTADOS E DISCUSSÃO}

\subsection{ANÁLISE DO CATALISADOR}

A curva de difração de Raios $\mathrm{X}$ do pó da perovsquita $\mathrm{BaCeO}_{3}$ obtido a partir do método de complexação combinando EDTA-Citrato com a razão molar de 1:1,5:1 e pH 11 está apresentada na Figura 1.

Figura 1 - Difratrograma do $\mathrm{BaCeO}_{3}$ obtido a partir do método de complexação combinando EDTA-Citrato com a razão molar de 1:1,5:1 e pH 11.

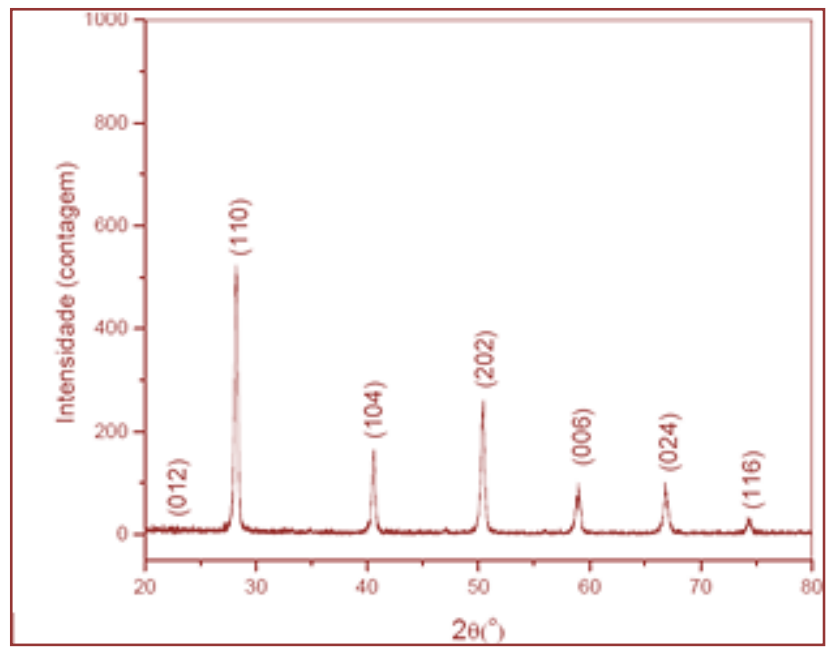


De acordo com os resultados mostrados pelo difratograma da Figura 1 a fase da perovsquita $\mathrm{BaCeO}_{3}$ foi obtida através do método de síntese adotado. A fase $\mathrm{BaCeO}_{3}$ foi confirmada a partir da carta padrão (ICSD - 79001). Em temperaturas de calcinação entre 800 e $900{ }^{\circ} \mathrm{C}$ pode haver traços de uma segunda fase, o óxido de cério $\left(\mathrm{CeO}_{2}\right)$, sendo este completamente decomposto em uma temperatura superior a $900 \stackrel{\circ}{\circ} \mathrm{C}$ [KOFERSTEIN et al., 2010]. Logo, nas condições de tratamento térmico adotadas, com uma temperatura de $1100 \stackrel{\circ}{ }{ }^{\circ}$ por 5 horas, a estrutura perovsquita está completamente desenvolvida, confirmada pelo difratograma.

Alguns dados cristalográficos estão apresentados na Tabela 1 os quais foram obtidos através do refinamento Rietveld, onde foi confirmada a estrutura da perovsquita $\mathrm{BaCeO}_{3}$ e os parâmetros de rede $\mathrm{a}, \mathrm{b}$ e c com valores de $90^{\circ}$ e tamanho de cristalito (TC).

Tabela 1 - Dados cristalográficos do pó da perovsquita $\mathrm{BaCeO}_{3}$.

\begin{tabular}{|c|c|c|c|c|c|}
\hline \multirow{2}{*}{$\mathrm{pH}$} & \multicolumn{3}{|c|}{ Parâmetros de rede (nm) } & \multirow{2}{*}{$\begin{array}{c}\mathrm{TC} \\
(\mathrm{nm})\end{array}$} & \\
\hline & $\mathrm{a}$ & $\mathrm{b}$ & c & & \\
\hline 11 & 0,878 & 0,623 & 0,622 & 133,2 & 1,38 \\
\hline
\end{tabular}

Após o refinamento pelo método de Rietveld utilizando o programa MAUD, pôde-se confirmar a estrutura cristalina ortorrômbica da perovsquita $\mathrm{BaCeO}_{3}$ (grupo espacial Pmcn). Conforme os dados apresentados na Tabela 1, o tamanho médio de cristalito (TC) é 133,2 nm, em concordância com dados da literatura [RYU et al., 1999].

As micrografias do pó obtidas através do Microscópio Eletrônico de Varredura (MEV) estão apresentadas na Figura 2.

Figura 2 - Micrografias do pó da perovsquita $\mathrm{BaCeO}_{3}$ obtidas através do MEV. (A) Micrografia aumentada em 20,5 kx (B) Micrografia aumentada em $136 \mathrm{kx}$.

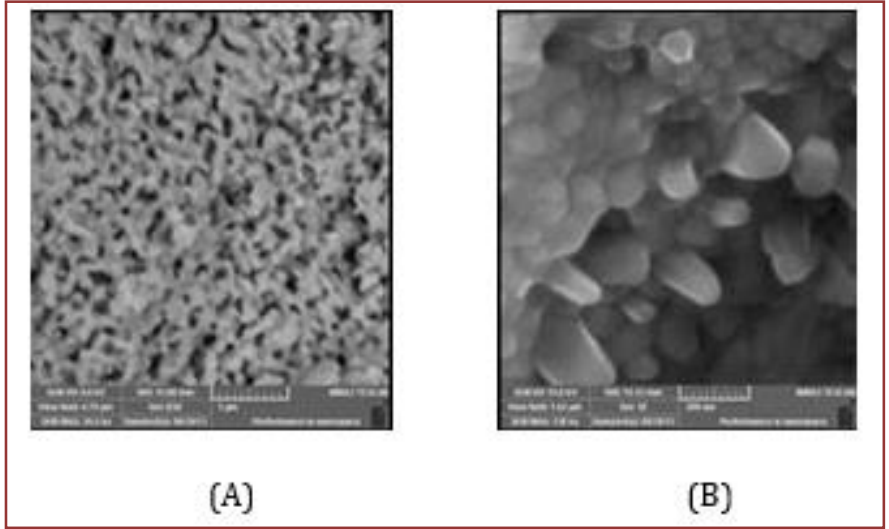

Na Figura 2 pode ser observado através das micrografias que os pós da perovsquita BaCeO3 formam aglomerados e apresentam estrutura monofásica e morfologia esférica irregular, em escala nanométrica. LOPES et al. [2012] em seu trabalho também analisou, através de microscopia eletrônica de varredura, pós da perovsquita BaCeO3 sintetizados pelo método de complexação combinando EDTA-Citrato e relatou partículas com formatos de pequenos bastonetes submicrométricos. Pós sintetizados com pH igual a 6 mostraram a formação de um segunda fase indesejável, identificada como óxido de cério (CeO2). Isso mostra que a amostra sintetizada com pH igual a 11 é uma boa escolha para se obter pós monofásicos do material $\mathrm{BaCeO3.}$

\subsection{ANÁLISE TERMOGRAVIMÉTRICA E DIFERENCIAL (TGA/DTA)}

Para verificar a conversão do óleo de soja em biodiesel, utilizou-se a técnica da termogravimetria. A Figura 3 mostra a perda de massa (\%) referente as amostras do biodiesel e do óleo de soja. 
Figura 3: Perda de massa (\%) do óleo de soja e do biodiesel em função da temperatura $\left({ }^{\circ} \mathrm{C}\right)$.

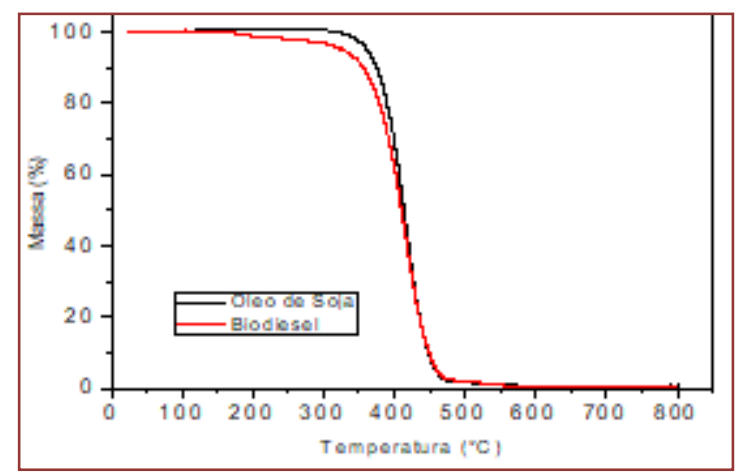

Analisando a Figura 3, vemos que uma pequena parte do óleo foi convertida em biodiesel. Para $250^{\circ} \mathrm{C}$ a perda de massa foi de $98,048 \%$, ou seja, apenas $1,952 \%$ do óleo de soja foram convertidos em biodiesel etílico para as condições reacionais estabelecidas. De acordo com LEONARDO [2012] a curva de TG do biodiesel etílico deveria somente mostrar perda de massa iniciando-se a $122^{\circ} \mathrm{C}$ com máximo em $208{ }^{\circ} \mathrm{C}$, finalizando em $250^{\circ} \mathrm{C}$ que é a temperatura final de degradação do biodiesel.

A Figura 4 a seguir mostra a curva Termogravimétrica Diferencial (DTG) tanto do biodiesel indicada pelo tracejado vermelho quanto do óleo de soja indicado pelo tracejado preto.

Figura 4: Análise DTG do óleo de soja e biodiesel

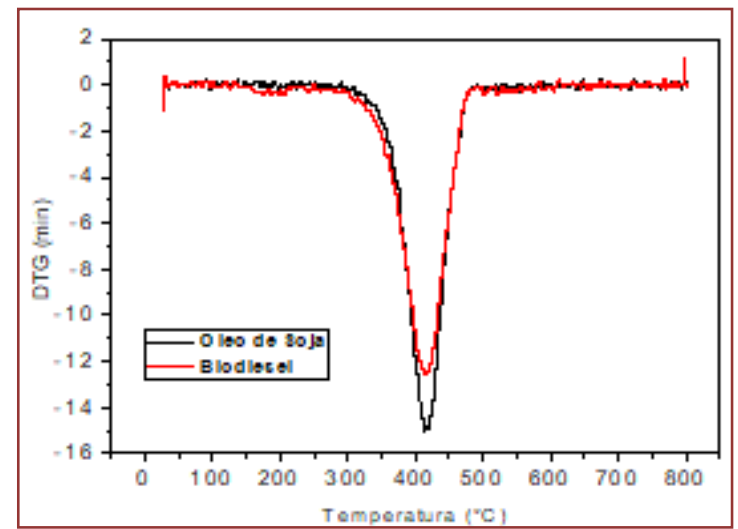

A partir da Figura 4 observa-se que há um pequeno desvio na temperatura de $200^{\circ} \mathrm{C}$ no que se refere à curva do biodiesel indicando que pequena parte do que foi convertido na reação química foi volatilizado. Já os compostos do óleo de soja perdem massa em temperaturas próximas a $400^{\circ} \mathrm{C}$ fazendo com que as curvas do óleo de soja e do biodiesel estivessem bem próximas já que todo o óleo não foi totalmente convertido em biodiesel.

LIMA [2012] testou o catalisador $\mathrm{SrZrO}_{3}$ do tipo Perovsquita com tamanho de cristalito de $35,56 \mathrm{~nm}$ na reação de transesterificação metílica do óleo de soja sob condições reacionais de 3 horas, temperatura de $60^{\circ} \mathrm{C}$ e $3 \%$ de massa de catalisador obtendo conversão de 1,6\%. Os autores também fizeram testes catalíticos quando a perovsquita sintetizada em meio ácido e observavam uma mudança estrutural para tetragonal e cúbica e verificou que a fase tetragonal proporcionou conversão de $98 \%$.

\section{CONCLUSÕES}

A perovsquita $\mathrm{BaCeO}_{3}$ testada como catalisador na reação de transesterificação em biodiesel não apresentou considerável conversão nas condições reacionais estudadas (RM óleo-álcool 1:6, 1\% de massa de catalisador e tempo de reação de 3 horas). De acordo com alguns estudos que testaram o potencial catalítico de perovsquitas como catalisador na produção de biodiesel um aumento na \% de catalisador, bem como o tempo de reação favoreceu de forma significativa a conversão de oleaginosas em biodiesel. 


\section{AGRADECIMENTOS}

Aos laboratórios de Físico-Química e de Análises Magnéticas e Ópticas da Universidade do Estado do Rio Grande do Norte (UERN).

\section{REFERÊNCIAS}

[1] Almerindo, G. I. Catalisador heterogêneo Mg0 obtido por diferentes métodos para a produção de biodiesel rota etílica. Congresso Brasileiro da Rede Brasileira de Tecnologia de Biodiesel, 2007.

[2] Bail, A; Santos, V. C.; Souza, V. H.; Shirley, N.; Ramos, L. P. Uso de diferentes sólidos inorgânicos como Catalisadores heterogêneos de reações de transesterificação. Congresso da rede brasileira de tecnologia de biodiesel, v. 2, 2007.

[3] Castilho, A. P. et. al. Avaliação preliminar da produção de biodiesel por catálise heterogênea mediante ensaios experimentais. Congresso Brasileiro de Engenharia Química, 2009.

[4] Colombo, K.; Barros, A. A. C. Utilização de catalisadores heterogêneos na produção de Biodiesel. Evidência, v. 9, p. 7-16, 2009.

[5] Di Serio, M. Heterogeneous catalysts for biodiesel production. Energy and Fuels, v. 22, p. 207-217, 2008.<http://journeytoforever.org/biodiesel_make.html>, acessada em Janeiro 2015.

[6] Köferstein R., Jäger L., Ebbinghaus S. G. Sintering of a fine grained BaCeO3 powder obtained from a coprecipitation method, Journal Material Science, v. 45, p. 6521-6527, 2010.

[7] Leonardo, R. S.; Estudo da estabilidade de biodiesel com misturas de antioxidantes por um método de pdsc de baixa pressão. 2012, 52p. Dissertação de Mestrado, Universidade Federal do Rio de Janeiro, Curso de PósGraduação em Tecnologia de Processos Químicos e Bioquímicos. Rio de Janeiro - RJ.

[8] Lima, J. R. O. Desenvolvimento de materiais catalisadores heterogêneos aBase de estrôncio (sr) e zircônio (zr) para a transesterificação de óleos e gorduras - síntese, caracterização e performance reacional. 2012, Tese de Doutorado, Universidade Estadual Paulista "Júlio de Mesquita Filho", Instituto de Química. Araraquara-SP.

[9] Lopes, F. W. B.; Arab, M.; Macedo, H. P.; Souza, C. P.; Souza, J. F.; Gavarri, J. R. High tand methane conversion capability of $\mathrm{BaCeO}_{3}$ perovskite. Powder Technology, v. 219, pag. 186-192, 2012.

[10] MA, F.; Hanna, M. A. Biodiesel production: A review. Bioresource Technology, v. 1, p. 70, 1999.

[11] Macleod, C. S.; Harvey, A. P.; Lee, A. F.; Wiosln, K. Evaluation of the activity and stability of alkali-doped metal oxide catalysts for application to an intensified method of biodiesel production. Chemical Engineering Journal, v. 135, p. 63-70, 2008.

[12] Meher, L. C.; Sager, D. V.; Naik, S. N. Technical aspects of biodiesel production by transesterification: a review. Renewable and Sustaintable Energy Reviews, v. 10, 248-268, 2006.

[13] Nakatani, N.; Takamori, H.; Takeda, K.; Sakugawa, H. Transesterification of soybean oil using combusted oyster shell waste as a catalyst. Bioresource Technology, v. 100, p. 1510, 2009.

[14] Pinto, A. C. Biodiesel: an overview. Journal of Brazilian Chemical Society, v. 16, p. 1313-1330, 2005.

[15] Rashtizadeh E., Farzaneh F., Transesterification of soybean oil catalyzed by Sr-Ti mixed oxids nanocomposite. Journal of the Taiwan Institute of Chemical Engineers, 2013.

[16] Ryu, K. H., Hayle, S. M. Chemical stability and proton conductivity of doped $\mathrm{BaCeO}_{3}-\mathrm{BaZrO}_{3}$ solid solutions. Solid State Ionics, v. 125, p. 355-367,1999.

[17] Santiago, T. S. A.; Martins, M. I.; Cardoso, V. L. Síntese de catalisador do tipo perovskita para produção de biodiesel. Faculdade de engenharia química, Uberlândia, UFU, 2013.

[18] Santos, A. G.; Arab M; Patout L Souza C. P. LaNio.3 $\mathrm{Co}_{0.7} \mathrm{O}_{3-\delta}$ and $\mathrm{SrFe}_{0.2} \mathrm{Co}_{0.8} \mathrm{O}_{3-\delta} \mathrm{Ceramic}$ Materials: Structural and Catalytic Reactivity under CO Stream, Catalysts, v. 4, p. 77, 2014.

[19] Santos, A. G.; Silva, R.R.; Dantas, A. G. O.; Lobato, M. F.; Souza C. P., Efeito do pH, Razão molar de EDTA: Ácido cítrico: íons metálicos totais e do tratamento térmico na obtenção da BaCe03 com base no método de complexação EDTA-Citrato. Revista Verde, v.9, p. 149-162, 2014.

[20] Storti, F.; Lanfredi, S.; Nobre, M. A. L. Síntese, caracterização estrutural e análise do Potencial catalítico do $\mathrm{SrTiO}_{3}$ e das Perovskitas duplas de $\mathrm{Sr}_{1-\mathrm{x}} \mathrm{K}_{\mathrm{x}} \mathrm{TiCu}_{\mathrm{x} / 2} \mathrm{O}_{3}$, onde $\mathrm{x}=0$,2; 0,3 e 0,5, na Preparação de Biodiesel. 2014, p. 3051. Dissertação de mestrado, Universidade Estadual Paulista "Julio de Mesquita Filho", Programa de Pós Graduação em Química. São José do Rio Preto-SP.

[21] Tejuca, L. G.; Fierro, J. L.; Tascon, J. M. D. Structure and reactivity of perovskite type oxides. Advances in Catalysis, v. 36, p. 237-328, 1989. 
[22] Zabeti M., Daud W. M. A. W., Aroua M. K. Activity of solid catalysts for biodiesel production: A review. Fuel Process Technology, v. 90, p. 770-777, 2009.

[23] Zhang, Y.; Dubé, M. A.; Mclean, D. D. Biodiesel production for waste cooking oil: Process design and technological assessment. Bioresource Technology, v. 89, p. 1-16, 2003. 


\section{Capítulo 10}

Estudo da degradação do óleo de fritura e do sebo bovino utilizados como matérias-primas na produção de biodiesel

Jéssica Violin Berni

Matheus Pereira de Oliveira

Thiago Luiz Belo Pasa

Fernanda Naiara Campos de Almeida

Nehemias Curvelo Pereira

Resumo: Recentemente o biodiesel tornou-se mais atraente devido seus benefícios ambientais e também pelo fato de ser produzido a partir de recursos renováveis. 0 custo do biodiesel, no entanto, é o principal obstáculo para sua comercialização. Como alternativa o óleo de fritura e sebo bovino são utilizados como matéria-prima, cada uma com características diferentes. O sebo bovino apresenta um alto teor de acidez, constituído principalmente por ácidos graxos saturados, dificultando o seu uso individual na produção do biodiesel, com isso foi produzida uma blenda de óleo de fritura e sebo bovino. Foi realizada uma caracterização completa das matérias-primas com o intuito de determinar se houve degradação das mesmas. A reação de transesterificação para a produção de ésteres etílicos foi realizada utilizando etanol e o ácido sulfúrico como catalisador. As reações foram realizadas a $78^{\circ} \mathrm{C}$ e $350 \mathrm{rpm}$ em duplicata, com uma razão molar de 1:36:0,46 (Blenda:EtOH:H2SO4). Os resultados indicam que as matérias-primas contêm características que tornam possível a produção de biodiesel, obtendo rendimento de 94,5\% em ésteres etílicos.

Palavras-chave: Biodiesel, blendas, óleo de fritura, sebo bovino, degradação das matérias-primas. 


\section{INTRODUÇÃO}

O mundo atual está em constante busca pelo desenvolvimento sustentável, levando em consideração a importância da sustentabilidade aliada à viabilidade econômica. Juntamente com este dilema, surge o crescimento da população mundial e do consumo de alimentos, além do crescimento das indústrias que muitas vezes acarretam em problemas ambientais [CANESIN et al., 2014].

Como fruto das pesquisas com combustíveis alternativos e, entre eles, os biocombustíveis, tem-se o biodiesel, que por ser um combustível renovável, possui algumas vantagens ambientais.

No entanto, o alto preço da matéria-prima e dos catalisadores, são as principais dificuldades para a produção de biodiesel [MANGESH et al., 2007].

O Brasil possui como vantagem uma diversidade das matérias-primas para a produção de biodiesel, sendo um dos poucos países que possui grandes variedades de oleaginosas. Porém o crescente interesse por alternativas renováveis eleva as buscas por novas fontes de oleaginosas e de outras fontes, os resíduos. Como o caso das gorduras animais e residuais [FERRARI et al., 2005; JUNIOR 2010; MATA et al., 2009].

Esses resíduos representam grande potencial de oferta. Um levantamento primário de oferta de óleos residuais de fritura revela um potencial no país superior a 30 mil toneladas por ano. O Brasil produz anualmente cerca de 200.000 toneladas de sebo bovino, possuindo o segundo maior rebanho de gado bovino do mundo, sendo esta a segunda matéria-prima mais utilizada no Brasil, além de tudo, nosso país é também um grande produtor de etanol anidro e por isso torna-se mais vantajosa a produção de biodiesel em rota etílica [HOLANDA, et al., 2004; MANSINI, et al., 2007].

Segundo Knothe, et al. [2006] o método mais utilizado para a produção de ésteres alquílicos, ou biodiesel de óleos e gorduras, é a transesterificação. Esse método é eficiente na diminuição da viscosidade cinemática do biodiesel. A alta viscosidade de matérias graxas não transesterificadas conduz sérios problemas operacionais nos motores diesel, tais como a ocorrência de depósitos em várias partes do motor.

Quando o óleo de fritura é utilizado como matéria-prima, constituída principalmente de ácido linoleico e oleico, mudanças no procedimento da reação são frequentemente necessárias devido a presença de água e de ácidos graxos livres (AGL) [KNOTHE, et al., 2006].

Estudos utilizando sebo bovino em blendas estão cada vez mais aprofundados, o sebo bovino é uma matéria-prima com uma alta acidez e constituído principalmente por ácidos graxos saturados, diminuindo sua fluidez, dificultando assim a utilização dessa matéria-prima individual na produção do biodiesel, portanto uma diminuição da acidez do sebo bovino e uma melhoria nas qualidades oxidativas do biodiesel podem ser alcançadas com a modificação do perfil graxo, gerando blendas de ácidos graxos saturados, presentes no sebo bovino, com ácidos graxos insaturados, presentes nos óleos de fritura [LEUNG, et al., 2006, KNOTHE, 2005, MAGALHÃES, 2010].

Bouaid, et al. [2007] explica que a estabilidade oxidativa é uma questão importante sobre os ésteres alquílicos, a degradação das matérias-primas compromete a qualidade do combustível e consequentemente o desempenho do motor.

0 trabalho teve como objetivos utilizar e caracterizar as matérias-primas em tempos diferentes, comparando assim se houve degradação das mesmas e a influência na produção de ésteres etílicos.

\section{METODOLOGIA}

A determinação do índice de acidez foi realizada conforme o método oficial da AOAC - 940-28.

0 teor de umidade foi determinado utilizando-se um equipamento Karl Fischer, da marca Analyser, modelo Umidade controle KF-1000, pelo método ASTM D - 4377.

Para a determinação da massa específica foi utilizado um densímetro, marca Anton Paar, modelo DMA 5000 .

O índice de saponificação foi determinado através da metodologia do Instituto Adolfo Lutz [2008].

A análise de perfil de ácidos graxos foi realizada através do método apresentado pela metodologia do Instituto Adolfo Lutz [2008], utilizando um cromatógrafo da marca Thermo Scientific, modelo Trage GC Ultra, com uma coluna da marca SGE Analytical Science, modelo BPX 70. 


\subsection{OBTENÇÃO DOS ÉSTERES ETÍLICOS}

Os experimentos foram realizados em escala laboratorial, para a obtenção dos ésteres etílicos a partir da blenda de óleo de fritura e sebo bovino. Na reação de transesterificação, o álcool utilizado na reação foi o etanol anidro por possuir a vantagem de não ser tóxico e de ser biodegradável e como catalisador foi utilizado o ácido sulfúrico.

Para o preparo da blenda foi utilizado à metodologia de Oliveira [2013], com uma razão de 22:3 (óleo:sebo).

De acordo com a metodologia utilizada por Abreu [2012] e Oliveira [2013] a reação de transesterificação foi realizada em um balão de $2000 \mathrm{~mL}$ com 3 bocas equipado com um agitador, um condensador de refluxo e um termômetro. 0 balão foi imerso em banho de água com temperatura constante. As reações foram realizadas a $78^{\circ} \mathrm{C}$ e $350 \mathrm{rpm}$ em duplicata, com uma razão molar de 1:36:0,46 (Blenda:EtOH: $\mathrm{H}_{2} \mathrm{SO}_{4}$ ), a reação foi acompanhada por 8 horas.

Após o termino da reação de transesterificação, a mistura reacional foi submetida a um evaporador rotativo marca Fisatom, modelo 803, ligado a uma bomba hidro vácuo sob vácuo de $600 \mathrm{mmHg}$, e temperatura do banho a $60^{\circ} \mathrm{C}$ para a recuperação do álcool excedente. A separação dos éteres etílicos e da água foi realizada por decantação, em um balão de decantação.

Após a decantação e separação a fase superior é direcionada para a etapa de purificação dos ésteres etílicos. De acordo com a metodologia usada por Medeiros [2013] que realizou centrifugação com adição de água acidificada a $0,5(\mathrm{v} / \mathrm{v})$ de $\mathrm{HCl}$, a partir dessa metodologia foi realizada centrifugação com 2000 rpm por 8 minutos com adição de água basificada a 0,5\% (v/v) de $\mathrm{NaOH}$ e 10\% (v/v) de água destilada.

Para as análises dos ésteres, foi utilizado um cromatógrafo da marca Varian, modelo CP - 3800, com detector de ionização de chama [DIC], contendo uma coluna capilar específica para separação de ésteres [BP - X70 - SGE] de $30 \mathrm{~m}$ x 0,25 mm. Hélio foi utilizado como gás de arraste, numa razão split de 1:10. A análise foi realizada com programação de temperatura da coluna, iniciada a $110^{\circ} \mathrm{C}$, com aquecimento até $160^{\circ} \mathrm{C}$ a $8 \mathrm{C} / \mathrm{min}$ e $230^{\circ} \mathrm{C}$ a $3,5^{\circ} \mathrm{C} / \mathrm{min}$. A temperatura do detector foi mantida em $220^{\circ} \mathrm{C}$ e a do injetor em $260^{\circ} \mathrm{C}$.

Os componentes da amostra analisada foram identificados por meio da comparação dos tempos de retenção na coluna com os tempos de retenção de uma amostra padrão. Foi utilizado um FAME Mix [fatty acid methyl ester]. 0 padrão interno [PI] utilizado foi o éster metílico 23:0 Tricosanoato de metila [SigmaAldrich]. Este éster foi escolhido como PI por não ter sido identificado como componente da amostra de ésteres produzidos.

\section{RESULTADOS E DISCUSSÃO}

As características físico-químicas das matérias-primas foram determinadas de acordo com a metodologia de caracterização. Na Tabela 1 são apresentadas características do óleo de fritura.

Tabela 1: Características físico-químicas do óleo de fritura.

\begin{tabular}{|l|c|c|}
\multicolumn{1}{c}{ Características } & \multicolumn{1}{c}{ Este Trabalho } & OLIVEIRA, 2014 \\
\hline Umidade (\%) & $0,229 \pm 0,03$ & $0,110 \pm 0,02$ \\
\hline Índice de acidez (mg KOH/g óleo) & $2,08 \pm 0,5$ & $1,15 \pm 0,02$ \\
\hline Índice de saponificação (mg KOH/g óleo) & $232,6 \pm 1,7$ & $201,0 \pm 1,15$ \\
\hline Densidade $20^{\circ} \mathrm{C}(\mathrm{g} / \mathrm{mL})$ & 0,918 & 0,917 \\
\hline
\end{tabular}


Na Tabela 2 são apresentadas características do sebo bovino.

Tabela 2: Características físico-químicas do sebo bovino.

\begin{tabular}{|l|c|c|}
\multicolumn{1}{c}{ Características } & \multicolumn{1}{c|}{$\begin{array}{c}\text { Este } \\
\text { Trabalho }\end{array}$} & $\begin{array}{c}\text { OLIVEIRA, } \\
2014\end{array}$ \\
\hline Umidade (\%) & $0,215 \pm 0,03$ & $0,102 \pm 0,01$ \\
\hline Índice de acidez (mg KOH/g óleo) & $24,85 \pm 0,30$ & $21,88 \pm 0,03$ \\
\hline Índice de saponificação $(\mathrm{mg} \mathrm{KOH} / \mathrm{g}$ óleo) & $224,84 \pm 14,4$ & $210,0 \pm 0,62$ \\
\hline Densidade $20^{\circ} \mathrm{C}(\mathrm{g} / \mathrm{mL})$ & 0,896 & 0,896 \\
\hline
\end{tabular}

Foram utilizadas as mesmas matérias-primas na caracterização e reação que Oliveira [2013] utilizou, mas em tempos diferentes. Com isso podemos analisar que ocorreu um aumento nas características físicoquímicas, devido à vários motivos como armazenamento, exposição à luz, oxidação, hidrólise, entre outros.

Leung [2006] ressalta que o óleo de fritura tem uma acidez relativamente alta comparada com óleo puro, devido a presença de impurezas. 0 índice de acidez ficou de acordo com Leung, 2006 [2,1 mgKOH/g de óleo] e acima dos resultados de Oliveira [2013] e Uzun, et al. [2012]. 0 sebo bovino teve uma acidez baixa comparada a Magalhães [2010], [53 mg KOH/g óleo].

O índice de saponificação das matérias-primas ficou de acordo com Oliveira [2013], esse resultado é um indicativo do comprimento da cadeia do ácido graxo.

0 teor de umidade é um parâmetro importante, pois na presença de água, os ésteres podem hidrolisar a ácidos graxos de cadeia longa, causando um aumento na acidez do biodiesel [KNOTHE, et al., 2006].

A densidade está de acordo com Uzun et al. [2012], [0,96351 g/ml].

Na tabela 3 e 4 são apresentados a composição em ácidos graxos presentes nas matérias-primas.

Tabela 3: Ácidos Graxos presentes no óleo de fritura.

\begin{tabular}{|c|c|c|}
\hline Ácido graxo & $\begin{array}{c}\text { Este } \\
\text { Trabalho } \\
\%\end{array}$ & $\begin{array}{c}\text { OLIVEIRA, } \\
2014 \\
\%\end{array}$ \\
\hline Ácido Mirístico (C14:0) & - & 0,4 \\
\hline Ácido Palmítico (C16:0) & 14,8 & 11,6 \\
\hline Ácido Palmitoleico (C16:1) & - & 0,6 \\
\hline Ácido Heptadecanóico (C17:0) & 3,4 & - \\
\hline Ácido Esteárico (C18:0) & 14,1 & 3,6 \\
\hline Ácido Oleico (C18:1n9c) & 22,2 & 22,4 \\
\hline Ácido Linoleico (C18:2n6c) & 42,7 & 51,9 \\
\hline Ácido Linolênico (C18:3n3) & 8,7 & - \\
\hline Ácido Erucico (C22:1n9) & - & 0,8 \\
\hline
\end{tabular}

Podemos observar que no óleo de fritura há maior quantidade de ácidos graxos insaturados (oleico e linoleico), esta proporção também é encontrada por Oliveira [2013] e por Georgogianni, et al. [2009], [24,5\% de C18: 1n9c e 53\% de C18:2n6c]. No entanto, quanto maior a razão entre os ácidos graxos insaturados e saturados, menor o ponto de liquefação, aumentando assim a fluidez, proporcionando melhor condições de desempenho a baixas temperaturas [LEE, et al., 2011; KNOTHE, 2005].

Segundo Bouaid, et al. [2007] a oxidação dos ácidos graxos está totalmente ligada com o número de duplas ligações e sua posição. 0 ácido linoleico (C18:2n6c) é mais vulnerável a oxidação porque contêm grupos metileno que são alílico para duas ligações duplas. 
Tabela 4: Ácidos Graxos presentes no sebo bovino.

\begin{tabular}{|l|c|c|}
\multicolumn{1}{c}{ Ácido graxo } & $\begin{array}{c}\text { Este Trabalho } \\
\%\end{array}$ & $\begin{array}{c}\text { OLIVEIRA, 2014 } \\
\%\end{array}$ \\
\hline Ácido Mirístico (C14:0) & 4,1 & 1,4 \\
\hline Ácido Palmítico (C16:0) & 19,6 & 21,1 \\
\hline Ácido Esteárico (C18:0) & 25,6 & 26,3 \\
\hline Ácido Oleico (C18:1n9c) & 51,4 & 42,2 \\
\hline Ácido Linoleico (C18:2n6) & 3,8 & 2,3 \\
\hline
\end{tabular}

Os ácidos graxos presentes no sebo bovino foram os mesmos analisados por Oliveira [2013], nas mesmas proporções quantitativas.

Holanda [2004] cita que o ácido esteárico está presente em grande proporção no sebo bovino.

Frangrui [1999] explica que os teores mais elevados de ácidos graxos saturados como o ácido esteárico [C18:0] e palmítico [C16:0] faz com que o sebo bovino tenha propriedades de alto ponto de fusão e de alta viscosidade que são opostas a do óleo de fritura.

Devido essas características diferentes das matérias-primas, foi utilizada a blenda para a reação, assim, uma matéria-prima supre a necessidade da outra, a fim de atender as especificações exigidas pela ANP para o biodiesel.

Na tabela 5 são apresentadas as características físico-químicas do biodiesel produzido a partir da blenda de óleo de fritura e sebo bovino.

Tabela 5: Caracterização do biodiesel e as exigências da ANP.

\begin{tabular}{|l|c|c|}
\multicolumn{1}{c}{$\begin{array}{c}\text { Características } \\
\text { ANP }\end{array}$} & Este Trabalho & OLIVEIRA,2014 \\
\hline Densidade a $20^{\circ} \mathrm{C}[0,850-0,900]$ & $0,882 \mathrm{~g} / \mathrm{mL}$ & $0,881 \mathrm{~g} / \mathrm{mL}$ \\
\hline Umidade $[0,500 \mathrm{máx}]$ & $0,153 \%$ & $0,214 \%$ \\
\hline Acidez[0,500 máx] & $0,5 \mathrm{mg} \mathrm{KOH} / \mathrm{g}$ óleo & $0,315 \mathrm{mg} \mathrm{KOH} / \mathrm{g}$ óleo \\
\hline Teor de Glicerol livre $[0,02]$ & $0,017 \%$ & $0,011 \%$ \\
\hline Viscosidade a $40^{\circ} \mathrm{C}[3,0-6,0]$ & $6,83 \mathrm{~mm}^{2} / \mathrm{s}$ & $5,2 \mathrm{~mm}^{2} / \mathrm{s}$ \\
\hline
\end{tabular}

Com base nos valores apresentados na tabela percebe-se que o biodiesel apresentou resultados dentro dos padrões de análise para controle de qualidade exigido pela ANP, exceto a viscosidade cinemática, que é um dos parâmetros mais importantes do biodiesel, com $6,83 \mathrm{Mm}^{2} / \mathrm{s}$, cujo resultado é elevado se comparado ao limite da ANP [6,00 $\left.\mathrm{mm}^{2} / \mathrm{s}\right]$. Knothe, et al. [2006], explica que a viscosidade do biodiesel esta ligada como tamanho da cadeia e com o grau de saturação, incluindo o álcool que foi utilizado na reação de obtenção do biodiesel, porque a viscosidade dos ésteres etílicos é superior a do ésteres metílicos.

A Tabela 6 apresenta a composição em ésteres etílicos do biodiesel obtido por meio da blenda de óleo de fritura e sebo bovino.

Tabela 6: Composição de ésteres etílicos do biodiesel da blenda de óleo de fritura e sebo bovino.

\begin{tabular}{|l|c|c|}
\multicolumn{1}{|c|}{ Ésteres etílicos } & $\begin{array}{c}\text { Este Trabalho } \\
\%\end{array}$ & $\begin{array}{c}\text { OLIVEIRA, } 2014 \\
\%\end{array}$ \\
\hline Ácido Mirístico (C14:0) & 1,2 & - \\
\hline Ácido Palmítico (C16:0) & 18,3 & 3,4 \\
\hline Ácido Esteárico (C18:0) & 8,1 & 2,9 \\
\hline Ácido Oleico (C18:1n9t) & 66,1 & 38,5 \\
\hline Ácido Linoleico (C18:2n6c) & 3,3 & 55,2 \\
\hline Ácido Linolênico (C18:3n3) & 3 & - \\
\hline
\end{tabular}


As proporções dos ácidos não foram as mesmas analisadas por Oliveira [2013]. A partir dos ésteres etílicos foi determinada a conversão, apresentado na Tabela 7.

Tabela 7: Teor em ésteres.

\begin{tabular}{|l|c|c|}
\hline & \multicolumn{3}{c}{ Este Trabalho } & OLIVEIRA, 2014 \\
\hline Teor $(\%)$ & 94,5 & 96,7 \\
\hline
\end{tabular}

Para ser considerado biodiesel a porcentagem de ésteres etílicos final, após purificação, deve ser de pelo menos $96,5 \%$, valor exigido pelas normas da ANP.

\section{CONCLUSÕES}

Podemos observar que os resultados das características do biodiesel como: umidade, saponificação e densidade, apresentam valores parecidos com os encontrados na literatura. A acidez do óleo de fritura com 2,08 $\pm 0,5 \mathrm{mg} \mathrm{KOH} / \mathrm{g}$ se encontra dentro dos limites, mas a acidez do sebo bovino: $24,85 \pm 0,30$ mesmo estando de acordo com a literatura apresentou resultado elevado para a produção de biodiesel e por esse critério, foi produzida a blenda dessas matérias-primas, obtendo um biodiesel com uma acidez de $0,5 \mathrm{mg} \mathrm{KOH} / \mathrm{g}$; A viscosidade cinemática foi de $6,83 \mathrm{~mm}^{2} / \mathrm{s}$, esse resultado esta elevado comparado as exigências da ANP $\left[6,00 \mathrm{~mm}^{2} / \mathrm{s}\right]$.

Pode-se concluir que mesmo em tempos diferentes de utilização do óleo de fritura e sebo bovino, sendo matérias-primas de baixo valor comercial e de grande produção, suas características ainda são interessantes na produção de biodiesel, houve aumentos em alguns parâmetros, mas permanecem dentro das normas da ANP, obtendo rendimento de 94,5\% em ésteres etílicos.

\section{AGRADECIMENTOS}

Agradecimentos a CAPES pelo apoio financeiro.

\section{REFERÊNCIAS}

[1] Abreu, Paulo Giovanni de. HIGARASHI, Martha Mayumi. Cunha Junior, Anildo.

[2] Transesterificação com catálise ácida de resíduos de gordura de frango para produção de biodiesel: resultados preliminares. Revista Embrapa. 2012.

[3] Bouaid, A., Mercedes, M., Aracil, J. Long storage stability of biodiesel from vegetable and used frying oils. Fuel. v. 86, p. 2596-2602, 2007.

[4] Canesin, E.A., Oliveira, C.C., Matsushita, M., Dias, L.F., Pedrão, M.R., Souza, N.E. Characterization of residual oils for biodiesel prodution. Eletronic Journal of Biotechnology. v. 17, p. 39-45, 2014.

[5] Fangrui, M., Milford, A,H., Biodiesel production: a review¹. Bioresource Technology. v. 70, p. 1-15, 1999.

[6] Ferrari, R.A.; Oliveira, V.S.; Scabio, A. Biodiesel de soja - Taxa de

[7] Rendimento em ésteres etílicos, caracterização físico-química e consumo em gerador de energia. Química Nova. V. 28, no.1, p.19-23, 2005.

[8] Georgogianni, K. G.; Katsoulidis, A.P., Pomonis, P.J., Kontominas, M. G. Transesterification of soybean frying oil to biodiesel using heterogeneous catalysts. Fuel Processing Technology, v. 90, p.671-676, 2009.

[9] Holanda, A. Câmara, G.M.S. Potencial da cultura da soja como fonte de matéria-prima para o Programa Nacional de Produção e Uso do Biodiesel. In: Câmara, G. M. S. \& Heiffig, L. S. (coord.):Agronegócio de Plantas Oleaginosas: Matérias-Primas para Biodiesel. Piracicaba: ESALQ. p.123 - 153.2004.

[10] Instituto Adolfo Lutz, Normas Analíticas. Métodos Químicos e Físicos para Análise de Alimentos, v.1, 3aㅡ ed., São Paulo, 1985.

[11] Junior, R. M. C. Desenvolvimento e análise energética do processo de obtenção do biodiesel de microalga por metanólise Insitu. f.99. Dissertação (Mestrado em Engenharia). Universidade Federal do Paraná, 2010. 
[12] Knothe, G. Dependence of biodiesel fuel properties on the structure of fatty acid alkyl esters. Fuel Processing Technology, v. 86, p. 1059-1070, 2005.

[13] Knothe, G.; Van Gerpen, J.; Krahl, J.; Ramos, L. P., Manual de biodiesel,

[14] Ed. Edgard Blucher, Sao Paulo, 2006, 340p.

[15] Lee, H.V.; Yunus, R.; Juan, J.C.; taufiq-Yap, Y.H. Process optimization

[16] design for jatropha-based biodiesel production using response surface methodology. Fuel Processing Technology, v. 92, p. 2420-2428, 2011.

[17] Leung, D.Y.C., Guo,Y. Transesterification of neat and used frying oil: Optimization for biodiesel production. Fuel Processing Technology, v. 87, p. 883-890, 2006.

[18] Leung, D.Y.C., Koo, B.C.P., Guo,Y. Degradation of biodiesel under different storage conditions. Bioresource Technology. v. 97, p. 250-256, 2006.

[19] Magalhães, Fabio Carvalho. Blenda sebo/soja para produção de biodiesel:

[20] Proposta de um processo batelada homogêneo como alternativa para agricultura familiar. 2010, Dissertação (Mestrado em Química Tecnologia e Ambiental) - Programa de Pós-graduação em Química Tecnologia e Ambiental, Universidade Federal do Rio Grande, Rio Grande, 77p.

[21] Mangesh, G.K., Dalai, A.K. Waste Cooking OilsAn Economical Source for Biodiesel: A Review. Ind. Eng. Chem. Res. v. 45, p. 2901-2913, 2006.

[22] Mansini, Z.A.C., et al. 0 estudo da reação de transesterificação etílica do sebo bovino na obtenção de biodiesel, em diferentes condições de catálise. In: Encontro Regional da Sbqmg, 21. Uberlândia. 2007. Disponível em: <http://sec.sbq.org.br/cdrom/31ra/resumos/T1551-1.pdf>. Acesso em 16 de março de 2015.

[23] Mata, T. M., Martins, A. A., Caetano, N. S. Microalgae for biodiesel production and other applications: A review. Renew. Sustain. Energy Rev., v.5, n.86, 2009.

[24] Medeiros, J.F; Souza, G.K; Pereira, N.C; Gomes, M.C.S; Lima, O.C.M.

[25] Análise da Produção de Biodiesel de Óleo de Soja e Purificação por Centrifugação. Biochemistry and Biotechnology Reports. .v. 2, n. 3 p. 142-145, 2013.

[26] Oliveira, S.M; Dalcolle, J.C; Pereira, N.C. Tratamento e caracterização físico-química do óleo de fritura e sebo bovino para desenvolvimento de blendas líquidas capazes de serem destinadas para produção de biodiesel etílico. Fórum Ambiental da Alta Paulista. v. 9, n. 1, p. 112-122, 2013.

[27] Uzun, B.B., Kilic, M., Ozbay, N., Putun, A.E., Putun, E. Biodiesel production from waste frying oils: Optimization of reaction parameters and determination of fuel properties. Energy. v. 44, p. 347-351, 2012. 


\section{Capítulo 11}

Influência do teor de acidez na produção de biodiesel etílico de canola por rota alcalina

\section{Matheus Pereira de Oliveira \\ Fernanda Naiara Campos de Almeida \\ Jéssica Violin Berni \\ Thiago Luiz Belo Pasa \\ Nehemias Curvelo Pereira}

Resumo: Atualmente os países buscam formas alternativas que sejam menos agressivas à natureza para obter energia. 0 biodiesel surgiu como uma alternativa viável ecologicamente para a substituição parcial ou total do diesel fóssil. 0 índice de acidez é utilizado para determinar qual rota será utilizada a produção de biodiesel. Foi feita a produção de biodiesel com o óleo bruto de canola, que possui uma acidez elevada para a rota alcalina, porém não muito alta para utilizar a rota ácida. Também foram produzidos biodiesel do óleo neutralizado com o Magnesol 600R, que é um adsorvente comercial utilizado para tal fim e também com óleo de canola neutralizado com $\mathrm{NaOH}$. $\mathrm{Na}$ produção de biodiesel com o óleo de canola bruto não houve formação de fases. 0 produto final não pode ser chamado biodiesel porque nenhumas das transesterificações atingiram um teor de ésteres acima de $96,5 \%$ que é o mínimo indicado pela ANP. A viscosidade cinemática e a massa específica ficaram de acordo com os limites préestabelecidos. Apenas a mistura de ésteres etílicos formados pelo óleo de canola bruto não atingiram o teor de acidez máximo permitido pela ANP.

Palavras-chave: Biodiesel, Canola, Acidez. 


\section{INTRODUÇÃO}

Após o período sombrio que a crise mundial de 2008 trouxe para os países desenvolvidos, alguns deles já estão retomando o crescimento econômico e com isso, surge uma necessidade ainda maior que este crescimento respeite os conceitos de sustentabilidade. 0 cenário brasileiro atualmente é delicado, pois além da alta no preço dos combustíveis fósseis, a seca castiga nos locais dos reservatórios de água, forçando a ativação de usinas termelétricas que possuem um maior custo de produção de energia. 0 biodiesel, que estava esquecido, retorna mais forte no cenário energético brasileiro, pois com a alta do preço do diesel de petróleo, a produção de biodiesel se torna economicamente mais rentável. Uma medida provisória estabelecida pelo governo federal aumentou a porcentagem do biodiesel no diesel fóssil para $7 \%$ em novembro de 2014, estimando-se a inserção de aproximadamente 1,2 bilhões de litros de biodiesel a mais no mercado brasileiro [BLOG DO PLANALTO, 2014].

Dentre as rotas existentes para a transformação de óleos e gorduras em biodiesel, a transesterificação alcalina homogênea é a mais usual principalmente pelo seu baixo custo de produção em relação ao craqueamento catalítico e pirólise [PINTO et al., 2005].

A caracterização da matéria-prima é muito importante, sendo que a mesma irá definir qual a melhor rota para a produção dos ésteres. Clark et al. [1984] afirmou que utilizando a rota alcalina, para uma boa conversão de ácidos graxos em ésteres, o óleo deve possuir uma acidez abaixo de 0,5\% (m/m).

Van Gerpen et al. [2004] afirmam também, que a acidez elevada não é recomendada devido ao fato de o catalisador neutralizar os ácidos graxos livres, diminuindo a quantidade de catalisador disponível no meio reacional para a transesterificação dos triacilgliceróis, além de aumentar o tempo de reação.

Segundo Visentainer e Santos Júnior [2013], a reação de saponificação no meio reacional, formada pelos ácidos graxos livres, aumenta a solubilidade dos ésteres formados em meio ao glicerol, podendo atrapalhar na separação de fases ou até ocorrendo perda dos ésteres na hora da separação do glicerol com o biocombustível.

O presente trabalho pretende avaliar a eficiência de dois métodos de neutralização, a neutralização alcalina e a neutralização por um adsorvente específico. Para fins comparativos, foi produzido biodiesel do óleo de canola com a acidez elevada e com os óleos neutralizados por os dois métodos diferentes.

\section{METODOLOGIA}

Para a produção de biodiesel foi utilizado óleo de canola, fornecido pela empresa COCAMAR situada na cidade de Maringá no estado do Paraná. 0 etanol anidro foi fornecido pela usina pertencente ao grupo COCAFÉ, situado no município de Astorga no estado do Paraná.

\subsection{CARACTERIZAÇÃO DO ÓLEO DE CANOLA}

Para a caracterização do óleo de canola foi realizado o teste de acidez, por titulação de acordo com o método Adolf Lutz [2008]. A determinação de umidade foi realizada pelo equipamento Carl Fisher da marca Analyser, modelo unidade de controle KF-1000. Para a análise de massa específica, foi utilizado um densímetro digital da marca Atom Paar modelo DMA 5000. A análise de viscosidade cinemática foi feita em um reômetro digital da marca Brookfield modelo DV-III com spindle SC4-27 e velocidades de rotação entre 10 e $220 \mathrm{rpm}$. A determinação da composição de ácidos graxos foi realizada por cromatografia gasosa utilizando um cromatógrafo da marca Varian, modelo CP-3800, com detector de ionizador em chama (DIC), contendo uma coluna capilar específica para a separação de ésteres (BP - X70 - SGE) de 30 $\mathrm{m} \times 0,25 \mathrm{~mm}$.

\subsection{NEUTRALIZAÇÃO DO ÓLEO DE CANOLA}

\subsubsection{NEUTRALIZAÇÃO COM MAGNESOL 600R}

Para a neutralização do óleo de canola com o Magnesol 600R foi utilizado uma amostra de $200 \mathrm{~g}$ de óleo de canola aquecido a uma temperatura de $85^{\circ} \mathrm{C}$. Em seguida, transferiu-se uma quantidade de $2 \%(\mathrm{~m} / \mathrm{m})$ do magnesol 600R no óleo aquecido. A mistura ficou sob agitação durante o período de uma hora. Após o tempo de agitação, a mistura foi transferida para um funil de vidro, onde se realizou a filtração, com o auxílio de um papel de filtro e em seguida filtrada sobre vácuo por um filtro de membrana. 


\subsubsection{NEUTRALIZAÇÃO COM NAOH}

A neutralização do óleo com $\mathrm{NaOH}$ foi realizada de acordo com Cardello et al. [1995] com algumas adaptações. 0 método consiste em adicionar $1,5 \%$ de uma solução de $\mathrm{NaOH} 29^{\circ}$ Bé, em relação ao peso da amostra a $80^{\circ} \mathrm{C}$ e mantida por agitação durante o período de um minuto. Após a agitação, a amostra é centrifugada durante 10 minutos a uma velocidade de rotação de 7000rpm e retirado o sobrenadante.

\subsection{PRODUÇÃO DE BIODIESEL}

A produção de biodiesel foi realizada conforme o melhor rendimento obtido pelo planejamento experimental de Gomes [2010]. A produção de biodiesel manteve os mesmos parâmetros para os três tipos de óleo. Foi transferida uma quantia de $150 \mathrm{~g}$ de óleo de canola em um balão de três bocas de $250 \mathrm{~mL}$. A razão molar de óleo:etanol utilizada foi de 1:7,5 e 1\% (m/m) de hidróxido de sódio como catalisador. A velocidade de agitação foi mantida em torno de 300rpm e a temperatura reacional ficou na faixa de $45^{\circ} \mathrm{C}$. 0 tempo da reação de transesterificação ficou em torno de uma hora. A mistura foi transferida então para um evaporador rotativo a vácuo a uma temperatura de $85^{\circ} \mathrm{C}$ pelo período de 40 minutos para retirar o etanol que não reagiu com o óleo. 0 biodiesel rotoevaporado foi transferido para um funil de separação para a remoção do glicerol formado. 0 procedimento de lavagem foi de acordo com a metodologia utilizada por Geris et al. [2007] que consiste em utilizar $20 \%$ (v/v) de uma solução de ácido clorídrico a $0,5 \%(\mathrm{v} / \mathrm{v})$; seguido por outra lavagem a $20 \%$ (v/v) de uma solução saturada de $\mathrm{NaCl}$ e por fim, outra lavagem com água destilada. Para a remoção de umidade da amostra, a mesma foi seca em uma estufa a $90^{\circ} \mathrm{C}$ por um período de quatro horas.

\subsection{ANÁLISE DA QUALIDADE DO BIODIESEL}

Para a quantificação de ésteres formados na reação será utilizado o método de cromatografia gasosa, utilizando um cromatógrafo da marca Varian, modelo CP-3800, com detector de ionizador em chama (DIC), contendo uma coluna capilar específica para a separação de ésteres (BP - X70 - SGE) de $30 \mathrm{~m}$ x 0,25 $\mathrm{mm}$.

Para a determinação de acidez do biodiesel foi utilizado o método por titulação do Adolf Lutz [1985].

\section{RESULTADOS E DISCUSSÃO}

0 índice de acidez do óleo de canola bruto obteve o valor de 2,62\% (m/m). Os óleos de canola refinado com adsorvente magnesol 600R e com uma solução de $\mathrm{NaOH}$ obtiveram os valores de 0,53 e $0,46 \%(\mathrm{~m} / \mathrm{m})$ respectivamente. A viscosidade cinemática a $40^{\circ} \mathrm{C}$ o óleo de canola obteve o valor de $33,32 \mathrm{~mm}^{2} \cdot \mathrm{s}^{-1}$, enquanto que os índices de densidade a $20^{\circ} \mathrm{C}$ e umidade obtiveram os valores de $0,917 \mathrm{~g} \cdot \mathrm{cm}^{-3}$ e $0,253 \%$ respectivamente. Pela tabela 1 é possível observar a composição dos ácidos graxos presentes no óleo de canola, determinados por cromatografia gasosa.

Tabela 1: Composição de ácidos graxos do óleo de canola

\begin{tabular}{|l|c|}
\multicolumn{1}{|c|}{ Ácido Graxo } & Porcentagem \\
\hline Palmítico (C16) & $5,17 \%$ \\
\hline Oleico (C18:1) & $58,27 \%$ \\
\hline Linoleico (C18:2) & $22,6 \%$ \\
\hline Linolênico (C18:3) & $7,7 \%$ \\
\hline Outros & $6,26 \%$ \\
\hline
\end{tabular}

A produção de biodiesel com o óleo de canola bruto não houve separação de fases, porém a produção de biodiesel com os óleos refinados de canola obtiveram uma separação de fases bem nítida, demonstrada nas figuras 1 e 2 . 
Figura 1: Biodiesel do óleo de canola neutralizado com magnesol 600R.

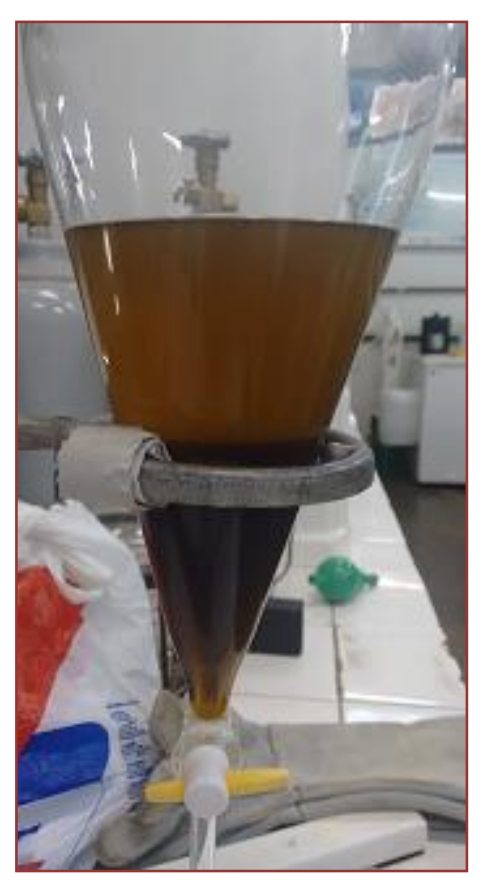

Figura 2: Biodiesel produzido com óleo de canola neutralizado com $\mathrm{NaOH}$.

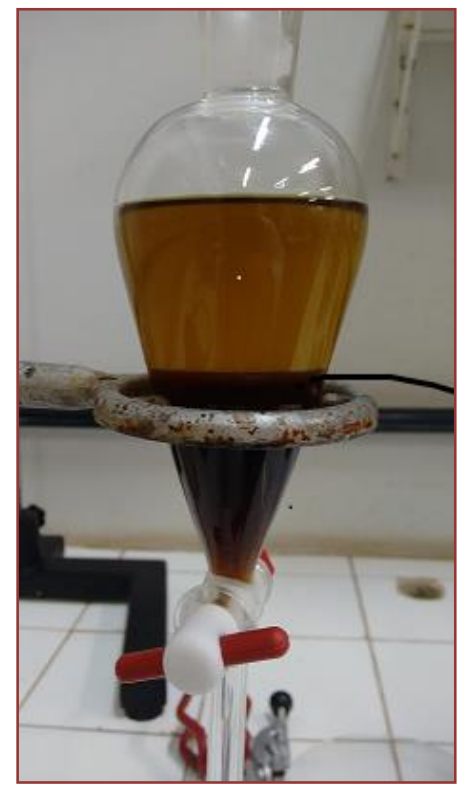

A quantificação do teor de ésteres foi obtida por cromatografia gasosa, como pode ser observada na figura 3. 
Figura 3: Cromatografia gasosa da mistura de ésteres do óleo de canola

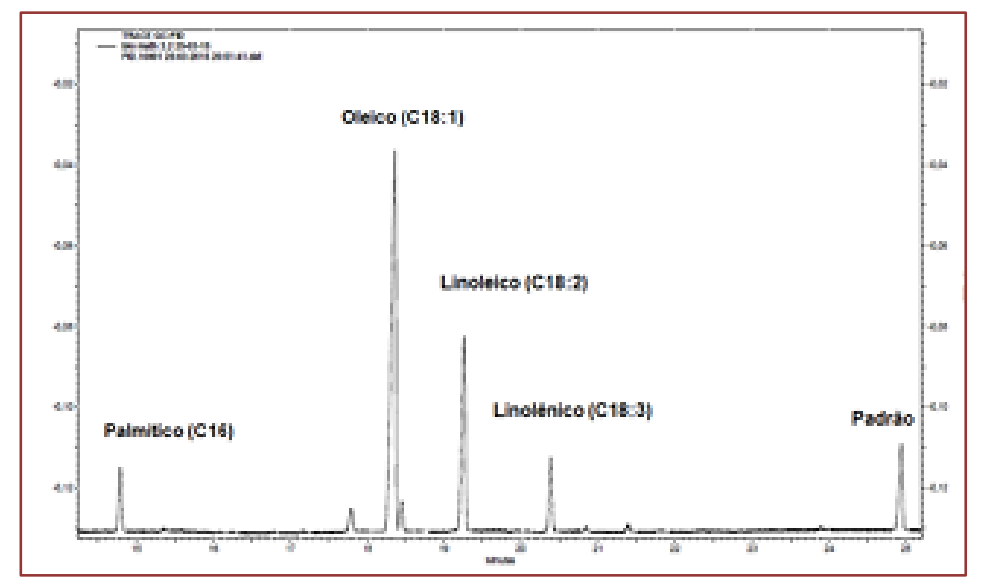

As taxas de conversão de triacilglicerol em ésteres, assim como a umidade e a acidez dos produtos finais podem ser analisadas pela tabela 2 .

Tabela 2: características físico-químicas do produto final

\begin{tabular}{|c|c|c|c|}
\hline Tipo de óleo & $\begin{array}{c}\text { Teor de } \\
\text { ésteres (\%) }\end{array}$ & $\begin{array}{c}\text { Acidez } \\
\text { mgKOH.g-1 }\end{array}$ & $\begin{array}{c}\text { Umidade \% } \\
(\mathrm{m} / \mathrm{m})\end{array}$ \\
\hline Canola bruto & 75,75 & 5,4 & 0,437 \\
\hline Canola neutralizado com Magnesol 600R & 96,1 & 0,47 & 0,182 \\
\hline Canola neutralizado com $\mathrm{NaOH}$ & 94,7 & 0,13 & 0,239 \\
\hline
\end{tabular}

A produção de biodiesel utilizando o óleo de canola bruto demonstrou uma baixa conversão de triacilgliceróis em ésteres etílicos. Segundo Visentainer e Santos Júnior [2013], ocorre saponificação dos ácidos graxos livres, aumentando a solubilidade dos ésteres e dificultando então a separação de fases. Outro fator para que não ocorresse separação de fases é a presença do etanol, pois por possuir uma cadeia mais longa, torna os ésteres etílicos mais miscíveis à glicerina [MA e HANNA, 1999; BRUNSCHWIG et al., 2011].

A reação de transesterificação com os óleos de canola refinados obteve uma alta taxa de conversão, porém os mesmos não podem ser denominados de biodiesel, pois segundo a ANP a conversão precisa ser acima de $96,5 \%$. A acidez dos ésteres produzidos com o óleo de canola neutralizado com $\mathrm{NaOH}$ e Magnesol 600R estão dentro da norma da ANP, que permite até $0,5 \mathrm{mgKOH} . \mathrm{g}^{-1}$, porém os ésteres produzidos com o óleo de canola bruto obtiveram uma acidez muito mais elevada do permitido. A umidade porém não está dentro dos padrões da ANP, que tolera valores de 0,05\%, isto deve-se ao fato de que o tempo de secagem na estufa não foi o suficiente para retirar a umidade. Os índices de densidade a $20^{\circ} \mathrm{C}$ e viscosidade cinemática a $40^{\circ} \mathrm{C}$ estão ilustrados na tabela 3.

Tabela 3: Densidade e Viscosidade cinemática dos ésteres etílicos

\begin{tabular}{|l|c|c|}
\multicolumn{1}{|c|}{ Éster etílico } & $\begin{array}{c}\text { Densidade } 20^{\circ} \mathrm{C} \\
\left(\mathrm{Kg}^{-3} \mathrm{~m}^{-3}\right)\end{array}$ & $\begin{array}{c}\text { Viscosidade } \\
\text { cinemática } \\
\left(\mathrm{mm}^{2} \cdot \mathrm{s}^{-1}\right)\end{array}$ \\
\hline Canola bruto & 877,6 & 3,49 \\
\hline Neutralizado com Magnesol 600R & 875,7 & 3,498 \\
\hline Neutralizado com $\mathrm{NaOH}$ & 876,5 & 3,495 \\
\hline
\end{tabular}

Segundo as normas da ANP os valores para a densidade a $20^{\circ} \mathrm{C}$ são aceitáveis de $850-900 \mathrm{Kg}^{-3} \mathrm{~m}^{-3} \mathrm{e}$ viscosidade cinemática a $40^{\circ} \mathrm{C}$ são conformes na faixa de $3-6 \mathrm{~mm}^{2} \cdot \mathrm{s}^{-1}$. Como pode observar na tabela 3 , todas as misturas de ésteres etílicos produzidas estão conforme com a especificação. 


\section{CONCLUSÕES}

Pode-se concluir que a acidez da matéria-prima é essencial para uma produção de biodiesel mais eficiente, e que existem outros métodos alternativos para neutralizar o óleo, como o adsorvente comercial Magnesol 600R, que foi desenvolvido especialmente para a remoção de ácidos graxos livres.

\section{AGRADECIMENTOS}

Agradeço primeiramente a Deus, por me dar saúde e capacidade para realizar as minhas atividades, a CAPES, pelo apoio financeiro para a realização desta pesquisa, aos meus amigos de laboratório que foram essenciais para a conclusão deste trabalho e ao meu orientador que me ajudou nas horas mais difíceis.

\section{REFERÊNCIAS}

[1] Blog Do Planalto. Dilma Anuncia Medidas para Aumentar o Percentual de Biodiesel no Óleo Diesel. Disponível em: < http://blog.planalto.gov.br/dilma-anuncia-medidas-para-aumentar-o-percentual-de-biodiesel-no-oleo-diesel/ > Acesso em: 25 jul. 2014.

[2] Brunschwig, C.; Moussavou, W.; Blin, J. Use of bioethanol for biodiesel production. Progress in Energy and Combustion Science. V.38(2), p.283-301, 2012.

[3] Cardelo, H. M. A. B.; Borghi, A. B. M. P.; Vila, M. M. D. C.; Gonçalves, L. A. G.; Clarificação Convencional de Óleo de sementes de Algodão (Gossipium hirsutum). Alim. Nutr. V.6, p.77-87, 1995.

[4] Freedman, B.; Pryde, E. H.; Mounts, T. L.; Variables Affecting the Yelds of Fatty Esters from Transesterified Vegetable Oils. Agricultural Research Service, U. S. Department of Agriculture, v.61, p.1638-1643, 1984.

[5] Geris R.; Santos, N. A. C.; Amaral, B. A.; Maia, I. S.; Castro, V. D.; Carvalho, J. R. M. Biodiesel de Soja - Reação de Transesterificação para Aulas Práticas de Química Orgânica. Química Nova, v. 30, p. 1369-1376, 2007.

[6] Gomes, M., C., S. Estudo da Produção de Biodiesel por Transesterificação Etílica e sua Purificação Utilizando Processos com Membranas 2012, 156p. Tese de Doutourado, Universidade Estadual de Maringá, Programa de Pós Graduação em Engenharia Química. Maringá-PR.

[7] Instituto Adolfo Lutz, Normas Analíticas. Métodos Químicos e Físicos para Análise de Alimentos, v.1, 3aㅗe․, São Paulo, 1985.

[8] Ma, F.; Hanna, M. A. Biodiesel production: a review. Bioresource Technology, v. 70, p. 1-15, 1999.

[9] Pinto, A. C.; Guarieiro, L. L. N.; Rezende, M. J. C.; Ribeiro, N. M.; Torres, E. A.; Lopes, W. A.; Pereira, P. A. P.; de Andrade, J. B.; Biodiesel: An Overview. J. Braz. Chem. Soc. V.16, p. 1313-1330, 2005.

[10] Van Gerpen, J.; Shanks, B.; Pruszko, R. Clements, D.; Knothe, G.; Biodiesel Production Technology. NREL, 2004.

[11] Visentainer, J. V.; Santos Junior, O. de O. Aspectos Reacionais e da Química Analítica na Produção e Controle de Qualidade do Biodiesel de Óleo e Gorduras. Editora da UEM, 2013. 


\section{Capítulo 12}

Gestão do potencial energético de gás de flare em unidades de processamento petroquímicas

\section{Gabriela de Carvalho Brito}

Samuel Mathias do Amaral Junior

Tomas Saiter Lins

Resumo: A crescente demanda por gás natural tem levado a uma busca constante por tecnologias para seu máximo aproveitamento, ou seja, métodos para evitar ou minimizar a queima inerente aos processos petroquímicos. Um dos pontos a ser atacado é a queima em flares, que são queimadores de gás natural que permanecem acesos para absorver descontroles operacionais e despressurizar o sistema, não utilizando a capacidade calorífica do gás para geração de energia útil. Assim, a atenuação do desperdício evidencia uma oportunidade sob o ponto de vista econômico, uma vez que o gás pode ser utilizado para suprir a demanda por gás combustível dentro da própria unidade. Esse insumo gera um dispêndio considerável para o balanço de faturamento e é um ponto que desperta possibilidade de economia para a gestão da planta. Além dos impactos econômicos, outro fator importante neste cenário está na emissão de gases contribuintes para o efeito estufa, oriunda da queima residual nos flares. Através de uma pesquisa bibliográfica, foi verificado que o Estado da Arte para o tema apontou técnicas de recuperação aplicadas ao redor do mundo, com uma deficiência para o Brasil. 0 trabalho investiga a viabilidade econômica da recuperação desse potencial energético visando o aumento da eficiência no processamento. Foi feito um estudo de caso da possível recuperação de gás em uma unidade de tratamento de gás, para uso como gás combustível. A recuperação mostrou-se economicamente viável, além de reduzir a emissão de gases causadores do efeito estufa.

Palavras-chave: Gás natural, flare, recuperação, potencial energético. 


\section{INTRODUÇÃO}

A queima em flares constitui uma necessidade básica para a segurança das instalações de processamento de petróleo e gás, sejam onshore ou offshore, embora contradizendo a política de máximo aproveitamento dos recursos fósseis, no ponto de vista de eficiência energética. 0 fomento das termelétricas movidas a gás natural, como resposta mais rápida para o aumento da segurança de fornecimento de energia elétrica a partir de 2001, trouxe consigo uma expansão no setor de gás natural, cuja oferta se mostra ainda insuficiente para atender a demanda atual [REGO, 2007].

Isso pode ser evidenciado pela análise de produção de gás nacional, que registrou déficit em 49,16\%, no ano de 2015, em relação à demanda do País, segundo o Ministério de Minas e Energia [MME, 2016]. As alternativas para o atendimento da demanda total provêm, então, da importação da Bolívia ou compra de GNL (Gás Natural Liquefeito) de mercados externos.

A queima em flares, que representa uma parcela do gás produzido, porém não disponível para a venda, apontou um valor médio de 3,83 milhões $\mathrm{de}^{3} /$ dia em 2015. Esse gás poderia ser utilizado, por exemplo, para suprir a demanda por gás combustível das próprias unidades petroquímicas, que consumiram em média 12,20 milhões de $\mathrm{m}^{3}$ /dia neste mesmo ano [MME, 2016].

Os gastos com gás combustível (custos), somados aos valores potenciais associados à queima (resíduo), embasam a necessidade do aproveitamento desta energia desperdiçada e denotam uma possibilidade de aumento de rentabilidade da Unidade.

A questão ambiental também deve ser considerada, uma vez que a queima de combustíveis fósseis contradiz o compromisso firmado pelo Brasil na Cúpula da ONU sobre Desenvolvimento Sustentável em 2015, cuja meta compreende reduzir em 43\% a emissão de gases do efeito estufa até 2030 [TORRES \& MUNIZ, 2016].

Estes fatores justificam o referente trabalho, cujo objetivo se concentra em avaliar a viabilidade econômica da implantação da recuperação do gás de flare. Para tal, é investigado o estado da arte e a possibilidade do uso de gás como combustível em determinados subsistemas que demandam carga térmica dentro da própria instalação. Tal recuperação pretende trazer vantagens ambientais e econômicas, além de contribuir para uma maior eficiência energética e sustentabilidade.

\section{QUEIMA DE GÁS EM UNIDADES PETROQUÍMICAS}

A operação em unidades petroquímicas é conhecida por utilizar altas pressões e vazões, caracterizando risco potencial à segurança das instalações e dos trabalhadores. Para a prevenção de descontroles e sobrepressões, é utilizado o sistema de tocha, ou simplesmente flare, que consiste em um conjunto de queimadores e vaso de acomodação do volume e depuração de frações líquidas arrastadas, projetado para a capacidade de alívio de todo o inventário da planta de processo [MOKHATAB; POE, 2014].

Figura 1. Esquemático do Sistema de Tocha

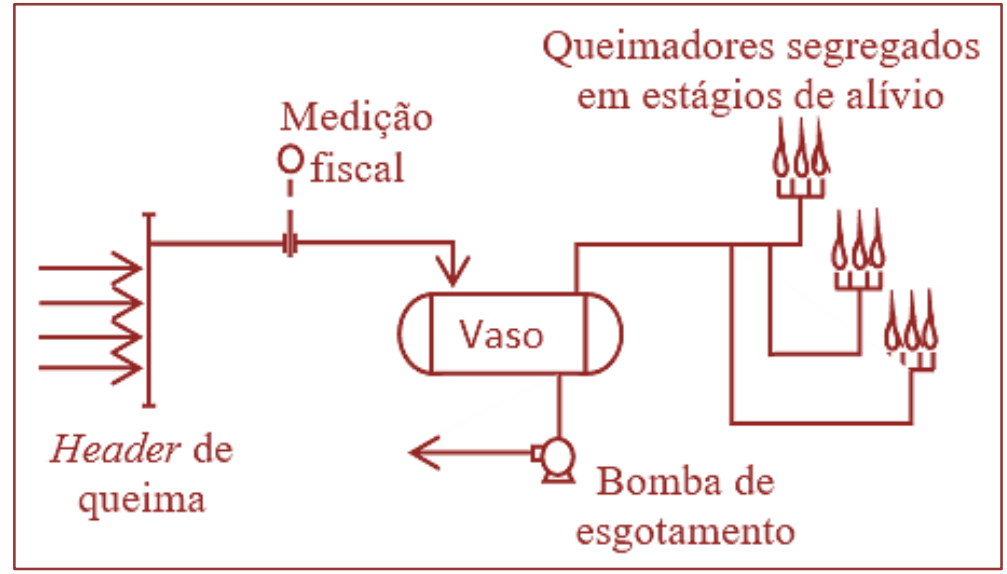

Fonte: Autores, baseado em Leite, 2012. 
Cada subsistema da unidade petroquímica é interligado a uma tubulação coletora (header), que recebe, principalmente, a fração gasosa nos vasos e equipamentos, com pressão ligeiramente superior à pressão atmosférica. 0 header então direciona o fluxo a um vaso blowndown para separação de frações líquidas que por ventura possam ter sido arrastadas ou condensadas ao longo da tubulação devido à alteração das propriedades que definem o estado da mistura gasosa (resfriamento ou queda da pressão). 0 esgotamento deste vaso pode ser realizado por drenagem fechada e o condensado pode ser aproveitado em outro sistema [LEITE, 2012].

\subsection{VAZÃO DE QUEIMA E REGULAMENTAÇÃO SEGUNDO ANP}

A origem da corrente gasosa que flui pela tubulação coletora pode ser verificada por passagens indevidas em válvulas de controle, gás residual das particularidades de cada subsistema, produto de reações químicas, desprendimento por dissociação (efeito flash), dentre outros. Estas origens possuem vazões volumétricas com pouca variação, diferente das despressurizações de emergência, ou alívios de segurança, como em aberturas abruptas de válvulas tipo PSV (pressure safe valve), que são válvulas de segurança contra pressões superiores às suportadas pelos vasos e equipamentos [MOKHATAB; POE, 2014].

A ANP, através da Portaria no 249/2000, regulamenta a queima de gás nas unidades de processamento. Dentre os limites estipulados, destaca-se o limite para queima de gás natural igual ou inferior a 3\% do volume de produção mensal de gás natural associado ao campo. As situações adversas e não previstas, devem ser negociadas com a ANP, no âmbito do Programa Anual de Produção [ANP, 2000].

Pela Tabela 1 é possível notar o volume de queima por Bacia produtora através da distribuição da movimentação de gás natural (em mil m³ /d), segundo o Boletim da Produção de Petróleo e Gás Natural.

Tabela 1 - Distribuição da movimentação de gás natural no Brasil (em mil m³ $/ \mathrm{d})$

\begin{tabular}{|l|c|c|c|c|c|}
\multicolumn{1}{c}{ Bacia } & \multicolumn{2}{c}{$\begin{array}{c}\text { Consumo } \\
\text { Interno }\end{array}$} & \multicolumn{2}{c}{ Queima } & \multicolumn{2}{c|}{ Disponível } & \multicolumn{2}{c|}{ Injeção } & \multicolumn{2}{c|}{ Produção } \\
\hline Santos & 2581 & 554 & 15043 & 19897 & 38075 \\
\hline Campos & 7828 & 2205 & 14673 & 262 & 24968 \\
\hline Solimões & 486 & 178 & 5603 & 7942 & 14209 \\
\hline Camamu & 99 & 3 & 5900 & 0 & 6002 \\
\hline Parnaíba & 41 & 4 & 4338 & 0 & 4384 \\
\hline Recôncavo & 153 & 105 & 1685 & 728 & 2670 \\
\hline Sergipe & 218 & 82 & 748 & 1597 & 2645 \\
\hline Espírito Santo & 356 & 44 & 159 & 0 & 1909 \\
\hline Alagoas & 6 & 15 & 1239 & 0 & 1260 \\
\hline Potiguar & 355 & 77 & 569 & 3 & 1004 \\
\hline Ceará & 0 & 9 & 73 & 0 & 82 \\
\hline Tucano Sul & 11 & 0 & 29 & 0 & 39 \\
\hline Total geral & 12134 & 3275 & 51408 & 30429 & 97246 \\
\hline
\end{tabular}

\section{ESTADO DA ARTE PARA SISTEMAS DE RECUPERAÇÃO DE GÁS DE FLARE}

Partindo da busca em uma base de dados internacional (Elsevier), utilizando as palavras-chave: "recuperação", "gás de flare", "gás natural", "flare" "sustentabilidade" e "emissões", foi possível identificar as tecnologias mais recentes sobre o tema, úteis para compreensão do tema e passíveis de reprodução. 


\subsection{RECUPERAÇÃO DE GÁS PARA SUPRIMENTO DE GÁS COMBUSTÍVEL NA ITÁLIA}

Na Itália, um estudo recente fez um levantamento de possibilidades reais para a recuperação de gás em uma refinaria, com nome não divulgado, no qual é apresentado um tratamento para o gás reutilizado, sua viabilidade econômica e o período de retorno. Foi apresentada uma metodologia para a seleção do sistema, em que um compressor de anel líquido foi escolhido. Foram descritos seu funcionamento e desenho básicos, os tratamentos químicos dos gases inertes e dos compostos ácidos [COMODIA et al. 2016]. Um esquema, em tradução livre, é apresentado na Figura 2:

Figura 2. Esquemático da recuperação de gás de flare em refinaria na Itália.

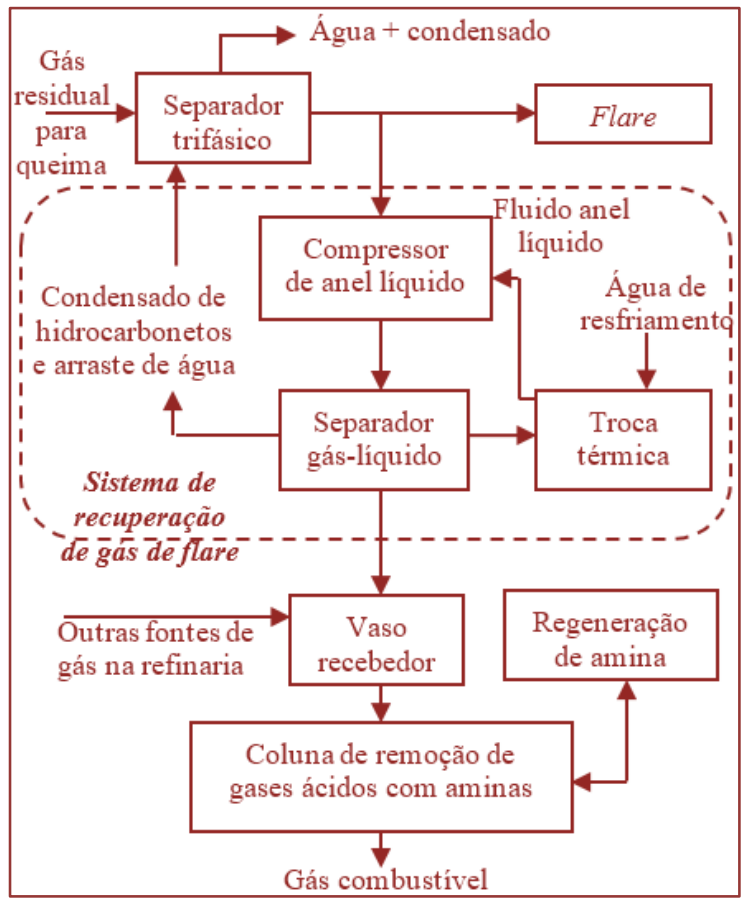

Fonte: Comodia et al (2016).

\subsection{DESENVOLVIMENTO E ANÁLISE DE DOIS MÉTODOS PARA A GERAÇÃO DE ENERGIA A PARTIR DE GÁS DE FLARE NO CANADÁ}

O estudo investiga dois cenários de reutilização de gás de queima para a geração de energia elétrica, apresentados por uma concessionária de energia elétrica em Saskatchewan, Canadá. O primeiro cenário considera uma mistura dos gases queimados com um combustível convencional utilizando o ciclo de Brayton, tecnologia já dominada no setor. 0 segundo simula o envio do gás residual para um estágio intermediário de uma turbina de gás já presente no arranjo original da unidade em que foi realizado o estudo de caso.

Após análises termodinâmicas e simulação, o estudo revela que o primeiro cenário é preferível em relação aos aspectos técnicos e econômicos, exceto em vazões baixas, inferiores a $0,8 \mathrm{~kg} / \mathrm{s}$ (faixa de referência: 0 a $2,14 \mathrm{~kg} / \mathrm{s}$ ), apontando a geração de eletricidade como alternativa vantajosa à ventilação ou queima desta fonte de energia.

Como um exemplo, para uma mistura média de $1,12 \mathrm{~kg} / \mathrm{s}$ de gás de flare e $0,756 \mathrm{~kg} / \mathrm{s}$ de gás natural tratado, o primeiro cenário gera $18,9 \%$ a mais de potência que o segundo cenário que gera 37,678 MW, de acordo com a simulação [HEIDARI et al, 2016].

\subsection{Recuperação de gás de flare no Egito: melhoria de sustentabilidade}

Realizado na refinaria de Suez (Suez oil processing company - SOPC), no Egito, o estudo baseia-se na implementação de um sistema de recuperação total do gás, utilizando-o internamente como combustível para aquecedores na refinaria, minimizando a quantidade de gás descartada. Para o tratamento de particularidades da composição local, como a presença de compostos corrosivos na presença de umidade, 
principalmente o $\mathrm{CO}_{2}$ e $\mathrm{H}_{2} \mathrm{~S}$, foi necessário prever um sistema adicional de adoçamento, ou seja, remoção de gases ácidos.

A análise econômica do projeto foi feita independentemente e considerando a receita gerada por créditos de carbono, que só são inseridos se o projeto for registrado pelo Mecanismo de Desenvolvimento Limpo (MDL). 0 método de análise foi de Taxa de Retorno Interna, mostrando-se viável com TIR em $25 \%$. A análise de viabilidade social foi feita com base nos empregos gerados pelo projeto e está dentro dos critérios de sustentabilidade do Egito. A Figura 3 apresenta um diagrama de blocos indicando as instalações existentes e as propostas pelo projeto de recuperação [ABDULRAHMAN et al, 2015].

Figura 3. Esquemático da recuperação de gás de flare na refinaria de Suez, Egito.

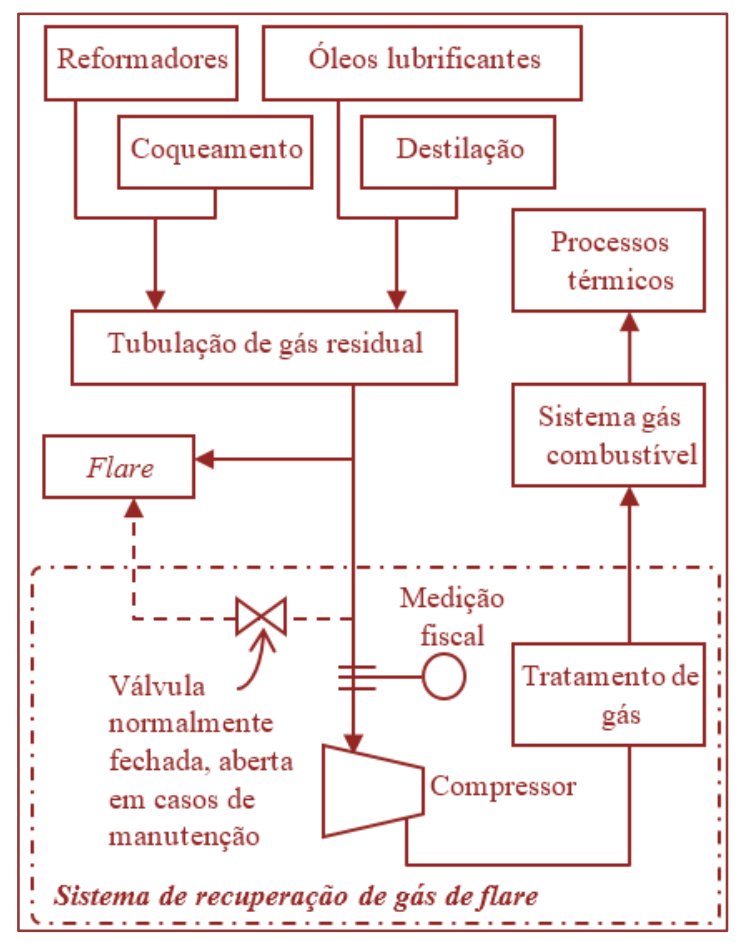

Fonte: Abdulrahman et al (2015).

\subsection{ALGUNS DOS PROJETOS EM ANDAMENTO NO IRÃ}

Os objetivos do projeto AMAK (Ab-Teymour, Mansuri, Marun, Ahwaz e Kupal) compreendem: compressão, desidratação e remoção de gases ácidos do gás associado à produção de petróleo em sete unidades de produção, assim como a transferência do gás tratado para as plantas de gás natural do Complexo Petroquímico Razi. 0 projeto AMAK vem sendo implementado desde 2010 e é composto sete estações de compressão. 0 objetivo está na redução da alta taxa de emissão por óleo produzido, cujos resultados visam acabar com a queima de 6,8 milhões de metros cúbicos de gás natural altamente ácido. Assim seria evitada a emissão de 18.000 toneladas/dia de poluentes, com uma taxa de retorno (TIR) de $28 \%$ e tempo de retorno em 30 meses.

Na ilha de Kharg-Irã, no Golfo Pérsico e nos campos offshore relacionados, os projetos Kharg e Behregansar se destacam por conter a maior parte do gás queimado de natureza ácida, o que representa uma barreira técnica e financeira substancial para acabar com a queima, apesar dos esforços de longo prazo para aliviar a situação. A atividade de projeto à luz do Mecanismo de Desenvolvimento Limpo neste campo foi projetada para capturar e tratar gás nos campos de petróleo no mar Soroosh \& Nowrooz para o uso em instalações de processamento de petróleo, de geração de energia e em uma instalação petroquímica. A infraestrutura é composta por: 
- Compressão de gás e desidratação nas plataformas dos campos de petróleo;

- Linhas do sistema de coleta e transporte de gás;

- Instalações de recepção em terra (separadores e tratadores).

Kharg e Behregansar representam os campos com maior queima no Irã, com um valor estimado de 15,3 milhões de $\mathrm{m}^{3} / \mathrm{d}$ [TAHOUNI et al, 2016].

\subsection{COMPARAÇÃO ENTRE TRÊS MÉTODOS DE RECUPERAÇÃO DE GÁS DE FLARE NA REFINARIA DE ASALOOYE - IRÃ}

Um estudo comparativo simulou a viabilidade econômica de três mecanismos distintos. Diferente dos demais retratados, este estudo desconsidera o uso do gás recuperado como combustível, mas investiga outras possibilidades de geração de produtos finais, descritas a seguir.

\subsubsection{TECNOLOGIA GAS-TO-LIQUID}

Compreende um mecanismo de produção de combustíveis líquidos a partir do gás natural, no caso, utilizando o gás residual como insumo, ao invés daquele destinado à queima em flares. A tecnologia utiliza o processo químico denominado síntese Fisher-Tropsh.

\subsubsection{PRODUÇÃO DE ELETRICIDADE A PARTIR DE TURBINAS A GÁS}

Diz respeito a uma tecnologia já dominada, em que uma turbina converte a energia cinética de um fluido em movimento para energia mecânica e esta é convertida em energia elétrica. Para simulação, foi utilizado o ciclo de Brayton, com alta eficiência comprovada e amplamente utilizado.

\subsubsection{COMPRESSÃO}

Refere-se ao aproveitamento do gás para a comercialização ou uso nas instalações da unidade. A seleção do compressor compreende uma decisão importante para o projeto, uma vez que a razão de compressão necessária agrega custos à instalação do projeto. A pressão disponível no cenário avaliado apresentava-se baixa, em 3,5 bar (próxima à pressão atmosférica) exigindo alta taxa de compressão. Sendo assim, foi selecionado um compressor alternativo, por apresentar tal possibilidade e ser de tecnologia já conhecida.

\subsubsection{AVALIAÇÃO ECONÔMICA}

Comparando os três métodos, o estudo indicou a maior taxa de retorno TIR para a compressão de gás de $200 \%$, seguido da tecnologia GTL com TIR de $125 \%$ e TIR de $21 \%$ para a geração de eletricidade. Quanto ao tempo de retorno, a compressão também apresentou o melhor resultado com 0,5 anos, GTL com 0,8 anos e uma considerável diferença com a geração de eletricidade, com 4,76 anos. 0 estudo aponta o uso da compressão como melhor alternativa, porém recomenda a tecnologia GTL quando há recursos disponíveis para investimento e há déficit de combustíveis líquidos no mercado [RAHIMPOUR et al, 2012].

\subsection{SITUAÇÃO NO BRASIL}

No País, a preocupação da ANP em regular e controlar a queima em flares é percebida através dos Termos de Compromissos firmados com as empresas do setor, com implementação de planos de ação para o aproveitamento e minimização da queima do gás associado à produção de petróleo. 0 mais recente foi firmado em 2010, com a Petrobras (ANP, 2016). As tecnologias adotadas nas empresas fazem parte da gama de informações com níveis de proteção da informação, dificultando a dissipação do know how, porém experiências no exterior com resultados positivos para a viabilidade econômica de mecanismos de recuperação de gás queimado em flares em unidades petroquímicas indicam possibilidades para replicação no Brasil. 


\section{METODOLOGIA}

Como prática já dominada de obtenção de conhecimento e aprendizagem sobre o tema, no trabalho é adotada a pesquisa científica em associação à prática na indústria.

Segundo Yin (2005), o estudo de caso permite uma investigação para se preservar as características holísticas e significativas dos eventos da vida real.

Quanto à abordagem do tema, este trabalho caracteriza-se como uma pesquisa quantitativa, expondo as características e propriedades do processo selecionado, comparando com a diferença em valor monetário do potencial energético e da emissão evitada de $\mathrm{CO}_{2}$ na atmosfera como resultado da queima em flares.

O levantamento do estado da arte, constituído principalmente de artigos de periódicos presentes no Capítulo 3, torna-se fundamental para embasar a proposta do referente trabalho.

\section{ESTUDO DE CASO}

A Unidade de Tratamento de Gás de Cacimbas (UTGC) criada em 2006, é hoje responsável por $9 \%$ do gás natural entregue aos consumidores [MME, 2016]. Além de contribuir para a oferta nacional, a UTGC ainda ocupa uma posição estratégica para o processamento do gás associado à produção de petróleo no norte do Espírito Santo.

Situada no município de Linhares, o Polo Cacimbas totaliza uma capacidade de processamento de 16 milhões $\mathrm{m}^{3} / \mathrm{d}$ [MME, 2016], embora esteja processando atualmente $9 \mathrm{MMm}^{3} / \mathrm{d}$.

Figura 4. UTGC (em destaque: ground flare)

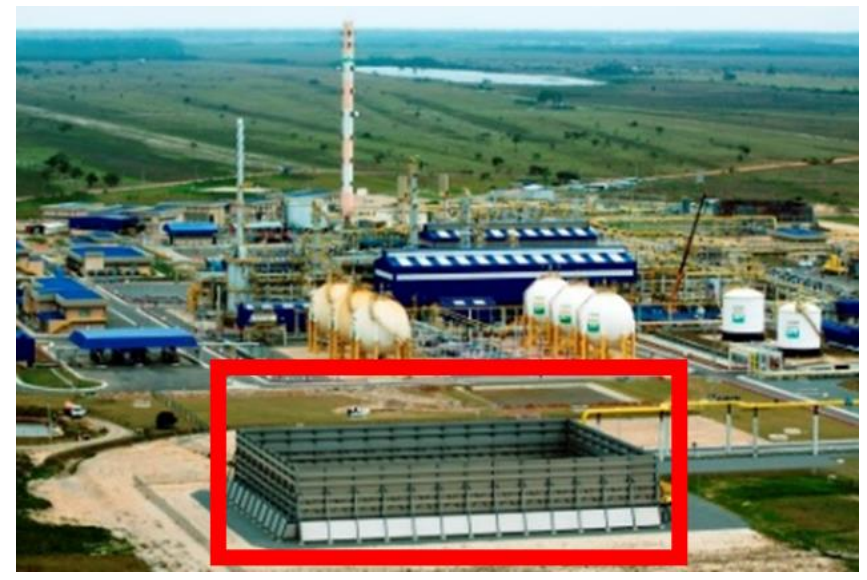

Fonte: Petrobras, 2012.

\subsection{INSUMOS DISPONÍVEIS: COMPOSIÇÃO DE ENTRADA}

A análise cromatográfica da composição do gás de queima no flare é realizada periodicamente, uma vez que esses parâmetros são monitorados pela agência reguladora. Para o estudo, é considerada uma composição típica de gás associado à produção de petróleo, pois caracteriza a maior parcela do gás que é produzido no Brasil (67,1\% em 2014) [ANP, 2015]. A sugestão para o estudo de caso é considerar a composição de alimentação em percentual molar semelhante ao da entrada da UPGN 2 da Reduc, que tem uma riqueza expressiva. 
Tabela 2 - Composição de cromatografia de gás

\begin{tabular}{|c|c|}
\hline Composição (\% molar) & $\begin{array}{l}\text { Entrada da UPGN2 da Refinaria Duque de } \\
\text { Caxias - RJ (REDUC) }\end{array}$ \\
\hline $\mathrm{C}_{1}-$ Metano & 77,94 \\
\hline $\mathrm{C}_{2}-$ Etano & 11,93 \\
\hline $\mathrm{C}_{3}-$ Propano & 6,11 \\
\hline $\mathrm{nC}_{4}-$ Butano & 1,32 \\
\hline $\mathrm{iC}_{4}$ - Isobutano & 0,84 \\
\hline $\mathrm{nC}_{5}-$ Pentano & 0,23 \\
\hline $\mathrm{iC}_{5}$ - Isopentano & 0,29 \\
\hline $\mathrm{C}_{6}-\mathrm{Hexano}$ & 0,05 \\
\hline $\mathrm{C}_{7}-$ Heptano & 0,02 \\
\hline $\mathrm{C}_{8}-$ Octano & 0 \\
\hline $\mathrm{N}_{2}-$ Nitrogênio & 0,63 \\
\hline $\mathrm{CO}_{2}$ - Dióxido de carbono & 0,64 \\
\hline PCS - Gás Ideal, Kcal/m³ (@1atm, 20C) & 10922,1 \\
\hline Densidade relativa $(\operatorname{ar}=1)$ & 0,7229 \\
\hline$\%$ riqueza & 8,860 \\
\hline$\%$ diluentes & 1,270 \\
\hline
\end{tabular}

Fonte: Borges (2003).

\section{RESULDOS E DISCUSSÃO}

\subsection{ASPECTOS ECONÔMICOS}

A negociação do gás natural praticada no mercado diz respeito ao conteúdo energético nele contido e seu valor é calculado em US\$/MMBTU (dólares por milhão de BTU), sendo baseado no poder calorífico superior, cuja referência adotada pelo Ministério de Minas e Energia é de PCS $=9.400 \mathrm{Kcal} / \mathrm{m}^{3}$.

Considerando o preço de 9,752 US\$/MMBTU (média desde 2014, para os preços praticados pela Petrobras para distribuidoras, isentos de tributos e encargos) e o preço de 15,762 US\$/MMBTU para venda aos consumidores [MME, 2016], é possível estimar uma perda mensal de US\$294.633,01 (distr.) a US\$ 476.212,46 (consumidor). A vazão de queima considerada para o cálculo foi de $27.000 \mathrm{~m}^{3} / \mathrm{d}$, ou seja, 0,03\% do volume processado segundo o MME (2016).

Tabela 3 - Valor monetário perdido do gás residual queimado

\begin{tabular}{lcc|c|}
\hline Preço Petrobras para Distribuidora (Dist) & 9,752 & US\$/MMBTU \\
\cline { 2 - 3 } Preço Petrobras para Consumidor (Cons) & 15,760 & US\$/MMBTU \\
Vazão de queima & 27000 & $\mathrm{~m}^{3} / \mathrm{d}$ \\
\hline Vazão convertida em energia & 1007,086 & $\mathrm{MMBTU}$ \\
\hline Valor monetário do gás queimado (Dist) & $294.633,01$ & US\$/mês \\
Valor monetário do gás queimado (Cons) & $476.212,46$ & US\$/mês \\
\hline
\end{tabular}

Fonte: Autores, baseado nos Boletins Mensais de Acompanhamento da Indústria de Gás Natural, [MME, 2016].

\subsubsection{CONSUMO DE GÁS COMBUSTÍVEL}

O consumo de gás combustível para as demandas térmicas da própria Unidade pode ser verificado nos seguintes subsistemas no Polo Cacimbas:

- $\quad$ Sistema aquecimento de óleo térmico;

- S S Sção de secagem do gás de alimentação por adsorção em leito sólido;

- G Gás combustível para circuito de refrigeração mecânica;

- G Gás combustível para compressão para exportação no gasoduto.

As demandas térmicas requisitadas acarretam em um alto dispêndio para o faturamento da Instalação. Comparado às vazões médias de entrega de $9 \mathrm{MMm}^{3} / \mathrm{d}$ notadas no período de referência para o referido 
trabalho, o consumo de gás combustível representa cerca de 3\% da produção e compreende um custo mensal de US\$2.946.330,10 para os valores praticados pela Petrobras para as distribuidoras.

Tabela 4 - Custo do gás combustível total

\begin{tabular}{|l|c|c|}
\hline Preço Petrobras para Distribuidora (Dist) & 9,752 & US\$/MMBTU \\
\hline Preço Petrobras para Consumidor (Cons) & 15,760 & US\$MMBTU \\
Vazão de gás combust. & 270.000 & $\mathrm{~m}^{3} / \mathrm{d}$ \\
\hline Vazão convertida em energia & 1007,086 & $\mathrm{MMBTU}$ \\
Valor monetário do gás queimado (Dist) & $2.946 .330,10$ & US\$/mês \\
Valor monetário do gás queimado (Cons) & $4.762 .125,58$ & US\$/mês \\
\hline
\end{tabular}

Fonte: Autores, baseado nos Boletins Mensais de Acompanhamento da Indústria de Gás Natural, [MME, 2016].

\subsection{ASPECTOS AMBIENTAIS}

Pela reação de combustão [1], e esta considerada completa, é calculada uma emissão 57,05 ton/d de $\mathrm{CO}_{2}$ para a atmosfera, considerando uma vazão de queima em $27.000 \mathrm{~m}^{3} / \mathrm{d}$.

$\mathrm{C}_{\mathrm{n}} \mathrm{H}_{(2 \mathrm{n}+2)}+[(3 \mathrm{n}+1) / 2] \mathrm{O}_{2} \rightarrow \mathrm{nCO}_{2}+(\mathrm{n}+1) \mathrm{H}_{2} \mathrm{O}[1]$

Tabela 5 - Cálculo das emissões de $\mathrm{CO}_{2}$ do sistema de Tocha

\begin{tabular}{|c|c|c|}
\hline \multicolumn{2}{|c|}{ Cromatografia do gás em \%mol } & Vazão molar (mol/d) \\
\hline C1 & 92,45 & $1.114 .352,68$ \\
\hline $\mathrm{N} 2$ & 1,58 & - \\
\hline $\mathrm{CO} 2$ & 1,47 & $17.718,75$ \\
\hline $\mathrm{C} 2$ & 2,23 & $53.758,93$ \\
\hline C3 & 1,05 & $37.968,75$ \\
\hline $\mathrm{H} 2 \mathrm{O}$ & 0 & - \\
\hline $\mathrm{H} 2 \mathrm{~S}$ & 0 & - \\
\hline $\mathrm{H} 2$ & 0 & - \\
\hline $\mathrm{CO}$ & 0 & - \\
\hline 02 & 0 & - \\
\hline iC4 & 0,27 & $13.017,86$ \\
\hline $\mathrm{nC4}$ & 0,38 & $18.321,43$ \\
\hline iC5 & 0,15 & $9.040,18$ \\
\hline $\mathrm{nC5}$ & 0,12 & $7.232,14$ \\
\hline $\mathrm{nC6}$ & 0,14 & $10.125,00$ \\
\hline $\mathrm{nC7}$ & 0,1 & $8.437,50$ \\
\hline nC8 & 0,02 & $1.928,57$ \\
\hline nC9 & 0,03 & $3.254,46$ \\
\hline $\mathrm{nC} 10$ & 0,01 & $1.205,36$ \\
\hline Poder Cal. & 39301,85 & $\mathrm{KJ} / \mathrm{m}^{3}$ \\
\hline Densidade & 0,6200044 & \\
\hline Total CO2 & $1.296 .361,61$ & $\mathrm{~mol} / \mathrm{d}$ \\
\hline Massa CO2 & 57,05 & ton/d \\
\hline
\end{tabular}

Fonte: Autores.

\section{CONCLUSÕES}

Pela análise, o valor monetário gasto por mês com gás combustível na instalação mostra-se expressivo (US\$ 2.946.330,10), além de representar uma parcela de gás não disponível ao consumidor final, em um mercado já deficitário. Parte dessa demanda poderia ser suprida pela recuperação do recurso energético desperdiçado na queima nos flares. Além de contribuir com as emissões de $\mathrm{CO}_{2}$ (57,05 ton/d), a queima representa um potencial financeiro significativo (US\$294.633,01). 
As tecnologias vistas no Estado da Arte apontam uma tendência para a maior viabilidade do uso do gás a ser recuperado como gás combustível, uma vez que, para esta finalidade, a gama de equipamentos requisitados no projeto apresenta-se de forma reduzida e de tecnologia dominada.

Por fim, é evidente o comprometimento ainda incipiente com este recurso no setor petrolífero brasileiro. A ANP, embora garanta a obrigatoriedade de investimento de 0,5\% do faturamento das empresas em pesquisa e desenvolvimento, segundo a Resolução no 47/2012 [ANP, 2012], não vislumbra por parte das empresas um compromisso com a causa, conforme constatado em pesquisa em base de dados específica. As empresas ainda contam com valores limítrofes elevados para a queima, de acordo com a Portaria nํㅜ 249/2000, o que não as impulsiona para um olhar mais crítico sobre o tema.

\section{REFERÊNCIAS}

[1] ABDUlRAHMAN, A. O., HUISINGH, D., HAFKAMP, W. Sustainability Improvements In Egypt's Oil\&Gas Industry By Implementation Of Flare Gas Recovery, Journal of Cleaner Production, v. 98, p. 116-122, 2015.

[2] AGÊNCIA NACIONAL DO PETRÓLEO, GÁS NATURAL E BIOCOMBUSTÍVEIS. PORTARIA ANP № 249, DE 10.11.2000 - DOU 3.11.2000. Disponível em: <

http://nxt.anp.gov.br/NXT/gateway.dll/leg/folder_portarias_anp/portarias_anp_tec>. Acesso em: maio 2016.

[3] AGÊNCIA NACIONAL DO PETRÓLEO, GÁS NATURAL E BIOCOMBUSTÍVEIS. RESOLUÇÃO ANP № 47, DE 21.12.2012 - DOU 24.12.2012. Disponível em: < http://nxt.anp.gov.br/NXT/gateway.dll/leg/resolucoes_anp/2012/>. Acesso em: maio 2016.

[4] AGÊNCIA NACIONAL DO PETRÓLEO, GÁS NATURAL E BIOCOMBUSTÍVEIS. Anuário Estatístico Brasileiro do Petróleo, Gás Natural e Biocombustíveis 2015. Disponível em: <

http://www.anp.gov.br/?pg=78136\&m=\&t1=\&t2=\&t3=\&t4=\&ar=\&ps=\&1465930711666>. Acesso em: maio 2016.

[5] BORGES, P. R. Propriedades termodinâmicas do gás natural. In: Artigo, Petrobras, Petróleo Brasileiro S/A, 2003. Publicação autorizada pela Petrobras - Gerência Executiva de Abastecimento-Logística - Documento AB-LO 08/2009, 29/09/2009.

[6] COMODIA, G.; RENZIB, M.; ROSSIB M. Energy efficiency improvement in oil refineries through flare gas recovery technique to meet the emission trading targets. Energy, v. 109, p. 1-12, 2016.

[7] HEIDARI, M.; ATAEI, A.; RAHDAR, M. H. Development and analysis of two novel methods for power generation from flare gas. Applied Thermal Engineering, v. 104, p. 687-696, 2016.

[8] LEITE, C. O. Underbalanced Drilling: Limits and Extremes, Chapter Flaring. IADC Technical Publications Committee. Pág. 537-575, 2012.

[9] MINISTÉRIO DE MINAS E ENERGIA; Secretaria de Petróleo, Gás Natural e Combustíveis Renováveis; Departamento de Gás Natural. Boletim Mensal de Acompanhamento da Indústria de Gás Natural. Brasília, 2016. 42p. Disponível em: <http://www.mme.gov.br/web/guest/secretarias/petroleo-gas-natural-e-combustiveisrenovaveis/publicacoes>. Acesso em: Maio 2016.

[10] MOKHATAB, S.; POE, W. A. Processamento e transmissão de gás natural. 1. ed. Elsevier, 2014.

[11] PETROBRAS. Petrobras assina contrato de serviço para adequação do Polo Cacimbas. 2016. Disponível em: < http://fatosedados.blogspetrobras.com.br/2012/05/23/petrobras-assina-contrato-de-servico-para-adequacao-dopolo-cacimbas/>. Acesso em: Maio 2016.

[12] RAHIMPOUR, M. R., JAMSHIDNEJAD, S. M., JOKAR, S. M., KARIMI, G., GHORBANI, A. H., MOHAMMADI, A.H. A comparative study of three different methods for flare gas recovery of Asalooye Gas Refinery. Journal of Natural Gas Science and Engineering, v. 4, p 17 a 28, 2012.

[13] REGO, E.E.; Entendendo a expressiva participação das termelétricas a gás natural no primeiro leilão de energia nova. Revista Brasileira de Energia, v. 13, p. 83-101, 2007.

[14] TORRES, Glaucia Cardoso Teixeira. MUNIZ, Tânia Lobo Muniz. A construção da consciência ambiental e a importância das Organizações Internacionais no enfrentamento das questões ambientais globais. Revista do Direito Público. Londrina, v.11, n.1, p.183-204, 2016.

[15] TAHOUNI, N.; GHOLAMI, M.; PANJESHANI, M. H. Integration of flare gas with fuel gas network in refineries. Energy, v. 111, p. 82-91, 2016.

[16] YIN, R. K. Estudo de caso: planejamento e métodos. 3. ed. Porto Alegre: Bookman, 2005. 


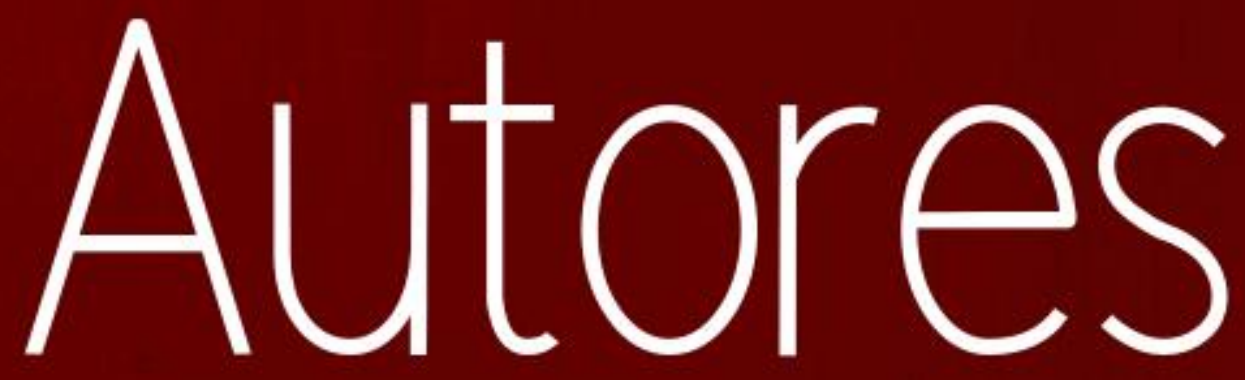




\section{DAVILSON EDUARDO ANDRADE}

Graduado em geologia pela UFMG em 1989. Mestrado em Geofísica pela UFBA em 1992. Possui 27 anos de experiência na Indústria de Petróleo (área de Exploração e Produção).

\section{ACTO DE LIMA CUNHA}

Possui doutorado em Engenharia de Processos (2014) e mestrado em Engenharia Química pela Universidade Federal de Campina Grande (2010), graduação em Engenharia Química pela Universidade Federal de campina Grande (2007). Atualmente é professor da Universidade Federal de Sergipe. Tem experiência com pesquisas na área de Engenharia Petróleo e Engenharia de Química com ênfase em simulações de fluxo em reservatório de petróleo e escoamento multifásico.

\section{ALEXSANDRO ROCHA DA SILVA}

Graduação em Ciência e Tecnologia pela Universidade Federal Rural do Semi-Árido - UFERSA (2013). Graduação em Engenharia Química pela Universidade Federal Rural do Semi-Árido UFERSA (2015). Mestrando em Ciência e Engenharia dos Materiais pela Universidade Federal Rural do Semi-Árido - UFERSA (2017). Tem experiência em pesquisa atuando no ramo de Biocombustíveis, Adsorção de compostos poluentes, Identificação e resolução de problemas envolvendo fungos patogênicos e Modelagem Molecular de pesticidas e herbicidas na agricultura.

\section{ALFREDO ISMAEL CURBELO GARNICA}

Possui graduação em Engenharia Química (1993) na Universidad Central de Las Villas (Cuba), Mestrado (1999) e Doutorado (2003) em Engenharia Química pela Universidade Federal do Rio Grande do Norte. Atualmente é professor associado IV do Departamento de Engenharia Química da Universidade Federal da Paraíba

\section{ALLISON RUAN DE MORAIS SILVA}

Possui graduação em Engenharia Química pela UFERSA e atualmente cursa mestrado em Engenharia Química com ênfase em desenvolvimento de processos biotecnológicos pela UFSC.

\section{AMANDA DUARTE GONDIM}

Doutora em Química pela Universidade Federal do Rio Grande do Norte. Professora de Química do Petróleo da Universidade Federal do Rio Grande do Norte. Atualmente é coordenadora da Rede Brasileira de Bioquerosene e Hidrocarbonetos Renováveis (RBQAV). Desenvolve projetos de pesquisa na produção de biodiesel e hidrocarbonetos renováveis, principalmente bioquerosene, através de processos catalíticos a partir de diversas fontes de biomassa.

\section{ANDARAIR GOMES DOS SANTOS}

Professora adjunta da Universidade Federal Rural do Semi-Árido - UFERSA. Possui graduação em Engenharia Química pela Universidade Federal de Campina Grande (2002), mestrado em Engenharia Química pela Universidade Federal de Campina Grande (2004), doutorado em Engenharia Química pela Universidade Federal do Rio Grande do Norte (2010) e, pós doutorado na Universidade de Toulon (2017) - CAPES/COFECUB (COMITÊ FRANCÊS DE AVALIAÇÃO DA COOPERAÇÃO UNIVERSITÁRIA COM O BRASIL).

\section{ANTÔNIO SANTOS SILVA}

Graduado em Química Industrial pela Universidade Federal de Sergipe (1973), pós-graduação em Matemática Aplicada pela Universidade Federal de Sergipe (1976), mestrado em Engenharia Química pela Universidade Federal do Rio de Janeiro (1978) e doutorado em Engenharia Química pela Universidade Federal do Rio de Janeiro (1983). Pesquisador I-C do CNPq, 1987-1991. 
Professor Associado I da Universidade Federal de Sergipe e do Núcleo de Pós-graduação em Matemática da Universidade Federal de Sergipe (2006). Professor adjunto doutor da Universidade Federal de Sergipe, Campus de Itabaiana (2006 - 2008) e atualmente Professor Associado Campus de São Cristóvão. Professor do Programa de Mestrado em Engenharia Química da Universidade Federal de Sergipe.

\section{ANTONIO SOUZA DE ARAUJO}

Doutor em Química Inorgânica pela Universidade de São Paulo e Pós-Doutorado em Kent State University (Ohio, Estados Unidos). Professor Titular do Instituto de Química da Universidade Federal do Rio Grande do Norte. Coordena o Laboratório de Catálise e Petroquímica da UFRN. É membro e consultor da American Chemical Society (ACS - Petroleum Research Fund), International Zeolite Association (IZA), Associação Brasileira de Análise Térmica e Calorimetria (ABRATEC) e Sociedade Brasileira de Catálise (SBCat). Tem como principais linhas de pesquisa: síntese hidrotérmica de zeólitas, materiais nanoestruturados, materiais híbridos micro-mesoporosos, catálise ácida, petróleo e petroquímica..

\section{BIANCA GABRIEL DE SOUZA}

Graduanda em Engenharia de Petróleo pela UFS. Estagiária de campo na EPG. Pesquisadora na área de simulação em métodos de recuperação de óleo via simulador CFX. Acumula participação em gestões do capítulo estudantil da SPE e da empresa júnior de engenharia de petróleo (SERPETRO)

\section{CAIO RAMOS VALVERDE}

Possui ensino técnico em petróleo e gás pelo Instituto Federal da Bahia.

\section{CAMILA GISELE DAMASCENO PEIXOTO MORAIS}

Mestrado em Ciência e Engenharia do Petróleo pela Universidade Federal do Rio Grande do Norte. Atualmente é professora do Instituto Federal de Educação, Ciência e Tecnologia do Pará. Tem como principais linhas de pesquisa: desenvolvimento de métodos analíticos para combustíveis, biocombustíveis e petróleo; avaliação e caracterização de combustíveis e biocombustíveis; e destilação catalítica.

\section{DIEGO ANGELO DE ARAUJO GOMES}

Tem experiência na área de Engenharia Química, com ênfase em Processos químicos, atuando principalmente nos seguintes temas: petróleo, tensoativo, microemulsão e emulsões, petroquímica e adsorção de hidrocarbonetos sobre zeólitas. Atuou durante 4 anos na coordenação de pesquisa e inovação do IFRN campus Mossoró. Desde 2016, ocupa a função de coordenador da Incubadora Tecnológica do IFRN campus Mossoró. Tem experiência no modelo de gestão de incubadoras CERNE 1.

\section{EDILSON DE JESUS SANTOS}

Possui graduação em Direito pela Universidade Tiradentes (2010), graduação em Engenharia Química pela Universidade Federal de Sergipe (1991), mestrado em Engenharia Química pela Universidade Estadual de Campinas (1994) e doutorado em Engenharia Química pela Universidade Estadual de Campinas (1998). Atualmente é professor Associado da Universidade Federal de Sergipe.

\section{EDUARDA COLARES BARBOSA FERREIRA}

Bacharel em Engenharia de Petróleo pela Universidade Federal de Campina Grande (2018). Especialização em andamento em Engenharia de Segurança do Trabalho, Faculdades Integradas de 
Patos (2020) e técnico em Segurança do Trabalho em andamento, Escola Técnica Professora Antônio Carlos Gomes da Costa (2020) . Atualmente Estagiária da Unilever Brasil Gelados.

\section{ELBA GOMES DOS SANTOS LEAL}

Possui graduação em Engenharia Química pela Universidade Federal da Paraíba(1998), especialização em Curso de Especialização Em Formação do Educador pela Universidade Estadual da Paraíba(2002), especialização em Curso de Especialização Em Gestão e Análise Ambien pela Universidade Estadual da Paraíba(2007), especialização em Programa de formação de recursos humanos (PRH 25) pela Universidade Federal de Campina Grande(2005), mestrado em Engenharia Química pela Universidade Federal de Campina Grande(2000), doutorado em Engenharia de Processos pela Universidade Federal de Campina Grande(2005) e pós-doutorado pela Universidade Salvador(2009). Atualmente é professor titular do Instituto Federal da Bahia, Coordenação de pesquisa campus Simões Filho do Instituto Federal da Bahia, e Sócio do Instituto Brasileiro de Tecnologia e Regulação. Tem experiência na área de Engenharia Química, com ênfase em Tecnologia Química. Atuando principalmente nos seguintes temas: Petróleo, biomassa, adsorção, efluente.

\section{FABIOLA DIAS DA SILVA CURBELO}

Possui graduação em Engenharia Química pela Universidade Federal do Rio Grande do Norte (1999), Mestrado em Engenharia Química pela Universidade Federal do Rio Grande do Norte (2002), com bolsa da ANP-PRH 14, e Doutorado em Engenharia Química pela Universidade Federal do Rio Grande do Norte (2006), também com bolsa da ANP-PRH 14. É professora e orientadora no curso de graduação em Engenharia Química (CT/UFPB) e docente permanente do Programa de Pós-graduação em Engenharia Química (UFPB)

\section{FERNANDA NAIARA CAMPOS DE ALMEIDA}

Graduada em Química Bacharelado e Engenharia de Produção, na Universidade Estadual de Maringá. Concluiu o mestrado em Engenharia Química, na UEM no ano de 2015, desenvolvendo estudos sobre os processos de secagem e extração de óleo da semente de moringa. Atualmente, é doutoranda no programa de pós-graduação de Engenharia Química na UEM. No doutorado, atua na área de desenvolvimento de um processo contínuo para remoção de H2S de biogás, com linha de pesquisa voltada para processos de separação e sistemas particulados.

\section{FERNANDA SILVA CALIXTO}

Graduanda em Engenharia de Petróleo pela Universidade Federal de Sergipe (2019).

\section{FRANCISCO KLEBSON GOMES DOS SANTOS}

Possui graduação em Engenharia Química pela UFCG, mestrado em Engenharia Química pela UFCG e doutorado em Engenharia Química pela UFRN. É professor associado da UFERSA. Tem experiência na área de Engenharia Química, com ênfase em Processos de separação e Biopolímeros.

\section{GABRIELA DE CARVALHO BRITO}

Engenheira de Petróleo e Mestre em Energia pela Universidade Federal do Espírito Santo. Pósgraduada em Docência do Ensino Superior. Dedica-se a pesquisa na área de Simulação Computacional de escoamento multifásico de fluidos e reatores de leito de lama. 


\section{GERALDINE ANGÉLICA SILVA DA NÓBREGA}

Possui graduação em Engenharia Química, mestrado em Engenharia Química e doutorado em Engenharia Química pela UFRN. De 2007 a 2011, professora do IFBA no curso de Exploração em Petróleo e Gás Natural na modalidade integrado e subsequente. Coordenadora do curso de 2008 a 2011. De 2011 até a presente data, professora do curso de Engenharia Química da Universidade Federal Rural do Semi-Árido - UFERSA. Tem experiência na área de Engenharia Química, com ênfase em Engenharia Química, atuando principalmente nos seguintes temas: sistemas microemulsionados, gás natural, tensoativos, simulação de processos e hidrodinâmica de coluna de absorção.

\section{GUSTAVO FERNANDES QUIXADÁ}

Bacharel em Ciência e Tecnologia pela Universidade Federal Rural do Semi-Árido (UFERSA) - 2016. Graduação em andamento em Engenharia Química pela mesma instituição (2019). Assistente Previdenciário no Instituto Municipal de Previdência Social dos Servidores de Mossoró - RN (2015 - Atual).

\section{HARIEL UDI SANTANA MENDES}

Graduado em Engenharia de Petróleo pela Universidade Federal de Sergipe (UFS). Pós-Graduado em Engenharia de Segurança do Trabalho pela Faculdade Pio Décimo. Mestre em Engenharia Química pela Universidade Federal de Sergipe (UFS). Atuou como Professor Substituto do Núcleo de Graduação em Engenharia de Petróleo da UFS. Atualmente é doutorando do Departamento de Engenharia de Petróleo da Universidade Estadual de Campinas (UNICAMP).

\section{JÉSSICA VIOLIN BERNI}

Formada na Fatec-Araçatuba no curso de Tecnologia em Biocombustíveis no ano de 2013. Formada na UME Unidade Modelo de Ensino no curso de Técnica em Química, no ano de 2012 CRQ: 04486856. Tem experiência na área de Microbiologia, com ênfase em Microbiologia Industrial e de Fermentação. Mestre do Programa de Pós-Graduação Stricto Sensu em Bioenergia (Associado em Rede), na Universidade Estadual de Maringá (UEM), bolsista da CAPES. Doutoranda do Programa de Pós-Graduação em Engenharia Química, na Universidade Estadual de Maringá (UEM), bolsista da CAPES. Graduanda em Engenharia Química na FEITEP (Faculdades de Engenharia e Arquitetura).

\section{JOSUÉ SANTIAGO DE ALMEIDA}

Engenheiro Mecânico e Bacharel em Ciências e Tecnologia com ênfase em Tecnologia Mecânica, ambos pela Universidade Federal do Rio Grande do Norte. Atua como gerente técnico do Laboratório de Combustíveis e Lubrificantes da UFRN (LCL-UFRN). Tem como principais linhas de pesquisa: estabilidade oxidativa de combustíveis e degradação de polímeros.

\section{KAROLLINE DEWANELE SANTANA ROCHA}

Graduanda em Engenharia de Petróleo pela Universidade Federal de Sergipe. Atuou na presidência do Capítulo Estudantil SPE/UFS por dois anos. Integrou a equipe que representou a UFS no IBA 2019. Já participou em grupo de pesquisa na área de biocombustíveis, hoje tem foco na reavaliação de campos maduros.

\section{LUCIA MARIA DE ARAUJO LIMA GAUDENCIO}

Graduada em Engenharia Química, Mestre e especialização em Engenharia Sanitária e Ambiental, doutora em Engenharia Ambiental. Foi Chefe da Coordenadoria de Meio Ambiente da Agência Nacional de Petróleo, Gás Natural e Biocombustíveis (ANP). Professora Associada da Universidade Federal de Campina Grande - Centro de Ciência e Tecnologia - Unidade Acadêmica de Engenharia Química. 


\section{MARIANA MARTINS DO VALE}

Possui graduação em Engenharia Química pela Universidade Federal da Paraíba (2017). Especialista em Gás Natural e Biocombustíveis . Pesquisadora no Programa de Recursos Humanos da ANP/MCTI - PRH - ANP no. 54 da UFPB, Edital 05/2013 do PRH-ANP/MCTI, de Novembro de 2014 a Maio de 2016 com ênfase em fluidos de perfuração de poços de petróleo. Tem experiência em controle de qualidade em combustíveis e Auditora interna em processos de acreditação na norma ISO/IEC 17025:2017.

\section{MATHEUS PEREIRA DE OLIVEIRA}

Possui graduação em tecnologia em biocombustíveis pela Faculdade de Tecnologia de Araçatuba (SP) (2012) e mestrado em Bioenergia pela Universidade Estadual de Maringá (PR) (2016). Tem experiência na área de Química tecnológica com ênfase em produção e caracterização de combustíveis e biocombustíveis.

\section{NEHEMIAS CURVELO PEREIRA}

Possui graduação em Química Industrial pela Universidade Federal de Sergipe (1970), mestrado em Engenharia Química pela Universidade Federal do Rio de Janeiro (1972) e doutorado em Engenharia Química pela Universidade Federal do Rio de Janeiro (1980). Atualmente é professor titular da Universidade Estadual de Maringá. Tem experiência na área de Engenharia Química, com ênfase em Operações Industriais e Equipamentos para Engenharia Química, atuando principalmente nos seguintes temas: secagem, sistemas particulados, separação sólido-fluido, processos de separação com membranas, secagem industrial e transferência de massa, produção de biodiesel, separação de biodiesel e glicerol.

\section{PAULO EDUARDO DA COSTA SANTOS}

Engenheiro Químico pela Universidade Federal Rural do Semi-Árido (UFERSA) - 2016. Possui experiência em indústria de cosméticos. Pós-Graduado em Engenharia de Segurança no Trabalho pela Universidade Potiguar (UnP) - 2018. Experiência na área de controle de qualidade e Boas práticas de Fabricação (BPF), objetivando garantir a excelência do processo produtivo de acordo com as legislações vigentes.

\section{PAULO VICTOR VIEIRA CUNHA}

Graduado em Engenharia de Petróleo pela Universidade Tiradentes (UNIT). Mestrando em Engenharia Química pela Universidade Federal de Sergipe (UFS).

\section{PEDRO LUIS ARAUJO DOS SANTOS}

Possui graduação em Ciências Contábeis pela Faculdade Maurício de Nassau - Salvador (2009). Tem experiência na área de Administração, com ênfase em Ciências Contábeis.

\section{REGINALDO FERREIRA DE SOUSA}

Graduado em Engenharia Química pela Universidade Federal Rural do Rio de Janeiro - UFRRJ (2009), pós-graduado em Engenharia de Petróleo pela Faculdade UCL (lato-sensu). Atuações profissionais como: professor, estagiário em gestão de manutenção, engenheiro de perfuração de poços marítimos e operador de ferramenta de perfuração direcional. 


\section{RICARDO GUILHERME KUENTZER}

Engenheiro Agrônomo, formado pela Universidade Estadual do Sudoeste da Bahia (UESB), em 2004; Mestre em Tecnologias Aplicáveis a Bioenergia pela Rede Faculdade de Tecnologia e Ciências (FTC), em 2017. Atualmente é Professor do Instituto Federal de Educação, Ciência e Tecnologia da Bahia (IFBA), Campus Simões Filho. Foi Secretário de Gabinete da Prefeitura Municipal de Irecê jan/out de 2013. Diretor de Ensino do Centro de Educação Tecnológica do Estado da Bahia (CETEB) e Membro do Conselho de Administração da Associação Centro de Educação Tecnológica do Estado da Bahia (ASCETEB), 2007/2012. Atualmente é Membro do Conselho da APA Joanes/Ipitanga. Membro do Conselho Superior de Pesquisa e Extensão (CONSEPE) do IFBA.

\section{RICARDO MATOS SANTOS}

Possui ensino-médio-segundo-grau pelo Instituto Federal da Bahia (2013). Atualmente é Estágio do Instituto Federal da Bahia. Tem experiência na área de Engenharia de Minas.

\section{RUI CARLOS DE SOUSA MOTA}

Possui graduação superior em Tecnologia Mecânica pelo Centro Federal de Educação Tecnológica da Bahia (1987),tendo atuado como técnico de planejamento e supervisor de manutenção em diversas empresas do ramo químico, petroquímico e de petróleo. Professor do Centro Federal de Educação Tecnológica da Bahia, onde ocupou de 2006 a 2008 as coordenações de Manutenção Mecânica e Petróleo e gás natural, de 2009 a 2010 a assistência do Departamento de Ensino, 2011 assumiu a chefia do departamento de ensino e a partir de 2012 a direção geral do Campus, possuo vasta experiência na área de Tecnologia Mecânica, e Petróleo e Gás com ênfase em Manutenção de Equipamentos industriais. Mestre em engenharia mecânica na área de materiais, Doutor em engenharia Mecânica, convênio IFBA / UFRN.

\section{SAMUEL MATHIAS DO AMARAL JUNIOR}

Engenheiro mecânico, mestre em energia com ênfase em Petróleo, Gás e Energias renováveis. Atua no processamento de gás natural em Unidade de Tratamento de Gás. Experiência em simulação estática para síntese de processamento.

\section{THIAGO LUIZ BELO PASA}

Possui graduação em Tecnologia em Processos Químicos pela Universidade Tecnológica Federal do Paraná (2012) e mestrado em Engenharia Química pela Universidade Estadual de Maringá (2015).

\section{TOMAS SAITER LINS}

Engenheiro de petróleo. Mestre em Energia com ênfase em Petróleo, Gás e Energias renováveis pela Universidade Federal do Espírito Santo. Dedica-se à pesquisa na área de rerrefino de óleos lubrificantes via extração por solventes de baixo impacto ambiental.

\section{VALTER JOSÉ FERNANDES JUNIOR}

Doutor em Química Analítica pela Universidade de São Paulo e Pós-Doutorado em Química Ambiental pelo INPE. Professor Titular do Instituto de Química da UFRN. Atuou como Pró-Reitor de Pesquisa da UFRN entre 2011 e 2016. Coordena o Laboratório de Combustíveis e Lubrificantes da UFRN. É consultor científico da FINEP, FAPESP, do NSF-National Science Foundation e CNPq. Coordena a Rede Norte/Nordeste de Laboratórios de Combustíveis. Tem como principais linhas de pesquisa: aplicação de materiais nanoestruturados para a reciclagem terciária de polímeros, desenvolvimento de métodos analíticos para combustíveis, biocombustíveis e petróleo, avaliação e caracterização de aditivos para combustíveis e biocombustíveis. 


\section{VICTOR HUGO DOS SANTOS RAMOS}

Possui Graduação em Química Industrial pela Universidade Federal de Sergipe (UFS). Mestre em Engenharia Química pela Universidade Federal de Sergipe (UFS).

\section{VÍTOR GAMA RODRIGUES}

Bacharel em Engenharia de Petróleo pela Universidade Tiradentes (2017). 


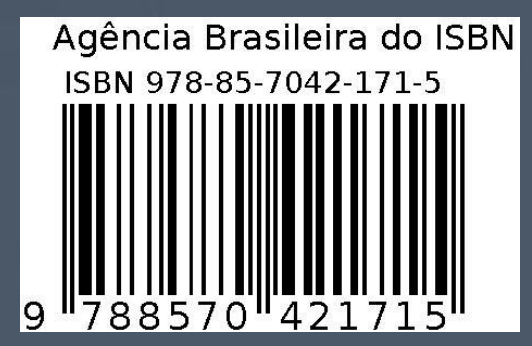

